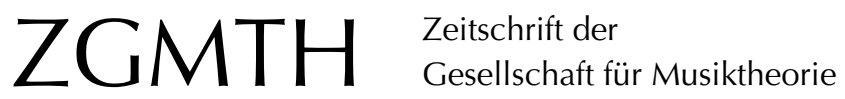

Rohringer, Stefan (2013): Zu Johannes Brahms' Intermezzo h-Moll op. 119/1. ZGMTH 10/1, 79-145. https://doi.org/10.31751/707

(C) 2013 Stefan Rohringer

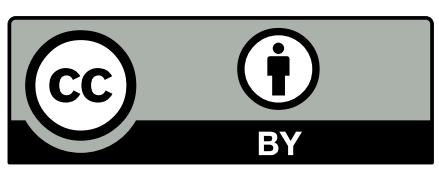

Dieser Text erscheint im Open Access und ist lizenziert unter einer Creative Commons Namensnennung 4.0 International Lizenz.

This is an open access article licensed under a

Creative Commons Attribution 4.0 International License.

veröffentlicht / first published: 06/07/2014

zuletzt geändert / last updated: 19/02/2016 


\title{
Zu Johannes Brahms' Intermezzo h-Moll op. 119/1
}

\author{
Stefan Rohringer
}

ABSTRACT: Im ersten Teil des Beitrags wird ausgehend von der Diskussion diverser Instantiierungen und Verknüpfungen satztechnischer Modelle in Johannes Brahms' Intermezzo h-Moll op. 119/1 eine teilweise Rekomposition des Originals vollführt. Der Vergleich zeigt, dass herkömmliche Formen musikalischen Zusammenhangs bei Brahms nicht einfach in die Latenz zurücktreten, sondern durch andere ersetzt werden. Eine Beschäftigung mit Beiträgen der Schenkeranalytik und die Verknüpfung von Überlegungen Moritz Hauptmanns zur Darstellung der Tonart mit der `Theorie der Tonfelder« nach Albert Simon und Bernhard Haas führen im zweiten Teil zum Postulat einer post-schenkerianischen Ursatzform. Auf dieser Grundlage folgt im abschließenden dritten Teil eine Schichtenanalyse der gesamten Komposition.

\section{Unterschiedliche Satzmodelle als Hörfolien in Brahms' Intermezzo}

Dass das Intermezzo h-Moll op. 119/1 zu den meist analysierten späten Instrumentalkompositionen von Johannes Brahms zählt ${ }^{1}$, dürfte sich der für eine Klavierminiatur ungewöhnlichen Komplexität des Tonsatzes verdanken. Insbesondere mit Blick auf das konstruktive Potential der hypertrophen Terzenschichtungen scheint das Stück Schönbergs Diktum von »Brahms the Progressive $«^{2}$ zu stützen. Demgegenüber haben sowohl Vertreter der Schenkerian Analysis als auch der sklassischen Harmonielehre gehend ungebrochene Verankerung der Brahms'schen Kompositionsweise in der traditionellen Mehrstimmigkeit behauptet.

Wer die Verankerung des Intermezzos in der traditionellen Mehrstimmigkeit erweisen möchte, muss aufzeigen, wie die im Stück vorherrschende Terzfallmechanik mit den Kategorien herkömmlicher tonaler Klangbildungs- und Fortschreitungslehre zusammengeht.

Brian Newbould unterlegt im Zuge seiner Reihenanalyse dem gesamten Intermezzo eine auf wechselnde Stimmen verteilte Folge stetig fallender Quinten. Für den eröffnenden Vierer entwirft er folgenden Fundamentalbass, der den harmonischen Rhythmus des Hintergrundes wiedergebe: ${ }^{3}$

1 Vgl. Schenker (o. J.), Salzer 1960, Hollander 1972, Domek 1976, Dunsby 1976, Clements 1977, Newbould 1977, Cadwallader 1983a und 1983b, Cai 1986, Forte/Gilbert 1982, Goebels 1983, Jordan/ Kafalenos 1989, Diergarten 2003, Danuser 2005, Breyer 2009, Rings 2012.

2 Schönberg 1950.

3 Ebd. 




Beispiel 1: Newbould 1977, Example $1^{4}$ zu Johannes Brahms, Intermezzo h-Moll op. 119/1, T. 1-4

Im Vordergrund sieht Newbould den harmonischen Verlauf durch die innerhalb der Terzenkette aufscheinenden Grundtöne markiert - jeweils zwei pro Takt. ${ }^{5}$

Felix Diergarten teilt Newboulds Einschätzung, der musikalische Zusammenhang im Werk sei wesentlich durch eine modifizierte Quintfallsequenz gewährleistet. Auch er unterlegt dem eröffnenden Vierer eine Basslinie, »die den harmonischen Verlauf verdeutlichen soll«. ${ }^{6}$ Anders als Newboulds Reihe, die der Konstruktion eines idealtypischen Zusammenhangs dient, ist Diergartens Zusatzstimme ein verschwiegener realer Stimmverlauf, der ein historisches Satzmodell impliziert:

Diese sideale Baßlinie erweist sich spätestens dann als plausibel, wenn sie als ıreale، Baßlinie zu den Oberstimmen hinzugespielt wird. In diesem Verdeutlichungsakt geht den ersten Takten allerdings etwas Wesentliches verloren: Die Konstruktion der virtuellen Baßlinie zeigt an, daß der eigenartig schwebende Zauber des Anfangs durch die Baßlosigkeit des baßbezogenen Modells hervorgerufen wird.?

Diergarten schlägt zwei unterschiedliche Rhythmisierungen der svirtuellen Basslinie « vor: Die binäre Teilung des Taktes erklärt in seinen Augen »den Eindruck von Beschleunigung [...], der in T[akt] 4 entsteht, wenn erstmals der 3/8-Takt explizit [...] erscheint ${ }^{8}{ }^{8}$ (Beispiel 2).

Sowohl Diergartens Basslinie(n) als auch Newboulds Reihe sind hinsichtlich der rhythmisch-metrischen Unregelmäßigkeit ihrer Grundtonfortschreitungen problematisch. So sehen beide Vorschläge Diergartens für die Sequenztakte 2 und 3 einen der melodischen Sequenz entgegen stehenden harmonischen Rhythmus vor: Der zweite Grundton in Takt 2 gilt zu Beginn von Takt 3 als noch nicht verlassen. Die Annahme jeweils zweier Grundtöne in den Takten 2 und 3 resultiert aus der Analogie zum Eröffnungstakt. Dieser wiederum muss zwei Grundtöne enthalten, da ansonsten kein von $h$ startender stetiger Quintfall unterstellt werden kann.

Beispiel 3 setzt diverse Hörfolien der Generalbassharmonik ${ }^{9}$ des 18. Jahrhunderts in ein Verhältnis zu den Takten 1-4 aus op. 119/1.

4 Newbould 1977, 33.

5 Ebd., 34: im ersten Takt auf drittem Sechzehntel ( $h$ ) und letztem Achtel (e), in den Takten zwei und drei auf viertem ( $a$ und $d$ ) und letztem Sechzehntel ( $d$ und $g$ ) und im vierten Takt auf zweitem Sechzehntel (cis) und zweitem Achtel (fis).

6 Diergarten 2003, 43f.

7 Ebd., 44.

8 Ebd.

9 Zu den historisierenden Aspekten in Brahms' späten Klavierstücken vgl. auch Breyer 2009. 


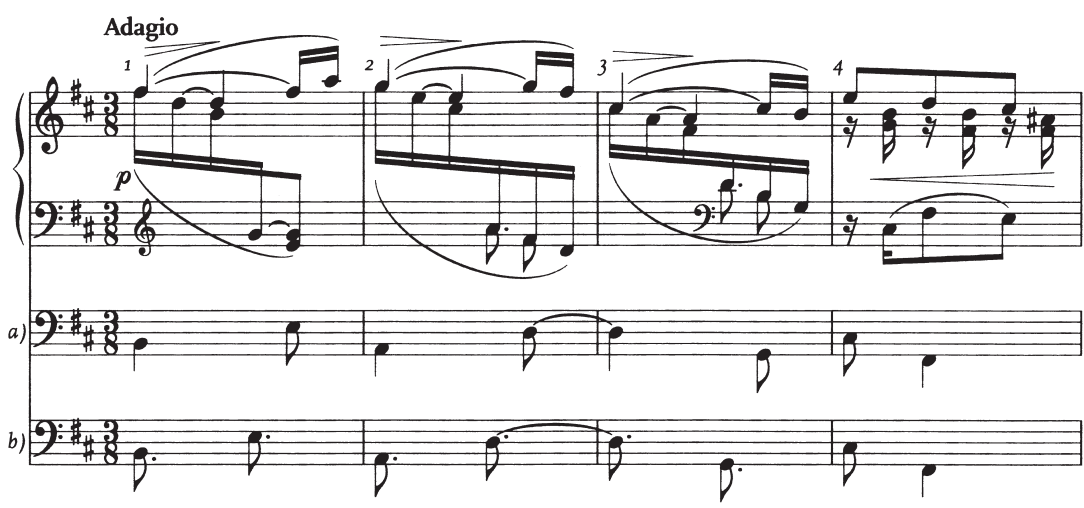

Beispiel 2: Diergarten 2003, Beispiel $1^{10}$ zu Johannes Brahms, Intermezzo h-Moll op. 119/1, T. 1-4

a)

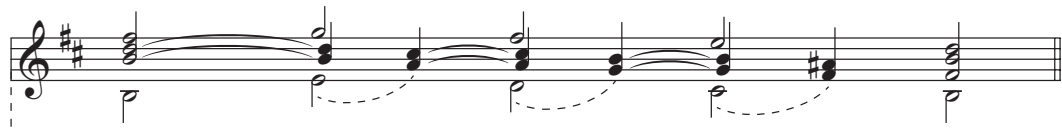

b)

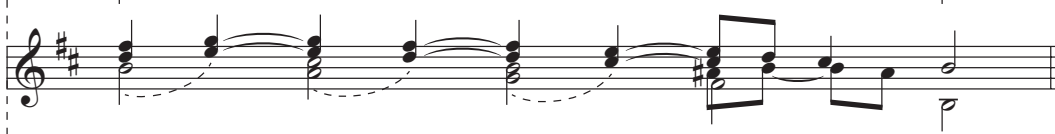

c)

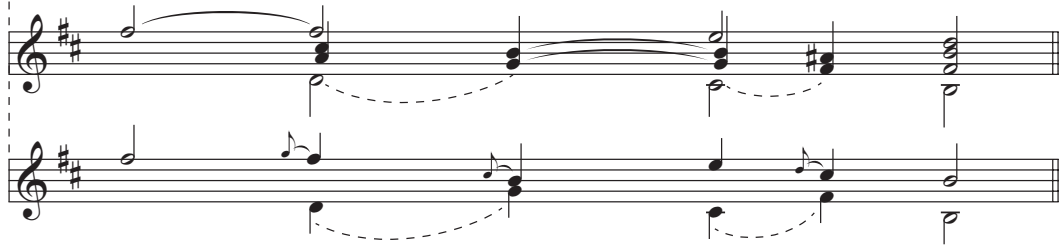

Beispiel 3: Johannes Brahms, Intermezzo h-Moll op. 119/1, Hörfolien a)-d) zu T. 1-4

Hörfolie a) zeigt einen Stufengang, der ab Takt 2 auf der Harmonisation der Bassstufen 4-1 einer einfachen Oktavregel in Moll basier ${ }^{11}$ und zu dem sich die eröffnende Tonika quasi auftaktig verhält. Der Quartgang 4-1 ist als fallende Stufensequenz eingerichtet, die einen übergeordneten Dezimensatz diminuiert. Auf dieser Anordnung beruht beispielsweise die Bourrée aus Georg Friedrich Händels Music for the Royal Fireworks (vgl. Beispiel 4). Aus Sicht der Schenkeranalytik handelt es sich um den paradigmatischen Beginn einer Quintzugmusik mit der Auskomponierung der oberen Nebennote $\left(g^{2}\right)$ zum Kopfton $\left(f i s^{2}\right)$, an die sich einen Terzzug 5-3 in eine Mittelstimme $\left(d^{2}\right)$ anschließt:

10 Ebd.

11 Robert O. Gjerdingen spricht vom >Prinner (2007, 45ff.). 


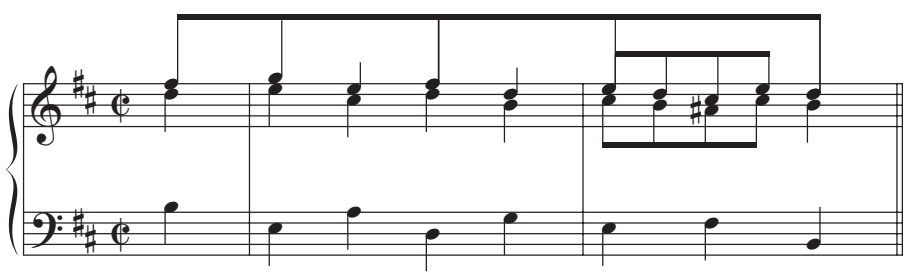

Beispiel 4: Georg Friedrich Händel, Music for the Royal Fireworks HWV 351, Bourrée, Stimmführungsskizze T. 1-2 (Originaltonart d-Moll)

Hörfolie b) unterlegt dem Anfang des Intermezzos die Bassstufen 8-5 der Oktavregel in Moll. Die Hörfolien a) und b) unterscheiden sich hinsichtlich der Zuordnung der einzelnen Akkordstationen zum jeweils übergeordneten Stufengang: In b) prolongiert die IV (als konsonierender Quartsextakkord) im Eröffnungstakt die vorausgehende I, in a) ist sie grund- und eigenständige Stufe zu Beginn von Takt 2, die ihrerseits durch eine nachfolgende VII prolongiert wird.

Gemäß Hörfolie b) sind in Takt 3 die VI und, als deren Prolongation, die II zu erwarten. Damit nähert sich Hörfolie b) der Einschätzung Diergartens. Deren Problematik aber legt der Abgleich mit Hörfolie a) offen: Der von Diergarten zu Beginn von Takt 3 angenommene Stillstand auf der III, der den Fortgang zur VI verzögert, verweist auf einen Wechsel der Diminutionsebene. Takt 3 des Originals und damit retrospektiv auch Takt 2, als dessen Analogie, verhalten sich nicht als Ritardation im Rahmen von b), sondern als Ausschnitt aus a). Unter der Voraussetzung, dass die melodische Sequenz die Zugehörigkeit beider Takte zu derselben Diminutionsebene impliziert, können die Takte 2 und 3 des Intermezzos den Zählzeiten 3 und 4 des ersten Taktes von Händels Bourrée zugeordnet werden. Die Töne $a^{1}$ in Takt 2 und $d^{1}$ in Takt 3, die in Diergartens Interpretation den Rang eigenständiger Grundtöne erhalten, werden zu Mittelstimmen der übergeordneten Stufen D und G, was auch ihrer metrischen Positionierung im Verlauf der Terzfallkette gerecht wird: Auf den ersten beiden Zählzeiten ereignen sich quasi-dominantische Scheinakkorde, die sich jeweils als Vorhalte über den latenten Folgestufen verstehen lassen.

Der Blick auf die Einrichtung bei Händel verdeutlicht freilich auch, dass die derart gelesene VI auf der nächst höheren Diminutionsebene ihrerseits nur eine Prolongation der III ist. Brahms suggeriert in den Takten 2 und 3 eine auf der Abfolge von Doppeltakten beruhende Taktordnung, bei welcher der Eröffnungstakt als >Auftakt zu verstehen ist. Allerdings kann auch diese Lesart nicht ungehindert über Takt 3 hinaus fortgesetzt werden. Vielmehr scheint es, als werde mit Takt 4 wieder gemäß b) verfahren, da hier die (durch die II prolongierte) $V^{\sharp}$ erreicht wird, während gemäß a), wo die eröffnende I regulär als Auftakt gesetzt erschiene (siehe Händels Bourrée), erst ein dritter Takt erreicht sein dürfte. Deutlich wird nun, dass die originalen Takte 2 und 3 strukturell der Darstellung der Dezime $d$-fis ${ }^{2}$ gelten, die Taktgruppe, die der Auskomponierung der strukturellen Dezime $e-g^{2}$ gilt, aber fehlt.

In Beispiel 3 zeigen die Hörfolien c) und d), wie von a) zum Brahms'schen Original gefunden werden kann: Im Hintergrund bleibt der Kopfton erhalten. In der Mittelstimme setzt der Vorhalt cis frei ein. Im Vordergrund des Originals kehrt schließlich wieder, was 
in a) vorausgesetzt wurde, aber im Hintergrund ausgespart bleibt: die Auskomponierung der Wechselnotenbewegung $\mathrm{fis}^{2}-\mathrm{g}^{2}-\mathrm{fis}^{2}$. Dass ein Hörer trotz der Auslassung des idealtypischen Takts 3 direkt zum idealtypischen Takt 4 finden kann, verdankt sich primär dieser Kompensation. Unterstützend verhält sich das Verhältnis von Melodie und Grund: Indem die Klänge entgegen einem bassbezogenem Hören nicht von ıunten` nach `oben`, sondern in entgegengesetzter Richtung entstehen, wird nicht nahegelegt, $g^{2} z u$ Beginn von Takt 2 als Vorhalt (über $d$ ) aufzufassen, sondern in direktem Anschluss an Takt 1 als Dezime über einem im Bass antizipierten e. Gleichwohl setzte sich ein solches Hören über das $a^{2}$ am Ende von Takt 1 hinweg, wo doch, um die Dezime e- $g^{2}$ zu sichern, $g^{2}$ der Oberstimme vorgezogen sein müsste. Eben jenes $a^{2}$ verweist auf die Sollbruchstelle gemäß Hörfolie b) - als Präpositio des nicht realisierten Vorhaltes $a^{2}-g^{2}$ (Beispiel 5):



Beispiel 5: Georg Friedrich Händel, Music for the Royal Fireworks HWV 351, Bourrée, Johannes Brahms, Intermezzo h-Moll op. 119/1, Zuordnung der Strukturmomente T. 1-4

\section{Rekomposition}

Die voranstehenden Überlegungen bilden die Grundlage der nachfolgenden Alternativfassung, die durchgängig im Sinne von a) verfährt.

Beispiel 6 zeigt eine Rekomposition der eröffnenden Phrase des Intermezzos als 16-taktige Periode. ${ }^{12}$ Damit wird der Formgebung des Originals gefolgt: Die insgesamt dreiteilige Anlage weist einen ersten Rahmenteil auf, der als sechzehntaktige modulierende Periode mit speriodischer ${ }^{13}$ Taktgruppenordnung angelegt ist. Auf eine dominantische Öffnung (T. 8) folgt ein Nachsatz gleicher Länge, der mit einer förmlichen Ausweichung in die $\mathrm{V}$ endet. Im alternativen Vordersatz bleibt die Achttaktigkeit erhalten.

12 Diese und verwandte Begriffe der Formenlehre nach William E. Caplin 1998.

13 Diese Begrifflichkeit nach Michael Polth: »Ein musikalisches Verhalten soll 'periodisch` heißen, wenn die (regelmäßige) Ausbildung von Anfängen und Schlüssen als Voraussetzung deutlich wird, wenn also das Fehlen eines Endes in der Tat eine Abweichung darstellt. sMetrisch heißt ein Verhalten, in dem sich Taktgruppen allein durch Anfänge begrenzen, ohne daß ein Ende ausgelassen wird.« $(2000,138)$ 



Beispiel 6: Alternativfassung zu Johannes Brahms, Intermezzo h-Moll op. 119/1, T. 1-16

Analog zur Bourrée Händels gehört die erste harmonische Position der Alternativfassung zwar bereits zur Quintfallsequenz, hat aber auch hier die Funktion eines Auftaktes: Der Eintritt in das auf Doppeltakten basierende Modell erfolgt erst mit Takt 2. Die Alternativfassung legt vorläufig nahe, die idealtypischen Takte 1 und 2 in Takt 1 des Originals zusammengezogen zu sehen. Anders als in Takt 2 und 3, wo durch die retrospektiv klärende Dezime auf der letzten Zählzeit die Bewegung der realen Oberstimme als Vorhaltsauflösung deutbar ist, lassen sich in Takt 1 des Originals Bass und Oberstimme nicht gemäß eines satztechnischen Standards aufeinander beziehen. Die Terzfallbewegung endet hier mit dem dritten Achtel, und die Melodie greift zum $a^{2}$ aus statt abzusinken. Anstelle der Dezime kommt so das dissonante Intervall der Quarte zustande. Der fehlende Stimmführungszusammenhang lässt daran zweifeln, ob es sich in Takt 1 überhaupt um einen ıAkkord`, geschweige eine (oder mehrere) eigenständige Stufe(n) handelt.

Die Eigenartigkeit von Takt 1 sensibilisiert für Unstimmigkeiten, die auch der Einbindung der Takte 2 und 3 in einen herkömmlichen Stimmführungszusammenhang entgegenstehen: In den Takten 2 und 3 entziehen sich die Nonen über den jeweiligen Harmonien - $e^{2}$ über D und $a^{1}$ über G - dem Stimmführungszwang zur Auflösung. Sie bleiben in der Deckung des Außenstimmensatzes liegen ${ }^{14}$, was sich als Reflex auf die Technik des Fingerpedals in barocken Texturen verstehen lässt. Durch diese Anlagerung zusätzlicher Kontrapunkte an einen regulären vierstimmigen Satz nimmt die Gestaltung der Takte 2 und 3 eine mittlere Position zwischen dem nach herkömmlichen Gesichtspunkten unkonturierten Takt 1 und dem im stärksten Kontrast dazu stehenden Takt 4 mit seiner klaren Trennung zwischen Melodie, Grund und Begleitung ein. Die Gestaltung der Takte 2 und 3 weist mit ihrem Anklang an Mixturtechniken auf das Ende des Stückes (T. 58ff.) voraus.

14 Freilich könnte man mittelbar $e^{2}$ ins $d^{1}$ und $a^{1}$ ins $g^{1}$ in den jeweiligen Folgetakten aufgelöst sehen. 
Soll gemäß des Originals in Takt 8 die Dominante erreicht werden, kann in Takt 7 keine Bewegung in die strukturellen Mittelstimmen gemäß Hörfolie a) erfolgen. Das dritte Glied des doppeltaktigen Quintfallmodells bleibt in der Alternativfassung daher unvollständig: Der strukturellen Oberstimme $e^{2}$ (T. 6) folgt keine Mittelstimme ais ${ }^{1}$ mehr nach. Auch der originale Takt 4 mit seiner Melodiebewegung $e^{2}-d^{2}-c i s^{2}$ schickt sich nicht an, den Tonraum zwischen $e^{2}$ und ais stufenweise aufzufüllen, sondern entspricht einer alternativen Diminutionsform (e-cis statt e-ais), die gewählt ist, um die Tenorklauselebene der (überspielten) Kadenz zu markieren.

Der Nachsatz der Alternativfassung weicht vom Original durch seine tonikalen Ganzschluss ab. Dies exemplifiziert weniger ein mögliches Ende des ersten Rahmenteils als vielmehr das der gesamten Komposition. Deren Schlusswirkung kann unter Rückgriff auf die Takte 4 und 5 des Originals erhöht werden: In Takt 4 sinkt die reale Oberstimme vom 4. zum 2. Ton und stellt damit den 1. Ton in Aussicht, der zu Beginn von Takt 5 eintreten könnte, dort aber durch den Rücksprung zum Ausgangston fis $^{2}$ verweigert wird. Die altisierende Durchgangsbewegung des Basses entspricht einer Form der Kadenzflucht und führt in den Sextakkord der I. Stufe, den gängigen Ausgangsakkord einer kadenziellen Konstellation.
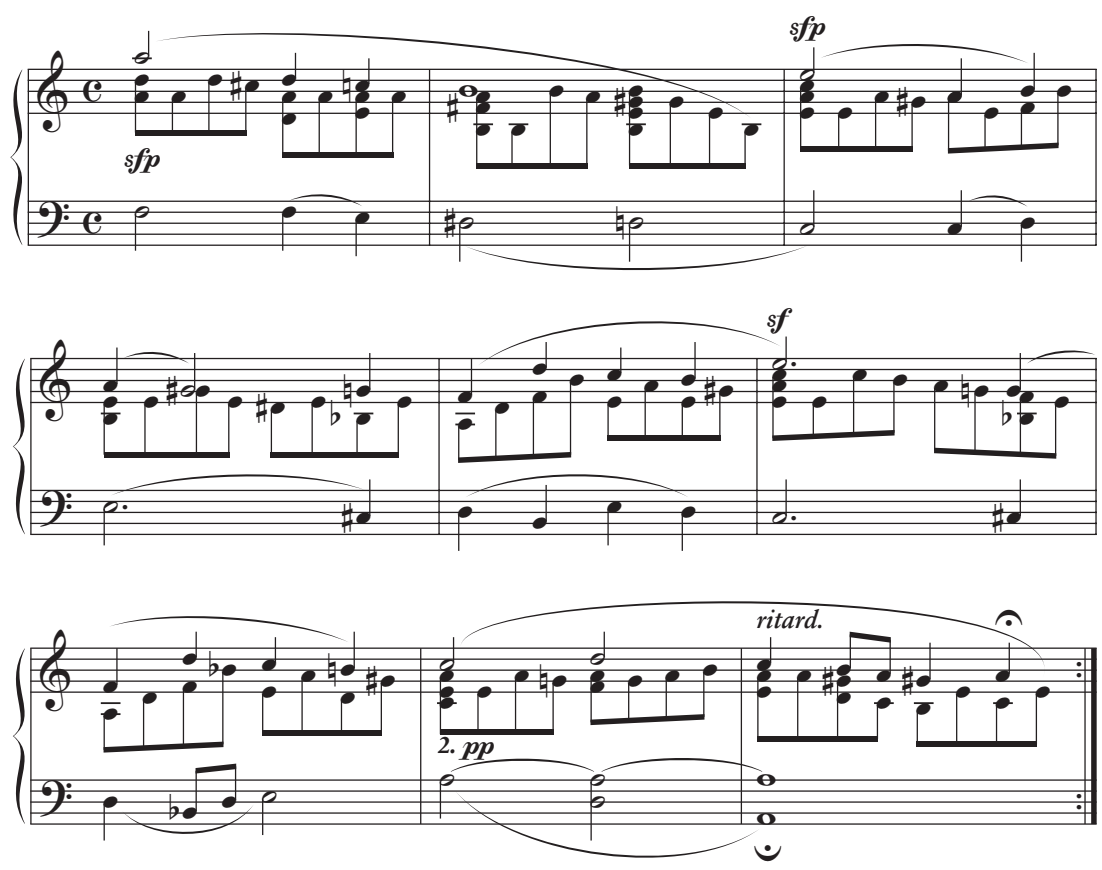

Beispiel 7: Robert Schumann, Sheherazade op. 68/32, T. 19-27

Im Schlussabschnitt von Robert Schumanns Sheherazade aus dessen Album für die Jugend wird in Takt 20 der durch die Prädominante in Aussicht gestellte Dominantklang als Sekundakkord gesetzt und führt mit Beginn des Folgetaktes auf den tonikalen Sext- 
akkord. Damit einher geht der charakteristische Rücksprung in der Oberstimme vom 2. zum 5. Ton. In Takt 23 ist die kadenzielle Situation noch entschiedener artikuliert, doch wiederholt sich die Situation aus Takt $21 . .^{15}$

Der Vergleich mit Schumanns Komposition legt es nahe, Takt 5 des Intermezzos als letzten Takt einer Taktgruppe zu interpretieren, der durch Rücksprung und Takterstickung zum ersten Takt einer neuen Taktgruppe erklärt wird. Entsprechend kann der Nachsatz der Alternativfassung auf zehn Takte erweitert werden:



Beispiel 8: Alternativer Nachsatz mit 10 Takten zu Johannes Brahms, Intermezzo h-Moll op. 119/1, T. 7-10

Bei Brahms steht die Platzierung der Kadenzflucht im Taktgefüge metrisch quer zu einer periodischen Taktgruppenordnung: Takt 4 hat die Funktion eines vorletzten Taktes, bildet aber den Abschluss der ersten Taktgruppe. Ein Blick auf die ersten drei Takte der Komposition zeigt allerdings, dass Takt 4 nicht zu spät, sondern zu früh eintritt: Regulär wäre seine Präsentation als siebter Takt. Auf harmonischer Ebene bleibt der erwartete h-Moll-Sextakkord in Takt 5 durch die Aussparung der Mittelstimmen aus: Zwar führt die verzögert einsetzende Begleitung, die im Durchgang von der sverschwiegenen Terz $d^{2}$-fis ${ }^{2}$ herzukommen scheint, auf die Mittelstimmen $h^{1}$ und $d^{1}$, durch die der Klang als I manifest werden könnte. Die gleichzeitige Fortsetzung der Basslinie aber, die den Kanon zwischen den Außenstimmen fortschreibt, gelangt infolge der Imitation des vormaligen Quartsprungs cis $^{1}-$ fis $^{2}$ in der Oberstimme (T. 4 zu T. 5) auf den Ton g: Retrospektiv wird ein harmonischer Quintfall $d$-g impliziert. Der Fundamentwechsel von sh nach >D Takt 5.1 ereignet sich stillschweigend (Beispiel 9). ${ }^{16}$

Auffällig ist, dass Brahms den Oberstimmenzug e-d-cis (T. 4) im Rahmen der Sequenz beibehält (T. 6), obwohl nun nicht II- $\mathrm{V}^{\sharp}$ in h-Moll, sondern II-V in D-Dur gesetzt ist. Die Wiederholung vermag darüber hinwegzutäuschen, dass die Zwischenkadenz zur III Teil eines anderen Sequenzmodells ist, durch den der kurzfristige Anstieg von I zu III vermittelt wird. Es handelt sich um einen chromatisierten Dur-Moll-Parallelismus mit den

15 Schumann überbietet diese Stelle noch ein drittes Mal, indem selbst bei der Wiederholung der Kadenz nicht in den Schlussklang, sondern in den Anfang des Stücks und von dort (zunächst) in die Wiederholung des zweiten Formteils gefunden wird: ein Sinnbild für den nicht abreißenden Erzählfluss der Sheherazade. Indem aber keine Seconda Volta gewählt ist, verzichtet selbst das endgültige Ende der Komposition auf eine definitive Formel.

16 Hier wird eine weitere Schwäche der `Quintfallsequenz-These ‘ deutlich: In dieser muss die G-Stufe in Takt 5 unbeachtet bleiben und damit der Umstand, dass Takt 7 melodische Sequenz von Takt 5 ist. Anders aber als in Takt 5 wird in Takt 7 durch die Bassführung fis- $d$ der - nunmehr im Rahmen einer Kadenz nach D-Dur - in Aussicht gestellte Sextakkord der III bestätigt. 


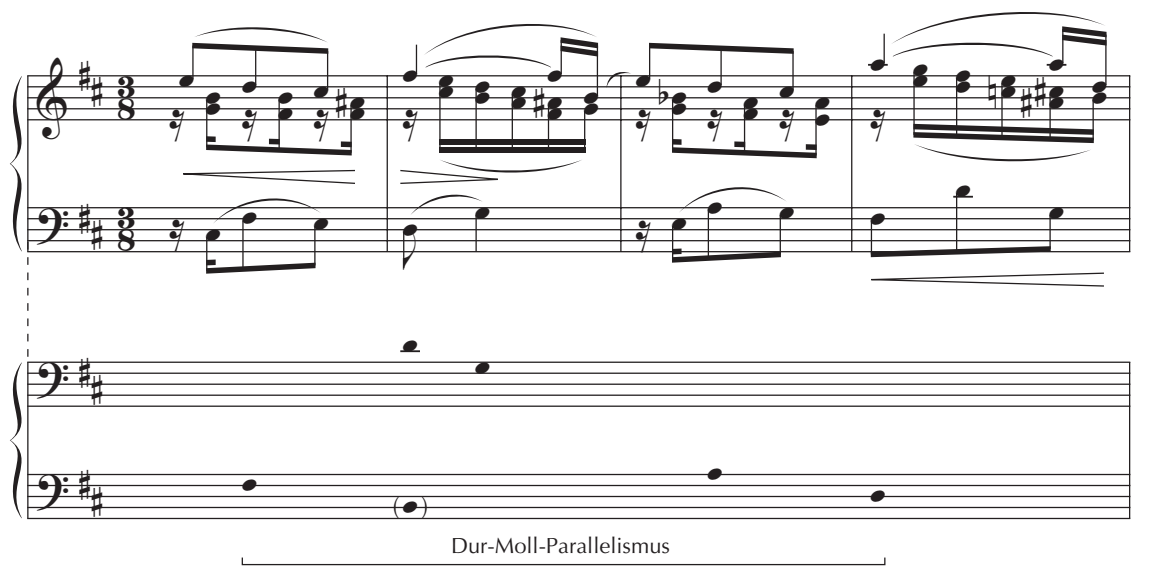

Beispiel 9: Johannes Brahms, Intermezzo h-Moll op. 119/1, Quintfälle und Dur-MollParallelismus T. 4-7

Gerüststufen Fis, h, A und D. Den Fis- und A-Stufen als Zwischendominanten ist jeweils eine lokale II als Prädominante vorangestellt. Die erste dieser Prolongationen geht nahtlos aus der Quintfallsequenz der Takte 2-3 hervor: II- $\mathrm{V}^{\sharp}-\mathrm{I}$ in Takt 4 ist zugleich Beginn der neuen Sequenz. Die zweite Prolongation (II-V-I in sharmonisch ${ }^{17}$ D-Dur) in Takt 6 führt in die Quintfallsequenz zurück, durch die am Ende von Takt 8 der dominantische Teiler der Haupttonart erreicht wird.

Dieses Ende kann im Sinne der periodischen Taktgruppenordnung als Halbschluss aufgefasst werden. Vor diesem Hintergrund liegt es nahe, nicht nur die Takte 4 und 5, sondern den gesamten Dur-Moll-Parallelismus als Teil einer äußeren Erweiterung des alternativen Nachsatzes zu verstehen, der dadurch auf insgesamt 14 Takte anwächst. Der Ausgriff zur III überbietet so die einfache Kadenzflucht. Damit in die aus Beispiel 8 bereits bekannte Schlusswendung zurückgefunden werden kann, wird die rückleitende Quintfallsequenz um einen weiteren Takt erweitert (Beispiel 10).

Das Beispiel der Bourrée aus Händels Music for the Royal Fireworks verdeutlicht die Funktion von Sequenzen in der Musik der traditionellen Mehrstimmigkeit spätestens seit dem Barock: Sie durchmessen den durch harmonische `Knotenpunkte ‘ (Felix Salzer) aufgespannten Tonraum. Und umgekehrt gilt: Erst durch die stringente Bewegung, mit der ein `Anfang diese Knotenpunkte aus. In der Komposition Händels beispielsweise führt die erste Sequenz auf die I in Terzlage zurück und dient damit der Prolongation der Anfangstonika in Form einer erweiterten Initialkadenz. Von dieser Art Abstimmung haben die ersten Takte der Brahms'schen Komposition nichts. Sie muten wie das Ergebnis einer kaleidoskopartigen Montage an, infolge derer Takte oder Taktgruppen aus standardisierten Kontexten 

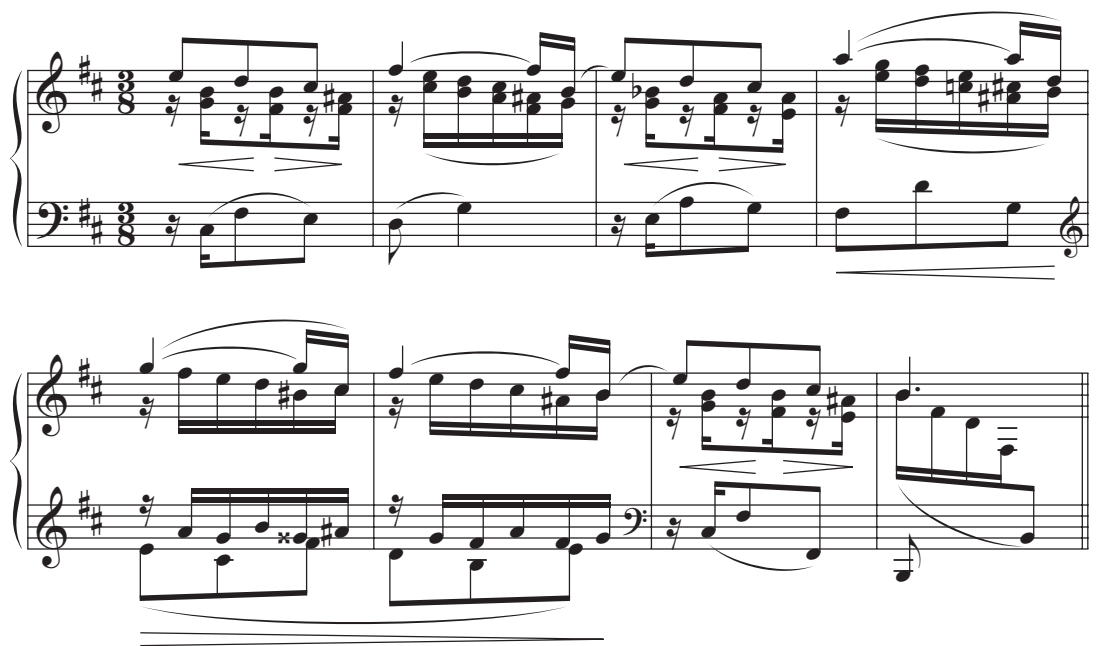

Beispiel 10: Alternativer Nachsatz mit 14 Takten zu Johannes Brahms, Intermezzo h-Moll op. 119/1, T. 7-14

herausgeschnitten und in eine ungewohnte Anlage gebracht worden sind. Die einzelnen Wendungen wirken hierdurch gleichsam sentfunktionalisiert.$^{18}$

Das scheint zunächst der These zuzuarbeiten, dem Intermezzo lägen traditionelle Strukturen (wie Quintfallsequenzen) zugrunde, die, obwohl sie nur in Latenz begegnen, den musikalischen Zusammenhang gleichwohl gewährleisteten. Verhielte es sich so, dann müsste die Gegenüberstellung eines Beispiels, das die entsprechenden Vorgänge manifest aufweist, helfen, die Vorgänge in der Brahms'schen Komposition zu verdeutlichen und ihre `Entfernung`von der idealtypischen Rekomposition fühlbar zu machen. Stattdessen aber führt die Konfrontation zum Zerfall des Originals in mehr oder weniger unverständliche Einzelheiten, die keinen übergeordneten Zusammenhang mehr ausprägen. Das aber besagt, dass die Träger des globalen musikalischen Zusammenhangs in Brahms' Intermezzo nicht bloß in die Verborgenheit zurückgetreten sind, sondern der Zusammenhang dort auf andere Weise hergestellt ist.

Nicht schlicht Latenz tritt an die Stelle des Manifesten, sondern ein neues funktionales >Programm (im Sinne Niklas Luhmanns) an die Stelle des alten. Insofern muss auch die obige Formel von der `Entfunktionalisierung، als vorläufig gelten: Der Zerfall des Originals tritt nur ein, wenn der Hörer durch eine Rekomposition dazu angehalten

18 Freilich könnte in der numerisch (akademisch-)korrekten Gliederung des ersten Formteils in zwei Teilsätze von jeweils acht Takten ein Moment der Kompensation gesehen werden. Auch hilft das langsame Tempo, die Fragilität der inneren Verfasstheit zu relativieren, unterstützt es doch die Vereinzelung der Ereignisse und dämpft die Erwartung eines standardisierten Fortgangs: »Das kleine Stück ist ausnehmend melancholisch, und ısehr langsam spielen ist nicht genug gesagt." (Brahms in seinem Brief an Clara Schumann vom Mai 1893, in der er die Übersendung einer Abschrift von op. 119/1 ankündigt, zit. nach Lietzmann 1927, 513) >Adagio als Tempovorschrift begegnet in Brahms' späten Klavierstücken ansonsten nur noch in op. 116/4. 
wird, es auf jene Form von Funktionalität zu beziehen, die für den musikalischen Zusammenhang im Werk global nicht mehr verantwortlich ist - hier: die `Ursatz-Tonalitätı. Ohne eine solche Manipulation wird der Hörvorgang hingegen offenkundig durch eine Dialektik bestimmt: Der Wechsel des >Programms` innerhalb des funktionalen Systems `Tonalität geht einher mit der Erfahrung der Limitation des bisherigen Hörens (und dessen begrifflicher Erläuterung). Unbestreitbar kann die Erfahrung dieser Limitation als ein Moment der Unwägbarkeit oder gar Befreiung große Lust bereiten; sie kann es aber nur, weil sie durch ein neues Programm gedeckt ist, das die ästhetische Gelungenheit des Werks verbürgt. ${ }^{19}$ Die Anschlussfähigkeit des neuen Programms wird durch den Rekurs auf geläufige Nahkontexte und satztechnische Einrichtungen ermöglicht. ${ }^{20}$ Dieses neue Programm wird hier als `Tonalität der Tonfelder $\iota^{21}$ verstanden.

Im Anschluss an Georg Friedrich Hegel ließe sich sagen: Die bisherigen funktionalen Bestimmungen werden nicht einfach vernichtet, sondern in ihrem bisherigen globalen Geltungsanspruch dadurch zurückgewiesen, dass sie Teil von etwas Komplexerem werden (im doppelten Sinne von `Aufheben`).

\section{Tonfelder und ihre Artikulation}

Die Artikulation von Tonfeldern begegnet in Brahms' Intermezzo in zweierlei Form. Dort, wo die traditionelle Mehrstimmigkeit aufgelöst wird, treten reihenartige Strukturen an die Stelle regulärer Stimmführung. Demgegenüber gibt es Abschnitte, wo die Felder mit herkömmlichen kontrapunktischen Mitteln auskomponiert werden. Insofern ließe sich zwischen sloser und sfester Kopplung` (Fritz Heider ${ }^{22}$ ) unterscheiden. Das Alternieren zwischen den unterschiedlichen Artikulationsformen der Tonfelder ist grundlegend für die Formbildung des Intermezzos.

Mit Blick auf den formalen Verlauf der Komposition wird folgende Zuordnung erkennbar: Die periodisch angeordneten Teilsätze des Rahmenteils beginnen jeweils lose

19 Den analytischen Diskurs der Gegenwart durchzieht die Behauptung sschöner Verwirrungen aller Art. Da derlei Rede in Zeiten der Postmoderne ihren Wert in sich selbst zu tragen scheint, bleiben entsprechende Analysen oftmals die Indizierung dessen schuldig, was eine ıschöne Verwirrung، von kompositorischer Indifferenz unterscheidet. Dieses Problem verschärft sich angesichts einer santiquarischen Historikı (Friedrich Nietzsche), die jedes Werk als historisch geschichtet versteht und entsprechend dekomponiert. Denn weder gewährleistet das sich wechselseitige Beleuchten differenter Strukturen (und/oder Strukturbegriffe), noch das Verständnis des gegebenenfalls zwischen ihnen bestehenden entwicklungsgeschichtlichen Zusammenhangs bereits die Erfahrung von Einheit. Im Gegenteil: Je weniger sub specie aeternitatis ıverloren gehtı, um so dringlicher stellt sich die Frage, was die Erfahrung von Zusammenhang ermöglicht. Freilich kann eine ‘Lösung` des Problems darin bestehen, jeglichen Begriff musikalischen Zusammenhangs preis zu geben. Demgegenüber wird hier mit Blick auf den historischen Ort der Komposition Brahms' am Begriff des musikalischen Zusammenhangs als Einheit festgehalten, der in Form einer (wie auch immer gearteten) Systematizität zu exemplifizieren ist.

20 Vgl. Rohringer 2009.

21 Auf eine gesonderte Einführung in diesen Ansatz wird hier mit Blick auf die bereits vorliegenden Darstellungen in Haas 2004, Polth 2006a und 2011 sowie Rohringer 2009 verzichtet.

22 Vgl. Heider 1926. 
gekoppelt (T. 1 und T. 9), während insbesondere das neugefasste Ende des zweiten Teilsatzes demgegenüber fest gekoppelt erscheint. Entsprechend sind auch die beiden Schlüsse am Ende des zweiten Rahmenteils gestaltet (T. 58ff. und T. 62ff.). Von größter Losigkeit ist die der Reprise vorangestellte Rückleitung der Takte 43-47.

Die Mitte der Komposition zeichnet sich durch die Umkehrung dieser Verhältnisse aus. Auch sie ist periodisch gegliedert. Die Anfänge beider Teilsätze sind hier jedoch stabil. Das trifft insbesondere auf den ersten Teilsatz mit seiner eröffnenden Initialkadenz zu. Schon deren Fortführung aber hat die Tendenz zur Losigkeit und mündet in einen mäandernden Halbschluss. Der Beginn des zweiten Teilsatzes findet nicht mehr zur ursprünglichen Festigkeit zurück. Eine kontrapunktische Gegenstimme in der Mitte des Satzes arbeitet dem von Beginn an entgegen (T. 31f.). Trotz energischer Gegenwehr ab Takt 37 führt die weitere Fortführung zu keinem geregelten Abschluss.



Beispiel 11: Johannes Brahms, Intermezzo h-Moll op. 119/1, Tonfelder T. 1-4

Beispiel 11 zeigt, wie die diatonische Terzfallkette $g^{2}$ bis $g$ in Takt 2-3 das Heptaton $g$-cis artikuliert. Es genügt ein einziges Glied der doppeltaktigen Quintfallsequenz zur Vervollständigung des Tonfeldes. Die Vorhaltsbildungen $g^{2}-f i s^{2}$ und $c i s^{2}-h^{1}$ helfen den Inhalt zusätzlich zu verdeutlichen, indem beide Begrenzungstöne des Heptatons besonders betont werden: Die Folge g-cis erscheint zunächst als melodisches Intervall im Gerüstsatz zwischen struktureller Ober- und Mittelstimme. Anschließend werden durch die äußerste Dehnung des Undezimen-Vorhaltes cis und $g$ im Außenstimmensatz zeitlich maximal aneinander gerückt.

Schlüssig ist aus dieser Perspektive nunmehr auch der eröffnende Takt: Das Heptaton g-cis geht aus einem anfänglichen Hexaton g-fis hervor. Der zunächst im Terzenarpeggio fehlende Ton a wird durch die Melodiebewegung der Oberstimme nachgereicht. Das eröffnende Hexaton verhält sich tonartlich androgyn: Die beiden potentiellen Leittöne - cis (in D-Dur) und ais (in h-Moll) - bleiben noch ausgespart. Die Differenz zwischen dem reinen und dem harmonischen Heptaton ${ }^{23}$ wird erstmalig in Takt 4 realisiert, wenn a durch ais ersetzt wird. 
Ein durchgängig traditionelles Satzbild zeigen hingegen die Takte 12-16. Die Kadenz wird in der strukturellen Oberstimme durch einen Quintzug eingeleitet. Beispiel 12 zeigt einen möglichen Mittelgrund für dessen Harmonisation:

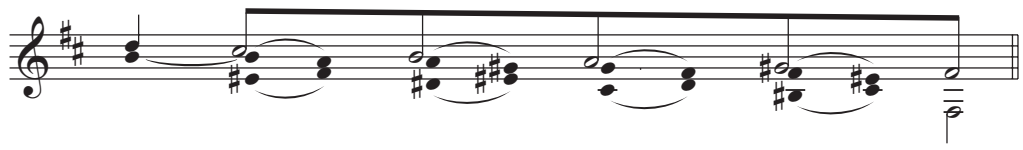

Beispiel 12: Johannes Brahms, Intermezzo h-Moll op. 119/1, paradigmatische Stimmführung T. 12-16

Die offenen Quintparallelen der verschobenen Dreiklänge über fis, $e, d$ und cis sind durch eine 6-5-Konsekutive vermieden. Hiermit korrespondiert eine 2-3-Dissonanzenkette der beiden Oberstimmen. Die Verwendung kleiner Sexten bringt eine Folge diskantisierender Zwischenkadenzen hervor.

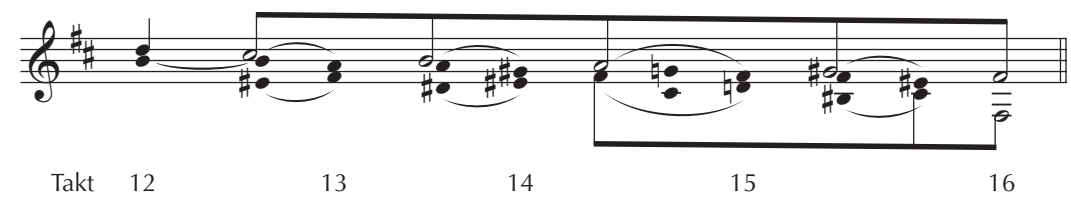

Beispiel 13: Johannes Brahms, Intermezzo h-Moll op. 119/1, Stimmführungsskizze T. $12-16$

Beispiel 13 zeigt die im Intermezzo vorgenommene Modifikation. Sie dient der Stabilisierung der förmlichen Ausweichung: Der lokalen melodischen Strukturbewegung 3-2-1 (a-gis-fis) wird eine Bassbrechung (fis-cis-fis) zugeordnet.

Diese Lesart erlaubt nicht nur eine Einordnung des zwischendominantischen Schritts zur fis-Stufe, sondern lässt auch den H-Dur-Septakkord als Verklanglichung der 6. Bassstufe in melodisch fis-Moll verständlich werden. Es handelt sich um eine Synkopendissonanz, durch die der zweigliedrige Sequenzablauf um ein drittes, prädominantisches Element erweitert wird. ${ }^{24}$ Ferner wird die Harmonisation des Mittelstimmenzuges $a^{1}-g^{1}-f_{i s}{ }^{1}$ erklärbar, der den lokalen 3. Ton prolongiert. Dessen alterierte Fortsetzung erscheint in diminuierter Form in den übergeordneten Parallelismus interpoliert: Statt eis/h-fis/acis/gis erfolgt zunächst eis/h-fis/a-cis/g. Die Station $d$-fis unterliegt im Vordergrund ei-

23 Ein harmonisches Hexaton wird dadurch gebildet wird, dass erste und letzte Quinte des sreinen Hexatons vermindert werden (hier: a-e-h-fis-cis-gis wird zu ais-e- $h$-fis-cis-g). Wird eine weitere reine Quinte an seinen Enden angelagert, entsteht ein harmonisches Heptaton (entweder zu harmonisch H-Dur bei Anlagerung von dis oder zu harmonisch h-Moll bei Anlagerung von $d$ ). Werden beide Quinten angelagert, entsteht ein harmonisches Oktoton zu $h$ (vgl. zu dieser Systematik Polth 2011, 227).

24 Diese Erweiterung führt zu einer ungewöhnlichen Betonung der zweiten Zählzeit, die an die für Sarabanden charakteristische `ordo artificialis` denken lässt. Zur Idee einer »verschleierten Sarabande« in op. 119/1 vgl. Goebels 1983. 
ner Verschiebung: Über $d$ wird ein verminderter Septakkord gesetzt. ${ }^{25}$ Der Ton eis ist Vorhalt zu fis. Die Auflösung geht jedoch - infolge des Kanons in den Außenstimmen - bereits mit dem verminderten Septakkord über his einher. ${ }^{26}$ Auf dem Hintergrund dieses Stimmführungsmodells erklärt sich der halbverminderte Septakkord in Takt 13.3 als Durchgangsakkord, was auch seiner metrischen Position entspricht. Durch Realteration wird, ausgehend von dis, ein Durchgang über $d$ geschaffen, der auf den ausgeworfenen Grundton cis führt:



Beispiel 14: Johannes Brahms, Intermezzo h-Moll op. 119/1, Stimmführungsdetail T. 12-13

Obwohl nominal identisch, verdankt sich der halbverminderte Septakkord Takt 13.3 damit einer anderen satztechnischen Konstellation als jener in Takt 12.1.



Beispiel 15: Johannes Brahms, Intermezzo h-Moll op. 119/1, Stimmführungsdetail T. 12-13

25 Demgegenüber geht Diergarten in der Taktgruppe 12 bis 16 gemäß der ২Quintfallsequenz-These von der Überlagerung zweier unterschiedlicher Quintfallmodelle aus: Das erste Modell beruhe auf fallenden »leitereigene[n] (Sept-)akkorde[n] «, das zweite Modell auf der Sequenz von »eigenständigen II-V-I-Kadenzeinheiten", bei denen die jeweils erreichte Stufe "subdominantisiert" wird $(2003,46)$. In einem Schaubild (ebd., Beispiel 4) werden die Stationen beider Modelle der originalen Sequenz zugeordnet. Die /leitereigene، Sequenz zieht Diergarten nur zur Erklärung einer einzigen Station heran: An die Stelle des originalen H-Dur-Septakkordes tritt in Takt 13 ein h-Moll-Septakkord. Diergarten räumt ein, dass diese Akkordstation weder in der originalen Sequenz vorkommt noch in der zweiten Sequenzfolge. Zur Erklärung des halbverminderten Septakkordes Takt 13.3 geht Diergarten von einer »metrischen` Unregelmäßigkeit« aus (ebd., 46). Mit Blick auf das erste Quintfallmodell wird die Terz $h-d^{1}$ dem nachfolgenden Basston gis zugeordnet. Hinsichtlich des zweiten Modells interpretiert Diergarten den halbverminderten Septakkord als verkürzten Dominantseptnonenakkord in A-Dur, der zur II in fis-Moll umgedeutet wird (ebd., 46f., Anm. 19). Der potentielle Fortgang nach A-Dur erkläre auch, »warum das folgende szwischendominantisch erreichte fis-moll eine solch trugschlüssige Wirkung entfalten kann.« (Ebd., 47)

26 Zu Recht merkt Diergarten an, dass sich der verminderte Septakkord «als >Einfärbung، des D-Dur hören und deuten « lässt (ebd., 48). Diese Beobachtung korreliert mit einem Verfahren, das Polth mit Blick auf das Intermezzo A-Dur op. 76/4 beschrieben hat: Demnach entstünden Tonfelder dadurch, »dass Brahms die fundierende Bedeutung der Rhythmik für das konstitutive Nacheinander bestimmter Töne partiell suspendiert.« $(2011,242)$ 
Beispiel 15 zeigt diese Erweiterung für den Anfang der Taktgruppe 12 bis 16 und zugleich weitere Details der satztechnischen Einrichtung, die aus einem Stimmtausch hervorgehen und dem Übergang zum Vordergrund der Komposition angehören: Die 2-3-Dissonanzenkette zwischen den beiden Oberstimmen erscheint im Brahms'schen Original in den Außenstimmen.

Auch der halbverminderte Septakkord über gis in Takt 12.1 wird über einen Durchgangsakkord erreicht - hier nicht in Form eines Grund-, sondern Sekundakkords. Jedoch ist im Übergang zu Takt 12 eine Fortführung gewählt, die der regulären widerspricht:

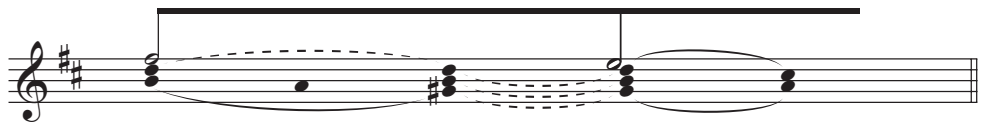

Beispiel 16: Johannes Brahms, Intermezzo h-Moll op. 119/1, hypothetische Stimmführung im Übergang zu T. 12

Gemessen an der Stimmführung von Takt 13 zu Takt 14 wird am Ende von Takt 11 eine Sequenz in A-Dur mit struktureller Oberstimme fis-a in Aussicht gestellt. Zwar ist A-Dur keine reguläre Ausweichungsstufe in h-Moll, wohl aber in D-Dur. Ein entsprechender Fortgang würde den melodischen Anschluss an den Kopfton wahren. Es käme zu einer paradigmatischen Anordnung in (D-)Dur, bei der auf 3-2 in der Urlinie ein Mittelstimmenzug in die Confinalis (a) führt. Eben dieses Modell erscheint im Original jedoch nach Moll transferiert, insofern der Zielton fis erreicht wird. Der Zug ereignet sich aus der Mittelstimme $d^{2}$ heraus. Lage und Fortführung im Original erklären den halbverminderten Septakkord nicht zur VII in A-Dur, sondern zur II in fis-Moll.

Obgleich die gewählte Fortführung von der Stimmführung her möglich ist, haftet dem originalen Übergang daher ein Moment von Diskontinuität an. Die lokale Integrität der mit Takt 12 einsetzenden Sequenzstruktur in fis-Moll unterstreicht deren versatzstückartigen Gebrauch. Das sensibilisiert für weitere klangliche Einzelheiten, die in dem Maße hervortreten, wie ein übergeordneter traditioneller Stimmführungszusammenhang verblasst.

Beispiel 17 zeigt die Tonfelder, wie sie mit den (erweiterten) Möglichkeiten der traditionellen Mehrstimmigkeit auskomponiert werden. Im vierten Takt des Nachsatzes (T. 8) findet mit dem harmonischen Heptaton zu h-Moll, trotz der Beibehaltung der satztechnischen Einrichtung der beiden vorausgehenden Takte, zunächst dasselbe Tonfeld Verwendung wie an analoger Stelle des Vordersatzes (T. 4). Die Realteration von ais zu a am Ende des Taktes spricht für eine erneute Rückkehr zum Heptaton g-cis. Die Fortsetzung bringt allerdings das harmonische Heptaton zu fis-Moll. Mit Ende des Formteils wird es durch die Wiederkehr des ais an prominenter Stelle zum harmonischen Oktoton zu fis ergänzt. Über das Oktoton lagert sich Takt 13 im Vordergrund eine sechs-tönige Subdominante. Die erstmalige Präsentation des Tones dis lässt sich als Vorgriff auf das dis in Takt 53 verstehen. Auffällig ist auch eine durch zwei verminderte Septakkorde gebildete vollständige Tonika in Takt 15. Der zweite der beiden Akkorde, der aus der Quinttonreihe gebildet ist, scheint zu der enharmonisch verwandten Klangbildung der Takte 56-57 in Verbindung zu stehen. 
Das harmonische Oktoton zu fis umfasst die sechs Töne des Konstrukts Ilb (fis-cis, $d$-a, ais-eis). Brahms inszeniert dessen Klangeigenschaft vornehmlich in den Takten 14 und 15. Hierbei ist der eingefügte Dur-Moll-Parallelismus von besonderer Bedeutung. Er motiviert dazu, nicht nur die diatonisch verwandten Stufen auf sfis` (als Beginn) und 'D (als Ziel) aufeinander zu beziehen, sondern auch den Ton eis als zugehörig zur Konstellation zu empfinden, der mit dem Schlusstakt des Formabschnitts seinen Grundton ais zugeordnet bekommt. Bemerkenswert ist darüber hinaus, dass mit jedem eingesprengten Tonfeld Töne ins Spiel gebracht werden, die das Oktoton zum Zwölftonfeld ergänzen: Die Subdominante steuert das dis bei, die Tonika das his und der Dur-Moll-Parallelismus (der das Heptaton g-cis artikuliert) die Töne e und $g$.
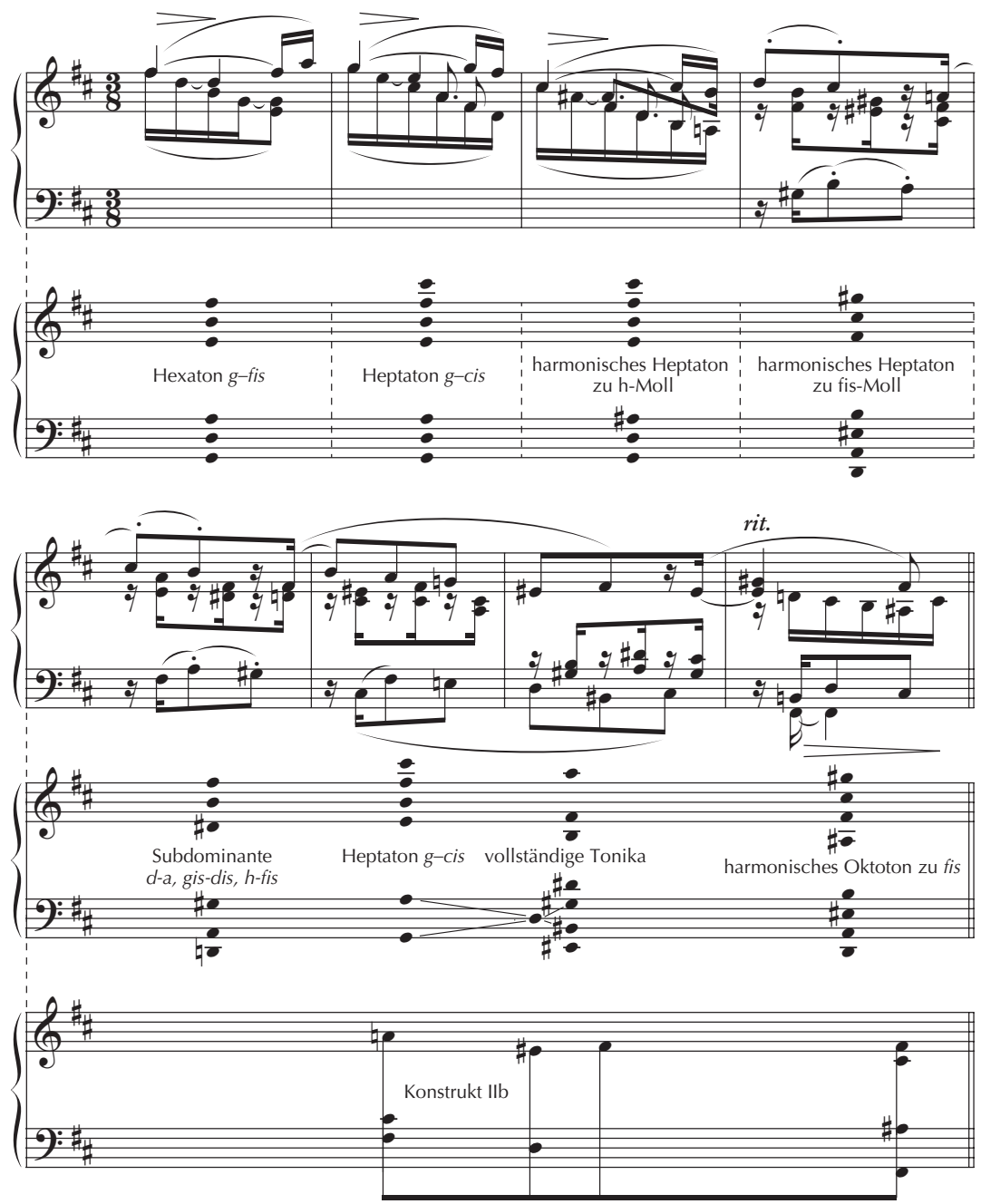

Beispiel 17: Johannes Brahms, Intermezzo h-Moll op. 119/1, Tonfelder T. 9-16 


\section{Tonfeldartikulation im Vergleich - Brahms' Intermezzo und Mozarts Prager Sinfonie}

Ein Vergleich mit einer Komposition Wolfgang Amadé Mozarts vermag den historischen Ort, durch den sich die Arbeit mit Tonfeldern im Brahms'schen Komponieren auszeichnet, zu präzisieren. Die Überleitung aus dem Andante der sogenannten Prager Sinfonie D-Dur KV 504 basiert satztechnisch auf einem `Fonte`(Joseph Riepel), das in Dur die VI und $\mathrm{V}$ der Zieltonart verbindet.

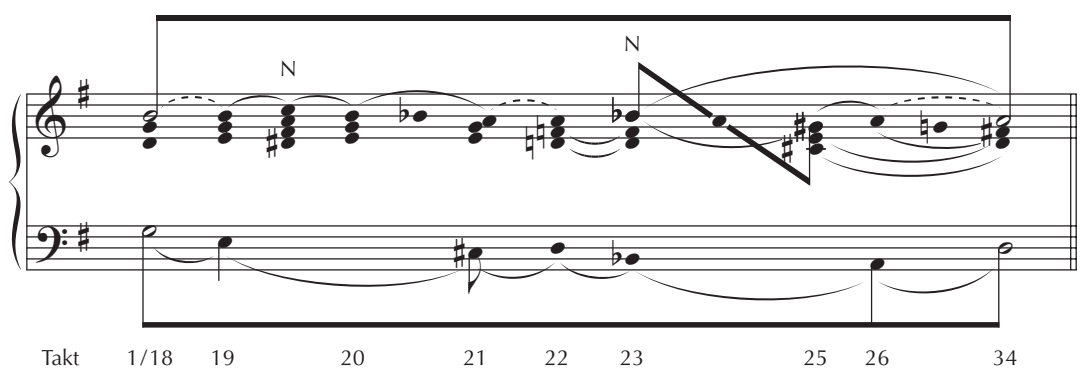

Beispiel 18: Wolfgang Amadé Mozart, KV 504,ii, Stimmführungsskizze T. 1-34

Beispiel 18 zeigt Stimmführung und Stufengang der Passage. Eingeleitet wird die Sequenz durch eine Quint-Sext-Auswechslung im Übergang von Hauptsatz zu Überleitung. Für Mozart charakteristisch ist die Gestaltung des Oberstimmenverlaufs mit Hilfe des Passus durisculus. ${ }^{27}$ Zunächst erfolgt die Auskomponierung der oberen Wechselnote zur lokalen Dominante der VI. Diese Dominante initiiert die Quintfallsequenz, da analog auch der V eine Zwischendominante vorangestellt wird. Als prädominantischer Signalakkord findet der übermäßige Quintsextakkord über der kleinen 6. Bassstufe Verwendung (nicht im Graphen verzeichnet!). Er geht aus einem doppelt-chromatischen Stimmtausch der I hervor. ${ }^{28}$ Dem Akkord vorangestellt ist die VI als reiner Dreiklang ohne ajoutierte übermäßige Sexte. Der Terzfall von der d- zur B-Stufe (T. 22f.) schafft eine Analogie zum Terzfall von der G- zur e-Stufe (T. 18f.).

Eine Besonderheit der Instantiierung des Modells in der Prager Sinfonie besteht in der auffälligen Eintrübung des prädominantischen Klanges mittels einer Vorhalts- und einer Wechselnotenbewegung. Mit Eintritt des zugehörigen Leittons gis werden zunächst $d$ und $f$ durch cis und e vorgehalten (T. 25), was auch als Antizipation von Terz und Quinte des dominantischen Zielklangs verstanden werden kann. Obgleich das in den Außenstimmen vorliegende Diskant-Tenor-Gerüst der Mi-Kadenz die harmonische Station hinreichend verdeutlicht, ist es ungewöhnlich, dass die charakteristische dominantische Struktur zunächst durch einen Klang vorgehalten wird, der - unter Voraussetzung der Enharmonik - in dieser Akkordstellung einen charakteristischen Vertreter der II in Moll darstellt.

27 Vgl. die entsprechenden Passagen in KV 332,i oder auch KV 380,i.

28 Dieses Verfahren beschrieben in Schenker 1956, Fig. 115,2. 
Dieser Klang und nicht der übermäßige Quintsextakkord wird entgegen schenkerianischen Konventionen in Beispiel 18 durch das Z-Zeichen mit dem vorherigen B-DurAkkord verbunden. Dieser ,Verstoßs soll hier auf ein Hören im Sinne der Theorie der Tonfelder verweisen. Aus deren Perspektive erklärt sich die ungewöhnliche Klangbildung als Konsequenz der Vervollständigung der subdominantischen Funktion in der Zieltonart. Der Ausgangsklang, die G-Stufe, enthält den Grundtton $g$ und den Quintton $d$ (T. 1-18). Die Dreiklangsterz $h$, ein Quintton, bekommt ihren zugehörigen Grundton e mit Eintritt der VI zugeordnet (T. 19). Der weitere Grundton $b$ wird durch seine melodische Isolierung und durch die plötzliche dynamische Zurücknahme bei seinem Eintritt (T. 20.4) besonders hervorgehoben. Die Wendung zur B-Stufe (T. 23) ergänzt den zugehörigen Quintton $f$ und bringt die `Rückseite` der vormaligen e-Stufe hervor, gis ist der letzte noch fehlende Quintton. Die besondere Pointe bei Mozart ist, dass gis zugleich mit seinem zugehörigen Grundton cis eintritt (T. 25). Dieser letzte achte Ton des Feldes verleiht der gesamten Instantiierung ihren besonderen Klang und unterscheidet sie von Vergleichsfällen. ${ }^{29}$

Mozarts Überleitung zeichnet sich dadurch aus, dass sich sowohl eine Deutung im Sinne der Ursatz-Tonalität als auch der Tonalität der Tonfelder zur Einrichtung des Tonsatzes kontingent verhält, denn - anders als bei Brahms - sind die Strukturen der UrsatzTonalität noch intakt. Gleichwohl vermag die Synchronizität, die zwischen der Einführung immer neuer motivisch-thematischer Prägungen einerseits und der fortschreitenden Artikulation des Tonfelds andererseits herrscht, auf Seiten des Hörers einen >Aspektwechsek (Ludwig Wittgenstein) motivieren, der den Wechsel von der Ursatz-Tonalität hin zur Tonalität der Tonfelder innerhalb des Systems Tonalität impliziert. ${ }^{30}$ Dementsprechend würden bereits bei Mozart nicht Tonfelder schenkerianische Strukturen einfärben, sondern schenkerianische Strukturen Tonfelder auskomponieren. Vor diesem Hintergrund erscheint das von Brahms im Intermezzo in den Takten 12-16 gewählte Verfahren als nicht sonderlich innovativ. Doch gibt es neben der von Mozart (hier) nicht gesuchten Zwölftönigkeit gleichwohl eine wesentliche Differenz. Sie betrifft die kontextuelle Einbettung beider Formabschnitte. Eine weiterführende Analyse des Andantes würde zeigen, dass die Überleitung nach einem in der Ursatz-Tonalität bekannten Standard verfährt, der gleichermaßen auf den Beginn der Exposition zurück- wie auf deren Ende vorverweist: Sie prolongiert den Wechsel von 3/I zu 2/V. ${ }^{31}$ Demgegenüber erscheint

29 Weder in KV 332,i noch in KV 380,i kommt es an entsprechender Stelle zur Vervollständigung des subdominantischen Tonfeldes. Jeweils fehlt der zur Ausgangsstufe srückseitige` Grundton.

30 Dazu beizutragen vermag auch eine Reihe weiterer Eigenschaften des Andantes. Stellvertretend sei hier auf die enigmatischen Melodiebildungen der Takte 35-36 (ein modifizierter Krebsgang zu T. 14-16) und 47-48 (ein metrisch irregulär eingerichtetes Übergreifen im Dienste der Brechung des lokalen Tonikadreiklangs) hingewiesen, deren Abstraktheit in starker Distanz zur galanten Melodiebildung des Satzanfangs Takt 1-2 steht. Der hierdurch motivierte `Aspektwechsek rückt die Artikulation von Quintenreihen in den Fokus der Wahrnehmung.

31 Freilich steht nach den bisherigen Beobachtungen zu vermuten, dass auch diese schenkerianische Struktur nicht den Hintergrund der Komposition (im Sinne der Ursatz-Tonalität) bildet, sondern ihrerseits eine Auskomponierungsform von Tonfeldern auf einer späteren Schicht darstellt (im Sinne der Tonalität der Tonfelder). Die Frage, welche Zweck-Mittel-Relation letztlich Gültigkeit haben soll, ist in der Diskussion. So hat Michael Polth mit Blick auf den Kopfsatz der Prager Sinfonie geäußert: 
die in die $\mathrm{V}$ ausweichende Taktgruppe im Intermezzo vergleichsweise isoliert. Sie ist nur lose an das Vorige angebunden, der Beginn des Mittelteils ist ausschließlich eröffnend gehalten. ${ }^{32}$ Aus der Gegenläufigkeit zwischen den - gemessen an der traditionellen Mehrstimmigkeit - lokal intakten Strukturen einerseits und ihrem Mangel an Anschluss andererseits resultiert der wehmütige melancholische `Brahms'sche Ton`.

sMangel an Anschluss` kommt mit besonderer Schärfe in den zur Taktgruppe 12-16 satztechnisch analog gehalten Schlussbildungen der Takte 58-61 und 62-67 zum Ausdruck. Der erste auf D-Dur zielende, aber am Ende von Takt 61 scheiternde Schluss ist das nachgereichte Ende des sich verlierenden Nachsatzes aus dem Mittelteil der Komposition (T. 31 ff.). Die Passage schlösse nicht nur harmonisch, sondern auch diastematisch gut an Takt 42 an, weil sie mit der oberen Wechselnote $h$ zu der im Mittelteil strukturell bedeutsamen lokalen Quinte a anhebt.
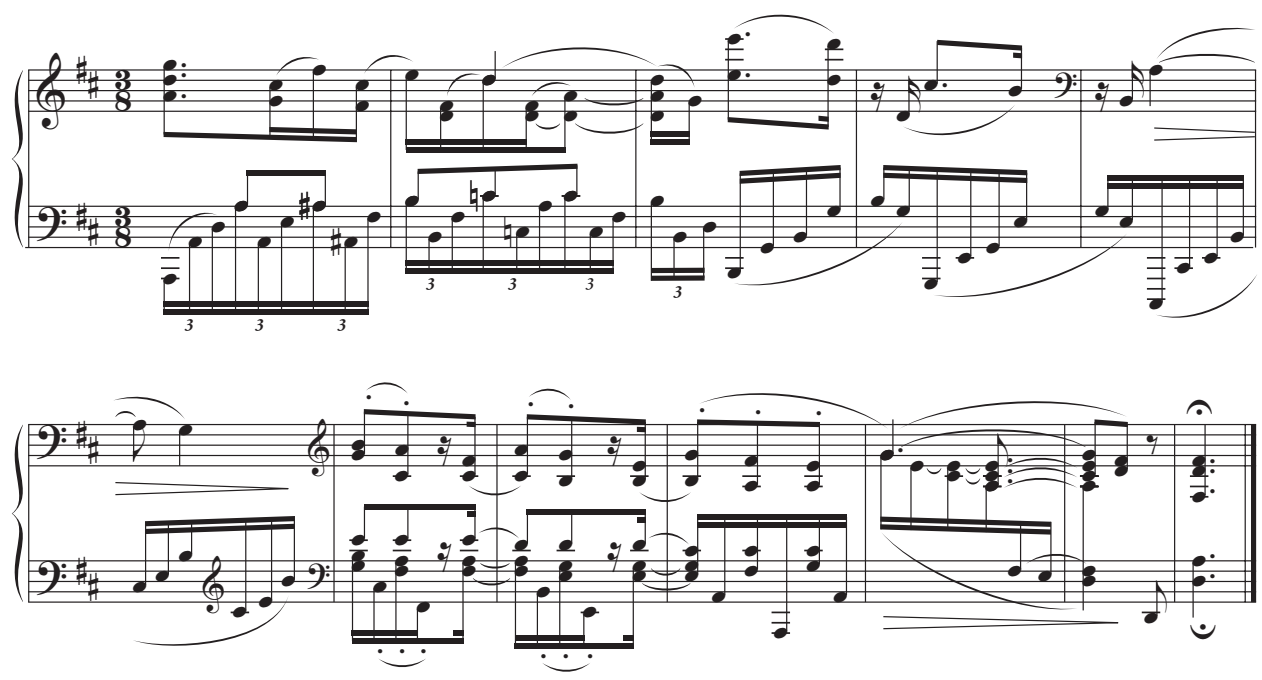

Beispiel 19: Alternativschluss in D-Dur zu Johannes Brahms, Intermezzo h-Moll op. 119/1

Umgekehrt kann der erste Schlussversuch in D-Dur auch getilgt werden und der zweite vorrücken. Diese Alternative lässt das Stück in der obligaten Lage enden.

»Weil die neuen harmonischen Zusammenhänge nicht unmittelbar durch die Funktionen der UrsatzTonalität zustande kommen, sondern dadurch, daß Mozart sich der Ursatz-Tonalität auf bestimmte Weise bedient, sollen die harmonischen Wirkungen, die aus dem besonderen Gebrauch resultieren, Metaeffekte heißen.« (2006b, 158) Demgegenüber hat Bernhard Haas bereits an Mozarts Klaviersonate B-Dur KV 570 ein auf der Tonalität der Tonfelder beruhendes Modell der Sonatenform exemplifiziert, bei dem die schenkerianischen Strukturen Auskomponierungsformen von hintergründigen Tonfeldern sind (2010; vgl. die Diskussion dieses Modells weiter unten im Haupttext).

32 Im Rahmen des im letzten Teil dieser Untersuchung folgenden Schichtenmodells wird diese Beobachtung ihren Niederschlag darin finden, dass die Takte 1-11 nicht im Hintergrund verankert werden. 



Beispiel 20: Alternativschluss in h-Moll zu Johannes Brahms, Intermezzo h-Moll op. 119/1

\section{Schenkeranalytik}

\section{Schenkers Skizzen}

Im Nachlass Heinrich Schenkers finden sich diverse Skizzen zu den späten Klavierstücken von Brahms. Unter den Aufzeichnungen zum Intermezzo op. 119/133 kommt einer Mittelgrund-Skizze besonderer Aussagewert zu. Sie gibt wesentliche Auskünfte über Schenkers Sicht der Gesamtdisposition des Stückes. Auf demselben Blatt findet sich zusätzlich eine der nächsten Schicht zugehörige fragmentarische Detailskizze.

Schenker liest die Quinte als Kopfton. Der Urlinie sind zwei Bassbrechungen zugeordnet: Die zweite geht mit dem Quintzug in der Urlinie einher. Dabei erscheint die III als Terzbrechung auf dem Weg zur V ; letztere ist durch die II prolongiert. Die erste Bassbrechung ist der zweiten subordiniert, sie prolongiert die Anfangstonika, wie Schenker durch seine Bogensetzung deutlich macht, und führt ebenfalls von der I über die III zur V*. Zwischen I und III ist zusätzlich eine V interpoliert - ein sstehengelassener Quintteiler.

33 Oster Collection, Film 34/item 2, 3 und 5 sowie Film 35/item 98. Mit Ausnahme eines einzigen Diagramms hat keine dieser Arbeiten Eingang in Schenkers Publikationen gefunden: Film 35/item 98 zeigt eine Vorstudie der Takte 9-16 zu Figur 87, 3d) in Schenker 1956. Reproduktionen aller Skizzen auf Papier sind derzeit leider nur in sehr unterschiedlicher Qualität erhältlich, was offenkundig der wechselnden Güte der Fotografien oder dem Zustand der originalen Skizzen geschuldet ist. Kaum leserlich sind 34/item 3 und 5, eingeschränkt leserlich ist 34/item 6, das im rechten unteren Bildrand die Entwurfsfassung zu 35/item 98 enthält. Gut leserlich sind hingegen 35/item 98 und 34/item 2. Eine komplette Edition aller Skizzen zu op. 119,1 planen Allen Cadwallader und William Pastille (vgl. 1999, 31, Anm. 16). 




Beispiel 21:

Heinrich Schenker, Skizze zu Johannes Brahms, Intermezzo h-Moll op. 119/1, Film 34/item $2^{34}$

Die in Schenkers Skizze fehlenden Taktangaben lassen sich recht einfach erschließen: Das Ende der ersten und der Beginn der zweiten Bassbrechung fallen mit der Reprise des Rahmenteils (T. 47) zusammen. Der sstehengelassene`Quintteiler markiert die förmliche Ausweichung in die V am Ende des ersten Rahmenteils (T. 16). ${ }^{35}$ Die III im Zusammenhang mit der ersten Bassbrechung ist die Tonart des Mittelteils. Die angestrebte $V^{\sharp}$ ist die Rückleitungsdominante (T. 46), die den Wiedereintritt des Rahmenteils vorbereitet.

Die Detailskizze gibt zusätzlich Auskunft über den dominantischen Teiler am Ende des ersten Teilsatzes (T. 8). Ferner verdeutlicht sie, dass Schenker den Mittelteil aus der Auskomponierung der oberen Wechselnote zum Kopfton hervorgehen sieht: Nach dem Wechsel von I zu III (unter Beibehaltung des Kopftons als realer Oberstimme) erscheint $g^{2}$ zunächst in Verbindung mit dem lokalen dominantischen Teiler A-Dur (T. 27-30). Die leicht variierte Wiederaufnahme von Takt 17 als Takt 31, lässt erwarten, dass der Mittelteil des Intermezzos ähnlich angelegt ist wie der Rahmenteil, nämlich als Periode mit Unterbrechung. Da der Nachsatz des Mittelteils zu keinem Abschluss in D-Dur gelangt, folgt auf die Wiederholung der III in Terzlage nicht die Vervollständigung einer Bassbrechung der lokalen Tonika D-Dur mit 3-2-1 in der strukturellen Oberstimme, sondern eine zweite Auskomponierung der oberen Wechselnote $g^{2}$, nunmehr in Verbindung mit der zur $\mathrm{V}^{\sharp}$ in h-Moll zurückleitenden II. Schenker führt noch die Analogie der Taktgruppe 47-54 zu Takt 1-8 aus, dann bricht die Detailskizze ab. ${ }^{36}$

34 Zitiert nach Cadwallader/Pastille 1999, 36.

35 Für Schenker ist der Ton ais im Schlussklang Takt 16 offenbar eine picardische Terz, die als solche nur dem Vordergrund zugehörig ist.

36 Dass die Detailskizze gerade hier abbricht, ist bemerkenswert: Im Schlussabschnitt der Komposition wachsen die Schwierigkeiten für die Schenkeranalytik an. Ob hieraus auf Probleme Schenkers bei der Fertigstellung der Analyse geschlossen werden darf oder sich der Abbruch äußeren Umständen verdankt, muss offen bleiben. (Eine Korrektur in der Bezeichnung des Stufengangs in der kompletten 
Eine genaue Datierung der Skizze ist nicht möglich. ${ }^{37}$ Gleichwohl legt ein Detail nahe, dass es sich um eine vergleichsweise späte Aufzeichnung Schenkers handelt: Die Zuordnung von Urlinie und Bassbrechung im Schlussabschnitt des Stückes weist dieselbe Kurzschrift auf, wie die Mittelgrund-Tafeln in Schenker 1956 für Sonatenformen in Moll. ${ }^{38}$

Die tonalen Verhältnisse im Intermezzo gleichen im Wesentlichen denen der Sonatenform in Moll mit der 5 als Kopfton, allein die Zuordnung der Formteile scheint verschoben. Setzt man den ersten Rahmenteil mit der Exposition, den zweiten mit der Reprise und den Mittelteil mit der Durchführung in Analogie, so erfolgt der Schritt zur III nicht bereits in Verbindung mit dem ersten Formteil, sondern erst mit dem Eintritt des zweiten. Freilich ist es gerade die Harmonisation der fallenden Urlinie im dritten Formteil, die Nähe und Ferne des Intermezzos zur Sonate gleichermaßen deutlich werden lässt: Auch in der Sonate ereignet sich im abschließenden Formteil der Abstieg von 5 nach 1. Gleichwohl ist es charakteristisch, dass der gesamte Quintzug auch im Vordergrund im Zeichen der I steht - beispielsweise dergestalt, dass vor dem abschließenden 2/V-1/I das Urlinie-Segment 5-4-3 mit einer Hilfskadenz zur I einhergeht (als Cantizans). Indem Schenker nun aber an dieser Stelle die besagte Kurzschrift bemüht, scheint er in Verbindung mit 5-4-3 eine spezifische Interpolation der III (als lokale Bewegung 3-2-1) mit entsprechender Bassbrechung anzunehmen. Freilich zeigt sich, dass diese Analogie im Intermezzo nicht vorliegt. Zwar weist die reale Oberstimme der Takte 61-63 einen manifesten Terzzug auf. Auch ist die 5 bereits zu Beginn des Zuges mit der III harmonisiert. Darin aber erschöpfen sich die Übereinstimmungen mit der Einrichtung einer regulären Moll-Exposition. Weder gibt es im Vordergrund des Intermezzos in Verbindung mit der 4 eine VII, noch in Verbindung mit der 3 eine unzweifelhafte III.

Genaueren Aufschluss darüber, ob und gegebenenfalls wie Schenkers Mittelgrundskizze und der Vordergrund des Intermezzos aufeinander beziehbar sind, lassen die analytischen Skizzen erwarten, die Schenkers langjährige Schülerin Angelika (Angi) Elias wahrscheinlich ab Oktober 1926 im Zuge ihres Unterrichts zu op. 119/1 angefertigt hat. ${ }^{39}$ Mit Blick auf Schenkers divinatorisches Selbstverständnis als Lehrer darf davon ausgegangen werden, dass Elias' Aufzeichnungen ein von Schenker autorisiertes Ergebnis sichern. Sie umfassen sowohl eine detaillierte Stimmführungsanalyse des vorderen als auch eine an den übergeordneten Knotenpunkten orientierte Darstellung des hinteren Mittelgrundes. In letzterer finden sich exakt jene Positionen wiedergegeben, die auch in der von Schenker selbst überlieferten Mittelgrundskizze (Film 34/item 2) enthalten sind:

Verlaufsskizze im Schlussabschnitt könnte ebenfalls auf Probleme Schenkers hinweisen. Hier ist eine Einschätzung der Vorgänge noch schwieriger, da das ursprünglich platzierte Stufenzeichen nicht leserlich ist. Ein Schreibfehler darf daher als ebenso wahrscheinlich gelten.)

37 Cadwallader/Pastille $(1999,36)$ sprechen von einer Darstellung, die repräsentativ für die `BrahmsMappe und einige der Figuren von Der Tonwille (Schenker 1921-1924) sei (»which is representative of a type of sketch that appears throughout the Brahms folder and occasionally in Der Tonwille - a middleground synopsis that summarizes the formal, harmonic, and contrapuntal properties of an entire piece $\ll)$.

38 Wie der Vergleich der Figuren 154,3 und 154,7 zeigt, bildet die Kurzschrift Anfang (5/I) und Ende (3/III) einer Moll-Exposition ab, bei dem die III noch unter der 5 eintritt.

39 Zur Angabe dieses Datum vgl. Cadwallader/Pastille 1999, 35. Zur Biographie von Angelika (Angi) Elias siehe Eybl/Fink-Mennel 2006, $241 \mathrm{f}$. 


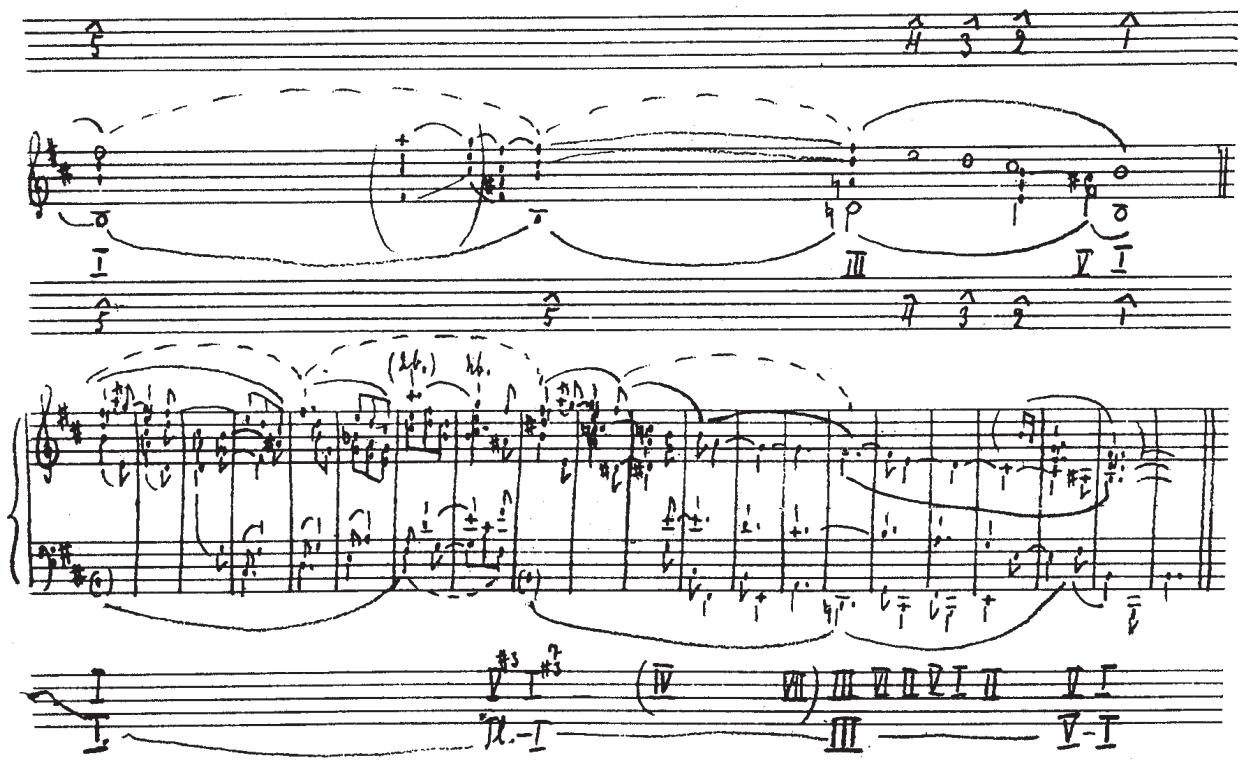

Beispiel 22: Stimmführungsskizze Schenker/Elias zu Johannes Brahms, Intermezzo h-Moll op. $119 / 1$, T. $47-67^{40}$

Die Aufzeichnungen von Elias bestätigen die oben gemachte Überlegung, wie Schenkers Zuordnung von 5/I und 3/III im Schlussabschnitt des Intermezzos zu lesen sei: Noch in Verbindung mit dem Kopfton (T. 61) erscheint die III. Auch lässt Elias durch die Zuordnung der III in der Stufenlegende keinen Zweifel daran, dass diese bis zum Eintritt von 2/V $\left[{ }^{\sharp}\right]$ prolongiert wird.

Schenkers Kurzschrift verweist hier also nicht auf das aus seinen (späteren) Sonatenanalysen bekannte Verfahren. Während dort eine Prolongation intendiert ist, bei der Anfang und Ende durch dieselbe Stufe markiert sind (es ließe sich von einer 'geschlossenen< bzw. ızirkulären، Prolongationsform sprechen), wird hier die eröffnende Stufe durch ausschließlich andere (untergeordnete) Folgestufen als prolongiert begriffen, bis eine neue (übergeordnete) Stufe eintritt (es ließe sich von einer `offenen` bzw. stransitorischen Prolongationsform sprechen). ${ }^{41}$ Von daher ist der bei Cadwallader/Pastille gegebenen Einschätzung zuzustimmen: »All of the details illustrated in Elias' fair-copy sketch are put into perspective in a graph in Schenker's hand «. ${ }^{42}$ Gleichwohl lässt der Schlussabschnitt auch eine alternative schenkerianische Deutung des Hintergrundes zu, welche für die besondere Klanglichkeit der Stelle womöglich mehr zu sensibilisieren versteht als die Deutung von Schenker/Elias.

40 Zitiert nach Cadwallader/Pastille 1999, 35.

41 Von einer stransitorischen` Form wäre auch bei der Überleitung in Mozarts Andante aus KV 504 (s.o.) zu sprechen: `Fonte` und Prädominante prolongieren die eröffnende I durch VI, $\mathrm{V}^{(\mathrm{b})}$ und III ${ }^{(\mathrm{b})}$ bis zum Eintritt der V.

42 Cadwallader/Pastille 1999, 36. 
Jede vierstimmige Quintfallsequenz unter durchgängiger Verwendung von Septakkorden kann durch die komplementäre Verknüpfung zweier Dissonanzenketten (7-6 und/oder 2-3) hergeleitet werden. Weitere Kontrapunkte können durch die Überterzung der Agensstimme(n) gewonnen werden. Allerdings entsteht dabei bereits im Übergang zur Fünfstimmigkeit das satztechnische Problem offener Quintparallelen. Sie werden in der Brahms'schen Komposition durch eine Verlagerung ins Innere des Satzes gemildert.

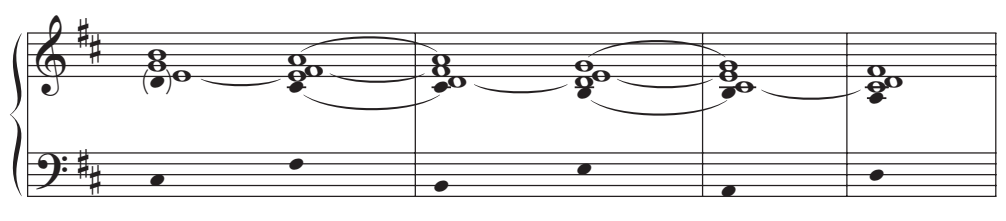
Takt 58
59
60
61

Beispiel 23: Johannes Brahms, Intermezzo h-Moll op. 119/1, Satzmodell, T. 58-61

Zur Instantiierung des Modells durch Brahms gehört, dass jede erste Akkordstation in den Takten 58 und 59 erst durch den nachschlagenden Bass vervollständigt wird. Zu Beginn von Takt 58 erscheint ein e-Moll-Sextakkord, der durch das Fortschreiten des Basses nach cis zum Akkordbestandteil eines halbverminderten Septakkords erklärt wird: $g$ ist zwar realer Bass, aber struktureller Tenor. Diese Lesart bietet sich auch für die beiden Folgetakte an, obwohl hier durch den Übergang zur Fünfstimmigkeit bei jeder ersten Akkordstation kein Sextakkord, sondern bereits ein Quintsextakkord vorliegt.

Würde Brahms ab Takt 62 nach dem Muster verfahren, das der Sequenz ab Takt 58 zugrunde liegt, ergäbe sich eine Fortsetzung, durch die mit Takt 65 in einen Schluss in D-Dur gelangt werden könnte. Tatsächlich aber ändert sich die Anordnung der Stimmen abermals. Die melodische Bewegung a-ais-cis am Ende von Takt 61 bringt eine neue Überterzung hervor. Dadurch dass der bisherige Tenor eliminiert wird, bleibt der Satz fünfstimmig. Die neue Stimme lässt sich als Patiens über dem noch liegenden Basston $d$ verstehen. Damit kommt es zu offenen Septimparallelen, die - wie zuvor die Quinten ins Satzinnere verlagert werden.

Die strukturelle Funktion der realen Bassbewegung ist aus der Perspektive herkömmlicher Mehrstimmigkeit ambig: Wird das Modell im Sinne des ersten Sequenzabschnitts ab Takt 58 gelesen, verbindet die reale Bassstimme strukturellen Tenor und strukturellen Bass. Damit stellt sich eine Situation ein, die der Mischung von dominantischem Akkordvorhalt und tonikaler Lösung in den Takten 2 und 3 vergleichbar ist.

Eine Eigenheit der Orthographie ist in diesem Zusammenhang auffällig: Brahms notiert ab Takt 58 die Oberstimmen beider Systeme in Achteln. Dadurch wird die Auffassung von cis und $h$ als nachschlagende Bassnoten optisch unterstützt. Es darf zwar als unwahrscheinlich angesehen werden, dass wegen fehlender Pedalvorschriften an die Pedalisierung eines jeden einzelnen Sechzehntel im Takt gedacht ist. Gleichwohl lässt die Notation offen, ob der Klang auf dem ersten Sechzehntel tatsächlich durch die reale Bassbewegung auf dem zweiten Sechzehntel unterquintiert wird, oder aber, ob die 
erwartete Auflösung des neu eingeführten Patiens sich stillschweigend auf der weiten Zählzeit ereignet und der Ton, der real erst mit dem kommenden Achtel erscheint, virtuell bereits als antizipiert gelten soll. Die fehlende Ausführung der potentiellen Mittelstimmen rückt somit die reale Mixtur von stufenweise fallenden Septakkorden klanglich in den Vordergrund. Das Quintfallmodell kennt nun keine alternierende Dissonanzauflösung zweier komplementärer Gerüstsätze mehr. Die Viskosität der Sequenz ist dadurch erheblich gemindert, die Septimen des neuen Patiens erstarren zu Klangstelen.

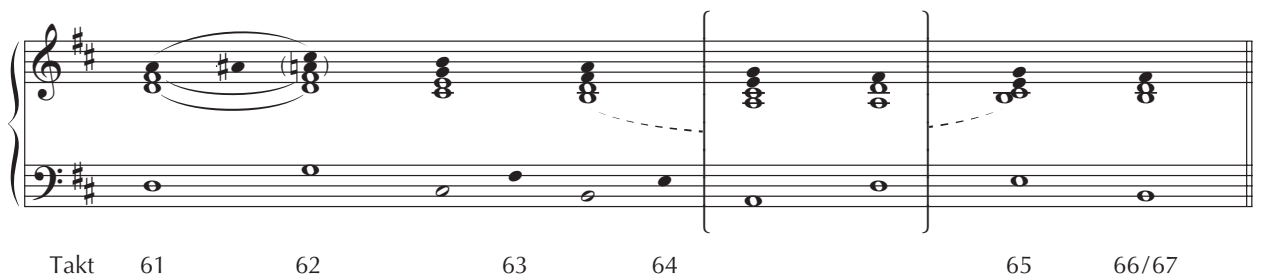

Beispiel 24: Johannes Brahms, Intermezzo h-Moll op. 119/1, Stimmführungsskizze T. 61-67

Bei Schenker/Elias sind die tontraubenartigen Terzschichtungen gleichsam durch einen barocken Filter hindurchgegangen. Schenker suggeriert, es handle sich um eine Sequenz, wie sie auch im frühen 18. Jahrhundert auftreten könnte. Wie die Optionstöne jenseits der Septime, 9 und 11, eingeführt werden, bleibt aufgrund fehlender Skizzen zum äußersten Vordergrund in der Analyse von Schenker/Elias ungeklärt.



Takt 61 63 63 64

Beispiel 25: Johannes Brahms, Intermezzo h-Moll op. 119/1, Fauxbourdonsatz T. 61-64

Beispiel 25 geht vom dreistimmigen Notat bei Schenker/Elias aus und reduziert die hierdurch implizierte reguläre vierstimmige Quintfallsquenz auf den ersten zum Taktschema metrisch kongruenten Gerüstsatz. Es ergibt sich ein auf der verbleibenden 7-6-Konsekutive basierender synkopierter Fauxbourdonsatz. Diese Reduktion ermöglicht eine Lesart der Prolongationsform Takt 61 ff. als ızirkulärı, da mit Takt 63 die Ausgangsstufe D-Dur als Sextakkord wiedererlangt ist. Aus dieser Perspektive wäre der von Elias eingezeichnete stransitorische` Stufengang nur eine Vordergrunderscheinung. Allerdings ändert sich das Bild abermals, versucht man die in Schenker/Elias im Rahmen ihres nur dreistimmigen Satzgerüstes nicht ausgeführte Präpositio der Synkopendissonanz herzuleiten. Dazu ist es notwendig, den Ton $h$ bereits in Verbindung mit der 3 in Takt 63 einzuführen (vgl. Beispiel 26). 


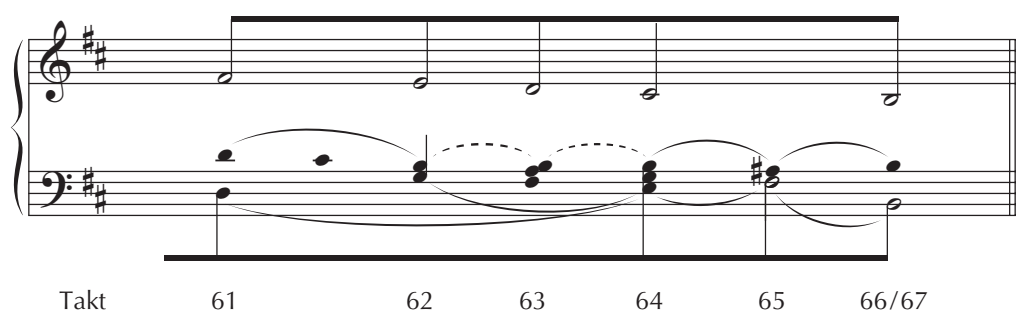

Beispiel 26: Johannes Brahms, Intermezzo h-Moll op. 119/1, Stimmführungsskizze T. 61-67

Eine sgeschlossene` Prolongation der D-Stufe durch einen Gang zum zugehörigen Sextakkord wird in der Folgeschicht nunmehr verunklart, da der Ton $h$ im Rahmen einer erweiterten Präpositio als Liegeton fungiert und über die fallende Sextakkordfolge hinweg gehalten bleibt. Der strukturelle Tenor mündet in dieser Deutung in den Durchgangston e, der auf die $\mathrm{V}^{\sharp}$ zielt. Die Bewegung g-fis-e über dem strukturellen Bass fasst die Harmonien im Oberstimmensatz zusammen. Das wiederum ermöglicht, den Sextakkord über g nicht mehr als II in D-Dur, sondern bereits als IV in h-Moll zu interpretieren, bevor er durch den Sextakkord über e zum Septakkord der II aufgefüllt wird.



Beispiel 27: Johannes Brahms, Intermezzo h-Moll op. 119/1, Reduktionen der Takte 62-67

Beispiel 27 zeigt weitere Reduktionen dieser Lesart in Richtung Hintergrund. 4-3-2 geht mit einem 'Leerlauf über der V ein. Die Prolongation der II in den Takten 62-64 schafft hier Abhilfe und löst zudem das `Problem` der mit 4/V unvermittelt eintretenden Septimdissonanz in der hinteren Schicht. In dieser Deutung endet der Raum der III bereits mit Takt 61.

Die vorangehende Diskussion lässt sich dahingehend zusammenfassen, dass der Versuch, die bei Schenker/Elias offen gelassene Herleitung einer stimmführungstechnisch korrekten Einführung der Synkopendissonanz in Verbindung mit 2/II zu einer alternativen Lesart des Hintergrundes führt, bei dem die Grenze zwischen der strukturellen III und nachfolgenden $V^{\sharp}$ vorverlagert erscheint. Durch die Gegenüberstellung beider Deutungen gewinnt die Klangbildung unter der 3 besonderes Aufmerksamkeit: Während aus der Perspektive des Generalbassatzes, der den realen Bass als Grundbass versteht - diese 
Sichtweise bei Schenker/Elias -, eine (wenn auch ggf. nur vordergründige) I vorliegt, wodurch a Septim ist, kann aus der Perspektive des Fauxbourdonsatzes, durch den der reale Bass die Qualität einer Zusatzstimme erhält, eine III angenommen werden, bei der a Akkordbestandteil und $h$, der vermeintliche Grundton, ein ajoutierter Ton ist. ${ }^{43}$

\section{Schenkerian Analysis}

Die darauf fußenden unterschiedlichen Möglichkeiten, die Sphären von I und III im Schlussabschnitt der Komposition in einem Schichtenmodell von einander abzugrenzen oder in einander übergehen zu lassen, kennzeichnet auch die in der Nachfolge Schenkers unternommenen Deutungsversuche der Schenkerian Analysis. ${ }^{44}$

Allen Forte und Steven E. Gilbert

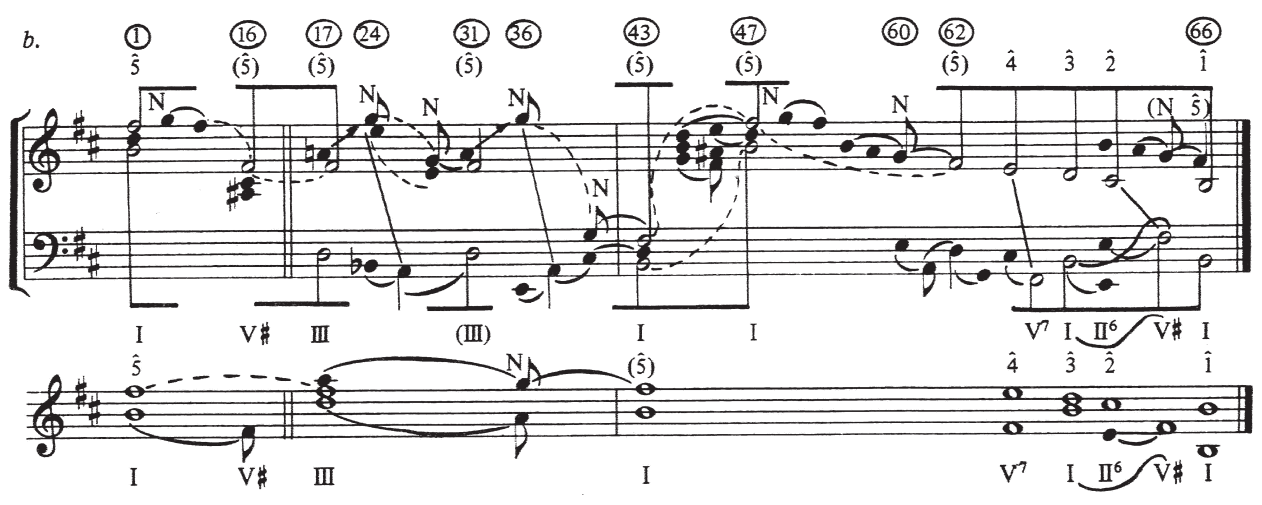

Beispiel 28: Johannes Brahms, Intermezzo h-Moll op. 119/1, Analyse nach Forte/Gilbert45

Forte/ Gilbert folgen in ihrer Interpretation der für Quintzüge in Moll idealtypischen Harmonisierung, bei der 5-4-3-2-1 mit zwei Bassbrechungen einhergeht. Freilich müssen dazu die Bezugspunkte im Bass quer zur satztechnischen Einrichtung gelesen werden: Sowohl fis als auch $h$ sind bei Forte/Gilbert strukturelle Basstöne. Auffällig ist die starke Abstraktion bei dieser Lesart. Forte/Gilbert suggerieren einen stabilen h-Moll-Kontext ab dem 4. Ton. Die III in Verbindung mit der 5 wird nicht sonderlich hervorgehoben. Der Umstand, dass die I in Takt 63 als Septakkord erscheint, erfährt nur indirekt dadurch eine Berücksichtigung, dass Forte/Gilbert nicht einen Quintsextakkord, sondern nur einen

43 Es muss offen bleiben, ob Schenkers gewählte Kurzschrift nicht doch auch auf diese zweite Möglichkeit hindeutet, obgleich die bei Elias ausgeführte Skizze diese nicht unterstützt.

44 Dass bereits vor ihrer Veröffentlichung im Jahre 1999 die Analysen Schenkers (oder die Aufzeichnungen von Elias) zu op. 119/1 innerhalb der Scientific Community der Schenkerians kursierten, darf angesichts der zum Teil signifikanten Abweichungen der jüngeren Analysen als unwahrscheinlich gelten.

45 Forte/Gilbert 1982, 215, Example 183. 
Sextakkord der II als Prädominante der strukturellen Dominante behaupten. Dies deutet darauf hin, dass Forte/Gilbert nicht von einer regulären Synkopendissonanz ausgehen, sondern von einem vierstimmigen Satz, in dem sich der Septakkord der I regulär auflöst. Der Ton $h$ in Takt 64 kommt ihrer Interpretation zufolge offenbar nur durch einen auf den Ausgangston fis zurückführenden Übergreifzug ins Spiel. Kurios mutet an, dass Forte/Gilbert zwar einerseits durch die Annahme einer stabilen 3/I die Voraussetzung für die reguläre Präpositio der Synkopendissonanz schaffen, andererseits aber auf die Herleitung dieses Akkordes zugunsten einer $2 / \mathrm{II}^{6}$ verzichten, wodurch der strukturelle Einflussbereich der III (vgl. Beispiel 25) gleichwohl implizit fortzudauernd scheint.

Felix Salzer



Beispiel 29: Johannes Brahms, Intermezzo h-Moll op. 119/1, Analyse nach Salzer ${ }^{46}$

Felix Salzers ist die früheste der Analysen. Sie akzentuiert Brahms' Mixturtechnik: Unter dem 4. und 3. Ton erscheinen zwei Septakkorde in Grundstellung. Anders als Forte/Gilbert liest Salzer folglich in Verbindung mit 5-4-3 keine Bassbrechung in h-Moll, sondern geht von einem - in seinem Sprachgebrauch - ’kontrapunktisch-strukturellen Klang، aus, also einer Auskomponierung, die nicht auf einem kadenziellen Zusammenhang beruht. ${ }^{47}$ Im Gegensatz zu Forte/Gilbert wird damit die reguläre Prädominante im Vergleich zur $V^{\sharp}$ zum strukturell gewichtigeren Akkord erhoben. Salzers Interpretation gleicht derjenigen von Forte/Gilbert allerdings darin, dass die III marginalisiert wird: Sie gilt ihm in Takt 61 als `Verzierungsklang`, der rückwärtig auf die vorausgehende I in Takt 55 bezogen wird. ${ }^{48}$ Offen liegt in Salzers Analyse das Problem der Vorgeschichte der 2/II. Salzer geht von einer regulären Synkopendissonanz aus, kann aber im Rahmen seiner vierstimmigen Analyse nicht zeigen, ob und gegebenenfalls wie sich der vorausgehende Septakkord der I als Präpositio verhält.

46 Salzer 1960, 251, Fig. 477d.

47 Ebd.

48 Ebd. 250, Fig. 477b Forts. 
Allen Cadwallader



Beispiel 30: Johannes Brahms, Intermezzo h-Moll op. 119/1, T. 60-67, Analyse nach Cadwallader ${ }^{49}$

Cadwallader löst das Problem der Präpositio dadurch, dass er die Bassbewegung Salzers reformuliert. Die III in Takt 61 wird nun zur Terzbrechung auf dem Weg von der I zur $V^{\sharp} .{ }^{50}$ Cadwallader sieht die Bewegung 5-4-3 in der Urlinie durch dasselbe Dezimarium abgestützt wie Salzer, doch wird in seiner Interpretation - angezeigt durch das Z-Zeichen - der Zielton $h$ zum strukturellen Tenor und damit zur Quinte der II erklärt, wodurch die Synkopendissonanz nunmehr vorbereitet ist. ${ }^{51}$ Auch zeigen bei Cadwallader die beigegeben Stufenzeichen (wie bei Schenker/Elias) an, dass der Wirkungskreis der III bis zu dem Augenblick reicht, da die II eintritt.

\section{Das Intermezzo op. 119/1 - ein Werk ohne Ursatz?}

Aufschlussreich sind die Lesarten aller drei Schenkerian-Analysen auch hinsichtlich des Übergangs vom Mittelteil zum Da capo des Rahmenteils:

Forte/Gilbert gehen davon aus, dass mit Takt 43, trotz der Tieferlegung, das im Vergleich zu Takt 47 hintergründigere Strukturmoment vorliegt. ${ }^{52}$ Zwar wird - wie bei Schenker selbst - die Auskomponierung der oberen Wechselnote zum Kopfton angenommen, doch vollzieht sich der Übergang nicht unter Verwendung der II, sondern quasi trugschlüssig mit der lokalen $V$ und unter Verwendung einer Verschiebung. Dem $g^{2}$ in Takt 36 wird nicht das als durchgängig verstandene cis (T. 41) als Basston zugeordnet, sondern das a aus Takt 37. In dieser Lesart spiegelt sich die Präferenz von Forte/Gilbert für authentische Schrittfolgen, die auch schon bei der Interpretation des Schlussabschnittes feststellbar war.

49 Cadwallader 1983b, 23, Example 7a Forts.

50 Angesichts von Cadwalladers Anliegen, die motivische Einheit des Brahms'schen Komponierens zu erweisen, verwundert diese Lesart nicht, da sie es erlaubt, einen motivischen Parallelismus mit dem ersten Abschnitt der Komposition zu behaupten. Konsequenterweise geht Cadwallader hier von einer Brechung in der Bassbewegung aus und kommt damit Schenkers Mittelgrundskizze sehr nahe.

51 Zusätzlich übernimmt Cadwallader von Forte/Gilbert den Übergreifzug 8-5.

52 Forte/Gilbert 1982, 215, Example 183. 
Anders Salzer, der zwar die Deutung der tonalen Reprise in Takt 43 mit Forte/Gilbert teilt, jedoch von einer plagalen Fortschreitung II-I ausgeht. ${ }^{53}$ Darin wird eine Akzentverlagerung auf den herkömmlich als prädominantisch verstandenen Klang spürbar. Das freilich steht der bei Schenker und Schenker/Elias behaupteten Gewichtung der Rückleitungsdominante entgegen. Salzer spricht von einem `Nebennoten-Durchgangsklang` und scheint von einer vergleichbaren Konstellation wie am Ende des Stücks in Takt 62 auszugehen. Dass dort der Akkord der II in den Rang eines skontrapunktisch-strukturellen Klangs erhoben wird, verdankt sich offenkundig allein seiner Verbindung mit der 4 der Urlinie.

Cadwallader wiederum steht mit seiner Deutung zwischen Forte/Gilbert und Salzer. In seinem Example 6 wird die Taktgruppe 43-46 ausdrücklich als >retransition bezeichnet. Auch Cadwallader ordnet dem $g^{2}$ als strukturellen Basston a, cis hingegen als strukturellen Tenor zu. Im Unterschied zu Fort/Gilbert unterstellt Cadwallader jedoch in Takt 43 einen kadenzierenden Quartsextakkord - was seine Rede von der `Rückleitung، zwar Plausibilität verleiht, im Vordergrund der Brahms'schen Komposition jedoch keinen satztechnischen Anhaltspunkt hat.

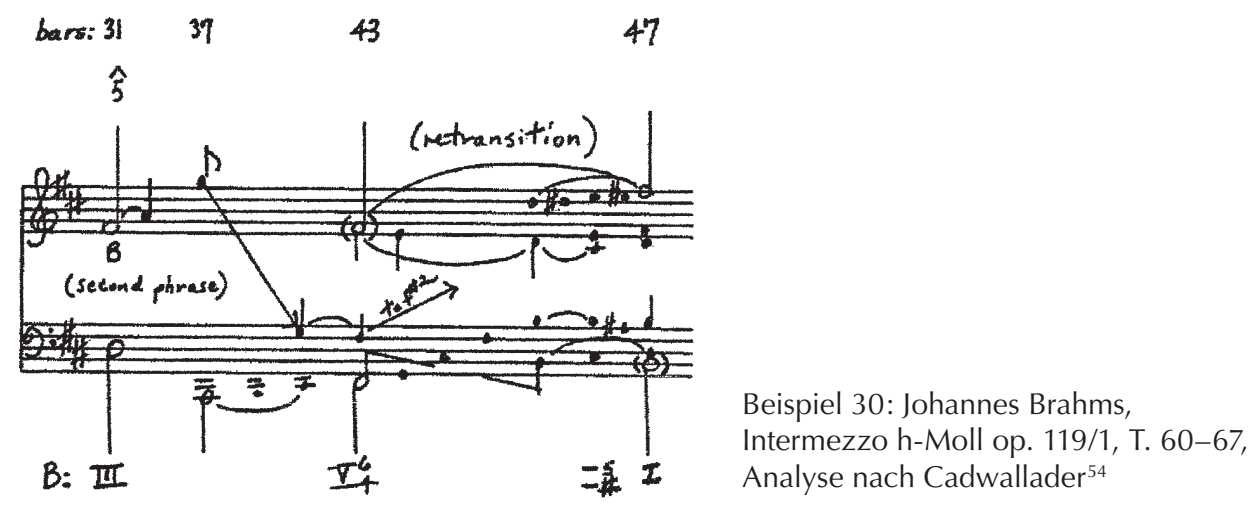

Da Cadwallader ausdrücklich sowohl das real erklingende fis als auch das nur in einer früheren Schicht unterstellte Fis notiert, erhebt sich die Frage nach der Grundlage seiner Annahme - zumal ausdrücklich ausgeschlossen zu sein scheint, dass dem einzig real erklingenden fis Bassfunktion zukommt. ${ }^{55}$ Durch die Annahme eines kadenzierenden Quartsextakkordes ab Takt 43 mit entsprechender Auflösung in die $V^{\sharp}$ in Takt 46 ist der bereits bei Schenker behauptete Rückleitungsmodus über eine vermittelnde $V^{\sharp}$ noch stärker geltend gemacht. Anders als Cadwallader gibt Schenker in seiner Analyse über die Verbindung von II und $\mathrm{V}^{\sharp}$ hinaus keine detaillierte Auskunft über die Bedeutung der Takte 43-46. Keinesfalls aber wird die strukturelle Bedeutung von Takt 43 höher angesetzt als die von Takt 47. Schenker und Cadwallader widersprechen folglich den Lesarten von Forte/Gilbert und Salzer. Ihre Argumentation wird durch die Wiedergewinnung der obligaten Lage in Takt 47 gestützt.

53 Salzer 1960, ebd.

54 Cadwallader 1983b, 21, Example 6. 
Ferner sind sowohl bei Schenker als auch bei Cadwallader die Rückleitungsdominante in Takt 46 und die strukturelle Dominante in Takt 65 durch die vorausgehende Brechung I-III-V aufeinander bezogen. Bei Forte/Gilbert sind zumindest zwei authentische Schritte einander zugeordnet. Bei Salzer hingegen tritt im Übergang von Mitte zu Schluss und im unmittelbaren Vorfeld des Schlusses die II anstelle der V und verliert ihre untergeordnete Funktion, Prädominante zu sein. Denkt man Salzers Akzentuierung weiter, so erhebt sich auch für den strukturellen Schluss der Komposition die Frage, ob die Annahme eines Ursatzes überhaupt gerechtfertigt ist. Auch die von Elias wiedergegebene Deutung gibt Anlass, hieran zu zweifeln. Zwar verzeichnet ihre Mittelgrundskizze deutlich eine reguläre Synkopendissonanz und deren reguläre Auflösung, doch bleibt die Frage nach der Präpositio auch hier unbeantwortet. In der Vordergrundskizze ist - ebenso wie bei Forte/Gilbert - angesichts des dreistimmig ausgeführten Akkordauszuges nicht erkennbar, aus welcher Stimme das $h$ als Patiens in der Synkopendissonanz herrührt. ${ }^{56}$ Jedenfalls wird Elias zufolge der Leitton ais nicht durch eine Auflösung des Tones $h$ gewonnen, sondern geht unmittelbar aus dem Grundton der II hervor, obgleich ein entsprechender Auflösungsvorgang in der Mittelgrundskizze über dem Stimmführungsauszug des Vordergrundes verzeichnet ist.

Für die Annahme einer strukturellen $\mathrm{V}^{\sharp}$-I-Bewegung am Ende der Komposition ergibt sich damit prinzipiell dasselbe Problem wie für die Behauptung quintfälliger Fundamentschritte in den ersten drei Takten. Die fortlaufende Kette von Terzfällen steht der Akzentuierung von Bassstufen hier wie dort entgegen. In diesem Zusammenhang ist bemerkenswert, dass gerade dem in den Takten 65 und 66 erreichte Kontra- $E$, dem tiefsten Ton des gesamten Stücks, eine Bassfunktion zugeordnet werden kann. Fraglos spricht die Registerbehandlung der realen Bassstimme nicht für eine II-V ${ }^{\sharp}-\mathrm{I}-$ Verbindung, denn mit dem Kontra- $E$ korrespondiert nicht das fis im Folgetakt, sondern das Kontra$H$ in Takt 67. Dies legt nahe, die letzte Folge fallender Terzen nicht als dominantische, sondern als subdominantische Klangbildung aufzufassen. Insofern kann der Hypothese einer regulären Bassbrechung und damit einer schenkerianischen Ursatzform für das Intermezzo begründet widersprochen werden.

Fazit

1. Die Anlagerung von zusätzlichen Terzkontrapunkten an Gerüststimmen des jeweiligen Satzmodells konterkariert das (spätestens) seit dem Barock gültige Prinzip, Klangfolgen aus dem Wechsel von Dissonanz- und Konsonanzstationen hervorgehen zu lassen. Brahms setzt sich über das Parallelenverbot hinweg und geht zu Mixturen über. Der Verzicht auf eine herkömmliche Stimmführung akzentuiert dabei die Eigenqualität der Töne. Sie sind nicht länger Zweck zum Mittel der Stimmführungskunst. Mixturen schaffen eine Möglichkeit Tonfelder zu artikulieren.

55 Cadwallader gibt an, ihm sei diese Lesart von John Rothgeb nahegelegt worden (vgl. 1983b, 15, Anm. 19).

56 Auch bei Schenker selbst (o. J.) ist der Ton nur im Rahmen des Übergreifens 8-5 verzeichnet, ebenso in Forte/Gilbert 1982. 
2. Die traditionelle Mehrstimmigkeit, deren tonaler Interpretation die Schenkeranalytik dient, hat die Abgeschlossenheit einer jeden durch eine Figur repräsentierten Bewegung zur Voraussetzung. Die Schwierigkeit, das Ende jener Bewegung zu bestimmen, welche die von Schenker (und anderen) behauptete Prolongation der III in Verbindung mit 5-4-3 in der Urlinie unterstellt, lässt es fraglich erscheinen, dass Brahms durchgängig nach derlei Grundsätzen verfährt. Die geringe Trennschärfe von III und I kurz vor dem Ende der Komposition ist ein Indiz dafür, dass Akkorde hier nicht als Stufen, sondern als Mittel der Auskomponierung eines gemeinsamen Feldes fungieren.

3. Der strukturelle Schluss des Stückes kann plagal aufgefasst werden, der Übergang vom Mittelteil zur Rückleitungsepisode (T. 42-43) als eine Analogiebildung. Aus der Perspektive der Tonfeldtheorie versammelt der verminderte Septakkord über e (T. 65) sämtliche Grundtöne der Subdominante. Dadurch kann die Behauptung, es handele sich um eine subdominantische Klangbildung, formalisiert werden. Diese Interpretation wird gestützt durch einen Vergleich mit dem korrespondierenden Schluss am Ende des ersten Rahmenteils (T. 16). Dort geht die $V^{\sharp}$ aus einem Mischklang hervor, der sich aus dem lokalen Grundton fis und dem verminderten Septakkord $h$-d-eisgis zusammensetzt. Dieser aber wurde im Takt zuvor als Grundtonreihe der lokalen Subdominante identifiziert.

Dass die reguläre Vollendung der Schenker'schen Bassbrechung in Zweifel gezogen wird, stellt die Komposition nicht nur jenseits des Paradigmas der Ursatz-Tonalität. Wird von einem plagalen strukturellen Schluss ausgegangen, so ist dies zugleich ein wichtiger Anhaltspunkt für Überlegungen, auf welche andere Art der Hintergrund der Komposition beschaffen ist.

\section{Stufengang - Kadenz - Tonfeld}

In einer früheren Untersuchung ${ }^{57}$ hat der Verfasser mit Blick auf die Salzburger Notenbuchtradition ein entwicklungsgeschichtliches Modell des stonalen Programms `Ursatz-Tonalitätı diskutiert, demzufolge die für die Zeit des Barock maßgebliche `Oktavzugmusikı im Laufe des 18. Jahrhunderts weitgehend aufgegeben und durch eine Binnendifferenzierung der `Terzzugmusikı ersetzt wurde..$^{58}$ Unter Rekurs auf die Systemtheorie Niklas Luhmanns wurde diese Entwicklung primär als Ergebnis innersystemischer Prozesse des tonalen Programms `Ursatz-Tonalität interpretiert, die durch den Wechsel von Komplexitätsaufbau, Komplexitätsreduktion und erneutem Aufbau von Komplexität bestimmt sind. ${ }^{59}$

Im Laufe der Untersuchung wurde deutlich, dass einzelne Kompositionen aus dem Nannerl Notenbuch ${ }^{60}$ nicht nur für den Übergang von einer Form der Ursatz-Tonalität

57 Rohringer 2010a.

58 Mit Oktav-, Quint- und Terzzug sind die drei Formen der Urlinie gemeint.

59 Ästhetische Wertungen sind nicht intendiert.

60 Als Beispiele dienten das Menuett C-Dur (Nummer 16) und ein Scherzo von Georg Christoph Wagenseil (Nummer 31). 
zu einer anderen stehen, sondern bereits Ausdruck einer Entwicklung sind, die aus der Ursatz-Tonalität selbst herausführt und ein Nachfolgeprogramm installiert, das einstweilen `Paradigma des Stufengangs` genannt wurde. Diese Namensgebung sollte zum Ausdruck bringen, dass der durch die Akkorde artikulierte Stufengang bestimmend für die Darstellung der Tonart ist (was impliziert, dass demgegenüber melodische Bewegungen nachrangig werden). Als Indikator wurde ein neuartiger Gebrauch der IV in Dur-Kompositionen angesehen, der sich nicht überzeugend als Modifikation des bisherigen tonalen Programms deuten ließ.

Dass die Schwierigkeiten der Analyse für eine veränderte Auffassung von der Tonart in den Kompositionen sensibilisieren, zeigt sich daran, dass auch Kompositionen dieser Neubewertung unterzogen werden können, die durchaus überzeugend mit der Schenkeranalytik zu dekomponieren sind. Das gilt beispielsweise für die nachfolgende Klavierfassung des Menuetts I aus Wolfgang Amadé Mozarts Violinsonate D-Dur KV 7 (Beispiel 32). Obwohl sich das Stück als Quintzug- ${ }^{61}$ wie auch Terzzugmusik ${ }^{62}$ deuten lässt, sollen die seinerzeit gemachten Beobachtungen hinsichtlich des >Paradigmas des Stufengangs` an ihm veranschaulicht und fortgeschrieben werden. ${ }^{63}$

Mozarts Komposition besteht aus zwei Reprisen von jeweils 10 und 12 Takten und kann sowohl auf thematisch-motivischer als auch harmonischer Ebene als binäre Form beschrieben werden. Die erste Reprise beginnt mit einem eröffnenden Vierer, einer Initialkadenz, die D-Dur als Anfangstonika postuliert, gefolgt von einem durch innere Erweiterung des ersten Zweier (T. 5-6) zum Sechser verlängerten Vierer, an dessen Ende die förmliche Ausweichung in die $V$ steht. Die zweite Reprise hebt mit einem `Ponte (Joseph Riepel) an, das von der V zur I zurückführt. Erwartungsgemäß hätte als Schlussreim der transponierte Sechser der ersten Reprise zu folgen und in den tonikalen Schluss zu führen. Mozart aber erweitert den Sechser nicht nur durch nochmalige Wiederholung des ersten Zweier zum Achter, sondern modifiziert inn zusätzlich dahingehend, dass die chromatisierte Quintsext-Auswechslung, durch die in der ersten Reprise die Ausweichung in die $\mathrm{V}$ vollzogen wurde, durch ein Oberquintpendel IV-I ersetzt wird (T. 15-16). Die verweigerte Analogie ${ }^{64}$ führt zur besonderen Betonung der IV. ${ }^{65}$

Beispiel 33 zeigt den durch die plagale Stufenfolge I-V-IV-I gebildeten Hintergrund der Komposition: Die entsprechenden Stationen sind Takt 4 (I), 10 (V), 15 (IV) und 22 (I). Mit Ausnahme von besagtem Zweier Takt 15-16 und seinen Wiederholungen werden auf der nächsten Schicht sämtliche plagale Schritte durch authentische Schritte ausge-

61 Die anfängliche Brechung (T. 1-2) führt auf den Kopfton.

62 Die anfängliche Brechung (T. 1-2) ist nur Teil eines Ränderspiels, das der Prolongation der 1 gilt. Der Kopfton wird durch Brechung von der 1 aus erst mit Beginn von Takt 5 erreicht.

63 Oftmals scheint die besondere Leistung bereits des äußerst jungen Komponisten Wolfgang Amadé Mozart darin zu bestehen, Entwicklungen, die bei Vorläufern und Zeitgenossen nicht selten ein starkes Moment von Diskontinuität aufrufen, durch den ostentativen Rückgriff auf ältere Verfahren in möglichst hohem Maße anschlussfähig zu machen.

64 Vgl. hierzu auch Rohringer 2010a, $253 \mathrm{f}$.

65 Von der Verwendung des Tones $g$ als Stufengrundton der IV (T. 15) ist seine melodische Verwendung als 4. Skalenton im rückleitenden Ponte (T. 13) zu unterscheiden. 

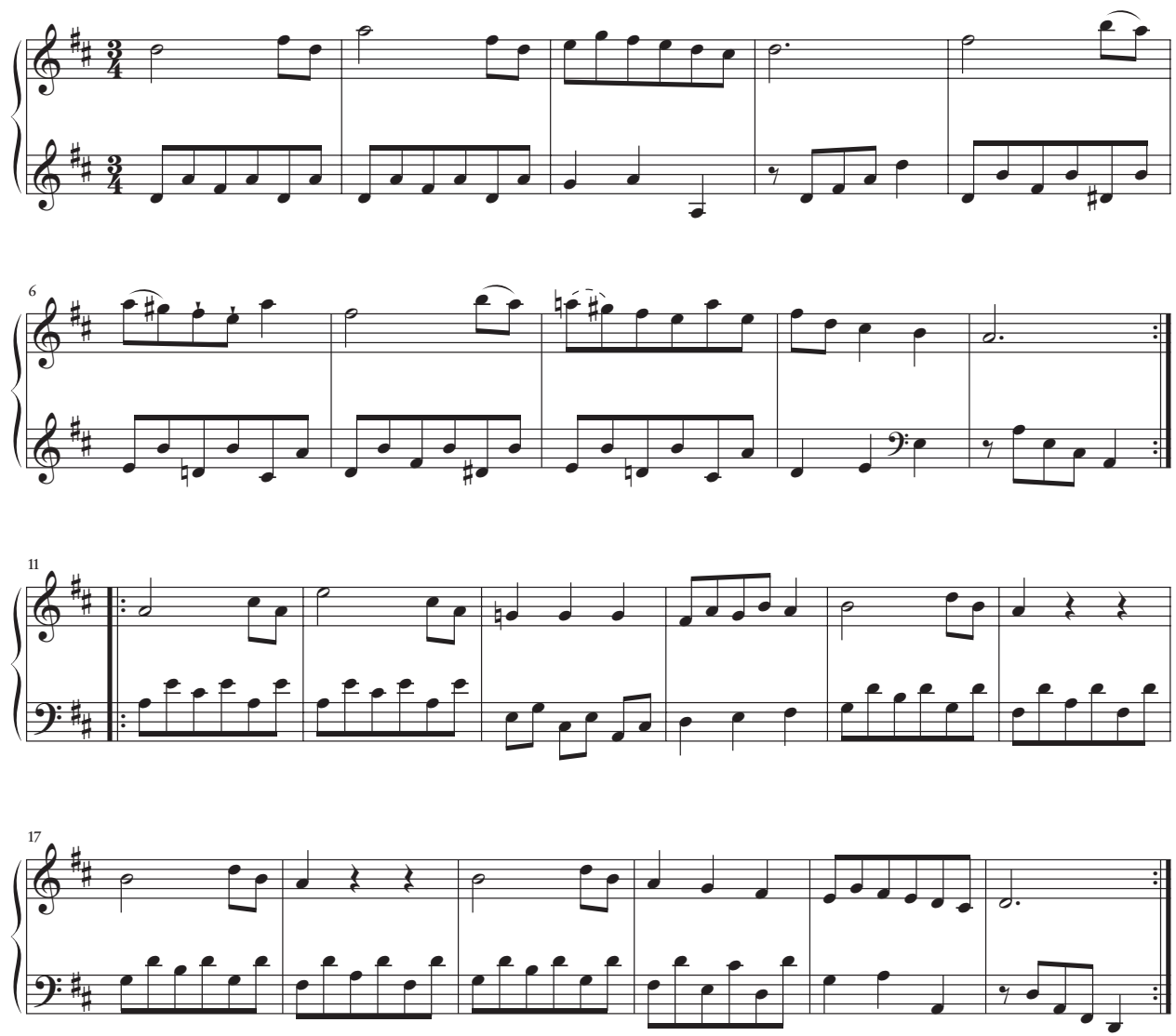

Beispiel 32: Wolfgang Amadé Mozart, KV 7, Menuett I, Klavierfassung



Beispiel 33: Wolfgang Amadé Mozart, KV 7, Menuett I, Klavierfassung, 'Paradigma des Stufengangs`: Hintergrund und Mittelgrund 
füllt: In der ersten Reprise erscheint I-V durch I-II ${ }^{\sharp}-\mathrm{V}$ authentisch vermittelt (T.5-6) ${ }^{66}$; das rückleitende Ponte schiebt eine I (T. 14) zwischen V (T. 10) und IV (T. 15) in der zweiten Reprise ein.

Sucht man nach einer theoretischen Grundlegung ${ }^{67}$ des 'Paradigma des Stufengangs` in der hier gezeigten Form, kann auf die Überlegungen zur Darstellung der Dur-Tonart bei Moritz Hauptmann zurückgegriffen werden. ${ }^{68}$ Denn obwohl Hauptmann implizit auf die authentische Stufenfolge I-IV-V-I rekurriert, gestattet es die letztlich architektonische Anlage ${ }^{69}$ seines Modells, bidirektional in die Zeit gebracht zu werden.

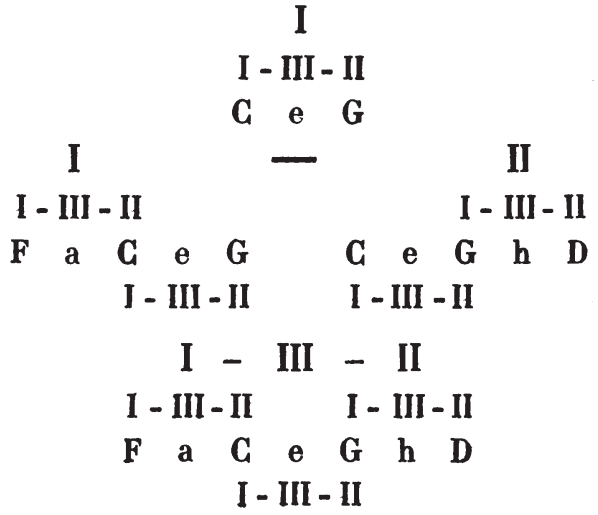

Beispiel 34: Hauptmann $1853^{70}$, Darstellung der Dur-Tonart

Ist die Schlusstonika eine Synthese höherer Ordnung, wie von Hauptmann behauptet, so besteht nicht nur die Möglichkeit die `Quintentzweiung`(II) - als das Mit-sich-inGegensatz-Kommen - der als ১Oktaveinheit gesetzten Anfangsstufe (I) - als unmittelbare Einheit - durch die nachfolgende quinttiefere Stufe zu betreiben und mittels der quinthöheren Stufe in die `Terzeinigung` der Schlusstonika (III) - als vermittelte Einheit - zu überführen (von `Dominante sein $` z u$ `Dominante haben $)^{71}$, sondern ebenso die Quintentzweiung durch die quinthöhere Stufe zu betreiben und mittels der nachgestellten quinttieferen Stufe den Weg zur Terzeinigung zu bereiten (von sSubdominante sein zu >Subdominante haben`). Entscheidend ist nicht, ob die Stufenfolge authentisch oder plagal erfolgt, sondern nur, dass sich die Stufen wechselseitig zu Tonika, Subdominante und Dominante bestimmen und die Schlusstonika als Resultat aus dieser Klärung hervor-

66 Die II wird ihrerseits authentisch durch die $\mathrm{VI}{ }^{\sharp}$ vermittelt.

67 Mit Blick auf die praktische Harmonielehre wurden bereits in Rohringer 2010a Oktavregeln nach Nauß und Koch zitiert (vgl. 249ff.).

68 Hauptmann 1853.

69 Dass sich der tonale Zusammenhang bei Hauptmann einerseits durch bestimmte Stufenverhältnisse konstituiert, andererseits aber nur in zeitlicher Folge eben dieser Stufen zur Darstellung gelangen kann, ist eine Analogie zur These Heinrich Schenkers, der in sich ruhende `Naturklang، bedürfe des Ursatzes, um in Bewegung gesetzt und damit zur Darstellung gebracht zu werden.

70 Hauptmann 1853, 27.

71 Vgl. ebd. $25 f$. 
geht. ${ }^{72}$ Diese Transformation findet ihre Bestätigung durch Hauptmann selbst, der zwar bei der Herleitung der Dur-Tonart nur unidirektional-authentisch verfährt, dort aber, wo es um die Stufendisposition im Formverlauf geht, gleichwohl die plagale Stufenfolge als Regelfall beschreibt. Hiervon grenzt Hauptmann die authentische Folge als Schlussfall ab. ${ }^{73}$

Allerdings ist mit dem `Paradigma des Stufengangs herstellung der aus den Harmonielehren des 19. Jahrhunderts bekannten Kadenzlehre unter expliziter Ergänzung der plagalen Stufenfolge gedacht. Vielmehr wird im Folgenden der Brückenschlag zur sTheorie der Tonfelder nach Albert Simon und Bernhard Haas vollzogen.

Dass die Tonmenge, die in anderen Zusammenhängen beispielsweise als ıHalbtonGanztonskalaı (deutsche Skalentheorie), ıoctatonic scale` (nordamerikanische Skalentheorie) oder als 2. Modus (Skalentheorie Olivier Messiaens) beschrieben wird, in der Theorie Albert Simons `Funktion` heißt, ist kein vernachlässigbarer ıfunktionstheoretischer Anachronismus. Die drei Optionen, das chromatische Total oktatonisch zu filtern, werden als Tonika, Subdominante und Dominante relativ zueinander zu bestimmt. Entsprechend wird bei Übergängen zwischen Tönen oder Tongruppen unterschiedlicher sfunktionaler Provenienz zwischen authentischen und plagalen Schritten differenziert.

Fraglos steht die Theorie der Tonfelder also in der Tradition der Harmonielehren (wahrscheinlich in der Nachfolge Riemanns ${ }^{74}$ ). Dort gewinnen `Funktionen ihre spezifi-

72 Vgl. dazu das genau entgegengesetzte Konzept bei Arnold Schönberg, dessen Kritik am Begriff ,Dominante gerade darauf gründet, dass die Tonika nicht in Abhängigkeit ihrer beiden Dominanten begriffen wird, sondern als Massepunkt, der Trabanten in seine Umlaufbahn zwingt. Schönberg bedient sich dabei der Naturtonreihe auf dieselbe Art wie Schenker, indem er das spätere Erscheinen der Quint dafür verantwortlich macht, »eine Abhängigkeit der Quint vom Grundton« zu behaupten. Entsprechend vergleicht Schönberg das Vorausgehen der beiden Dominanten mit einer Szene, in der »ein König seinen Vasallen, Zeremonienmeister, Quartiermacher voranschickt.« (Schönberg 1986, 34) Als Begründer des Gravitationsmodells kann möglicherweise Jean-Philippe Rameau gelten. Thomas Christensen (2008) vermutet eine Adaption der Gravitationslehre Issac Newtons.

73 Vgl. ebd. die Ausführungen im Kapitel ‘Enharmonische Verwechslung`, Abs. 301 mit denen im Kapitel `Schluss`, Abs. 313: „Wie aber der erste Theil eines Musikstückes [...] sich überhaupt nicht zu modulatorischer Mannigfaltigkeit bestimmen kann, indem er nur die Exposition eines Inhaltes und zwar einer Zweiheit von einem Hauptsatze und einem Nebensatze, des ersten in der Tonica, des zweiten in der Dominant, darzulegen hat, so werden andere Tonarten, und so eben auch die der Unterdominante, namentlich die Unterdominant selbst, erst in der weiteren Führung [...] ihren Platz finden können.« (Hauptmann 1853, Abs. 301, 205) Nachdem Hauptmann denselben Gedankengang wenig später erneut paraphrasiert hat, setzt er fort: „Daher kann die allgemeine Form: I-IV-V-I, welche die Unterdominant vor die Oberdominant setzt, eben nur für den Schluss gelten: nicht als modulatorisches Schema, nicht als Tonartfolge, nur als schliessende Accordfolge innerhalb der Tonart.« (Ebd., Abs. 313, 212)

74 Auf welchen musiktheoretischen Ansatz exakt der Rekurs auf Tonika, Subdominante und Dominante zurückzuführen ist, ist nicht bekannt. Angesichts des hohen Verbreitungsgrades der Funktionstheorie Riemanns und seiner Nachfolger, besteht zumindest die begründete Vermutung, dass die entsprechenden Rekurse in der ungarischen Musiktheorie bei Ernö Lendvai und Albert Simon (anders als bei Lajos Bárdos und Zoltán Gárdonyi, deren Terminologie von der Stufenlehre abstammt) auf den Kontakt mit der (nord-)deutschen Harmonielehretradition zurückgehen. Lendvai gibt zu Beginn seines grundlegenden Bartok-Aufsatzes dazu den recht allgemeinen Hinweis, dass der »Gesichtspunkt der klassischen Harmonielehre« (1953, 105) einer der Ausgangspunkte seiner Überlegungen sei. 
sche Bedeutung auf dem Hintergrund von Kadenzmodellen. Es erhebt sich daher Frage nach dem Verhältnis von Funktionsbegriff und Fortschreitungslogik in der Theorie der Tonfelder.

In den beiden von Bernhard Haas publizierten Bartók-Analysen von Albert Simon ${ }^{75}$ finden sich mehrere Beobachtungen in Bezug auf Tonika, Subdominante und Dominante als Tonfelder. Resümierend äußert Simon zu Staccato (Mikrokosmos Nr. 124):

In diesem Sinne ist a die Tonika und das Stück ist überhaupt tonal. Diese durch und durch organisierte Komplexität des Komponierens benennt Bartók in diesem Sinne mit einem einzigen Ton als Grundton: in $a{ }^{76}$

Gleichwohl gibt es nur einen (enigmatischen) Hinweis dazu, inwiefern die Funktionen kadenziell organisiert sind. So spricht Simon von »kadenzartigen Bestätigungen der funktionalen Richtung «. ${ }^{77}$

Mehr Aufschluss bietet die grundlegende Einführung in die Simon'sche Theorie durch Bernhard Haas. Dort heißt es:

Die Geschlossenheit der beiden Kadenzformen [gemeint sind die authentische Folge I-IV-V-I und die plagale Folge I-V-IV-I] ist als Vollständigkeit der drei Funktionen plus Wiederkehr der Anfangsfunktion. ${ }^{78}$

Es ist allerdings ein gewichtiger Unterschied, ob Geschlossenheit (des Kadenzvorgangs) auf Vollständigkeit (einer Menge an Funktionen) beruht, oder sich einem (dialektischen) Prozess verdankt (der einer bestimmten Menge an Funktionen bedarf).

Zudem scheinen kadenzielle Fortschreitungen nach Einschätzung von Haas von nur begrenzter Bedeutung für die Bildung musikalischen Zusammenhangs zu sein:

In dieser Weise werden speziell in der Musik des 19. Jahrhunderts oft größere Teile zusammengefasst. ${ }^{79}$

Bei allen angeführten Beispielen betrifft die Kadenzfolge immer nur einzelne Segmente und umfasst niemals das Gesamte der Komposition. ${ }^{80}$

75 Haas 2011.

76 Ebd., 313.

77 Ebd., 317. Eine zweite Bemerkung zielt offenbar auf Kadenzielles im Sinne von melodischer Endigungsformel, wenn Simon die zwei Tonfolgen $c-h-a$ und $c-b-a$ »jeweils wie kadenzierende Endungen zweier Halbperioden« (ebd. 304) interpretiert.

78 Haas 2004, 18.

79 Ebd.

80 In Richard Wagners Vorspiel zu Die Meistersinger von Nürnberg ordnet Haas T-S-D-T den Takten 1-14-27-41 zu, in César Franck Choral h-Moll für Orgel T-S-D-T den Takten 1-49-80-115 zu (ebd.). In seinen Analysen von César Francks Orgelfantasie in A-Dur und dem Lied Ihr Bild von Franz Schubert werden einzelne Fortschreitungen als authentisch oder plagal bezeichnet. Kadenzen haben bei der Organisation von Feldern in lokalem Zusammenhang auch hier den Status von Vehikel. So heißt es z. B.: »Das Konstrukt des Anfangs ist von einer authentischen Baßkadenz T-S-D-T getragen." (Haas 2004, 72) 
Haas sieht die Funktionsfolge auf spezifische Weise exemplifiziert. Das betrifft zunächst die Begrenzung auf je eine Stufe je Funktion:

An beiden Beispielen fällt auf, daß T stets als I., S als IV., und D als V. diatonische Stufe ausgeführt ist. Der Vorrang eines der vier Grundtöne bei der Subdominante und Dominante ist eine Analogiebildung zum Vorrang des einen Grundtons der Tonika. ${ }^{81}$

Damit ist aber noch nicht begründet, welchen tonräumlichen Abstand die drei verwendeten Stufen zueinander haben. Haas ergänzt:

[W] eiterhin ist das Quintverhältnis zwischen den genannten Stufen, bei dem die Tonika in der Mitte steht, maßgeblich [...]. ${ }^{82}$

Haas verweist in diesem Zusammenhang auf Arnold Schönberg, dessen »Ableitung der Diatonik aus drei quintverwandten Dreiklängen [...], so unhaltbar sie historisch [sei, sich] doch als richtig in dem hier beschriebenen System [das der Theorie der Tonfelder], dem Schönberg angehörte« erweise. ${ }^{83}$ Warum das Quintverhältnis »maßgeblich« ist, erfährt bei Haas keine nähere Erläuterung. ${ }^{84}$

In Haas' jüngeren Überlegungen zur klassischen Sonatenform mit Namen »Sonatenform $\| \ll^{85}$ spielen Kadenzfolgen keine explizite Rolle. Haas interpretiert die Sonatenform primär als einen Verlauf, durch den es zur Vervollständigung melodischer und akkordischer Tonfelder kommt. Haas folgt dabei der Beobachtung, dass »von den Tonvorräten her gedacht«, der Schenker'sche Ursatz nicht die vollständige Diatonik repräsentieren muss. ${ }^{86}$ Demzufolge sei die `Diatonie - so der von Heinrich Schenker verwendete Begriff - »als unvordenkliche Voraussetzung [aller Schenker'schen Verfahren] immer schon gegeben « ${ }^{87}$ Sie werde in der Ursatz-Tonalität des Spätbarocks durch spätere Schichten vervollständigt. ${ }^{88}$ Demgegenüber, so Haas, werde »im klassischen Sonatensatz [...] der historische Schritt vollzogen, dass im Stück selbst [...] die von Schenker verlangte ১Diatonie r gegeben wird. ${ }^{89}$ Damit wird implizit die Angemessenheit einer Analyse auf der Grundlage von Tonfeldern begründet.

81 Haas 2004, 18.

82 Ebd.

83 Ebd., 19.

84 Durch die Unterscheidung zwischen Grund- und Quinttönen innerhalb einer jeden Funktion, ist dieses vielmehr bereits vorausgesetzt.

85 Haas 2010.

86 Ebd., 278. Dies gilt nur dann, wenn die Urlinie ein Oktavzug ist. Liegt ein Quintzug vor, so handelt es sich - in C-Dur - um ein unvollständiges Hexaton $f$-e (ohne a), liegt ein Terzzug vor, so um ein unvollständiges Pentaton c-e (ohne a).

87 Ebd., 277. sDiatonie von sechs reinen Quinten (vgl. Rohringer 2010b).

88 Vgl. ebd.

89 Ebd., 278, Hervorhebung original. 




Beispiel 35: Haas 2010 ${ }^{90}$, Sonatenform II«, paradigmatischer Ursatz der Dur-Sonate

Beispiel 35 zeigt den paradigmatischen Ursatz der Dur-Sonate nach Haas. Dazu heißt es:

Die beiden Tonfelder halten einander die Waage: die 4 (f) des melodischen Tonfeldes kommt besonders gut zur Geltung nach dem fis des D-Dur-Akkordes. [...] Das akkordische Tonfeld dient dazu, das melodische zu ponderieren, und zwar so, dass zugleich der Gegensatz des Ausgangsklangs (= der Dominante in Dur[...]sonaten) zur Tonika ausgedrückt wird. ${ }^{91}$

Insofern es bei Schenker der in keiner Konkurrenz zu anderen Klängen stehende (tonikale) Dreiklang ist, der durch den Ursatz in Bewegung gesetzt wird ${ }^{92}$, markiert es bei Haas einen bedeutenden Unterschied, dass melodisches und akkordisches Tonfeld sich nicht auf dasselbe (tonikale) Tonfeld beziehen. ${ }^{93}$

90 Ebd., 273.

91 Ebd. - Der Gebrauch des Verbes sponderieren verweist dabei auf die Bildende Kunst, wo Ponderation das Abwägen, insbesondere bei der Komposition von Skulpturen, bezeichnet. Durch die entsprechende Anordnung der Körpersegmente kommt es zu einem Ausgleich der Gewichtsverhältnisse, so dass der Schwerpunkt nicht außerhalb des Körpers zu liegen kommt, was die Skulptur instabil machen würde.

92 Auch die V im Ursatz ist, da sie nach Schenker ganz aus dem Naturklang [gemeint ist hier die Obertonreihe] gegeben ist, keine konkurrierende Stufe (vgl. 1956, §15, 44f.).

93 Haas unterscheidet zwischen melodischen und akkordischen Tonfeldern. Im Falle der Dur-Sonate besteht das Heptaton der Dominanttonart (akkordisches Tonfeld) aus den Stufenpaaren V/II und I/V, im Falle der Moll-Sonate besteht das sharmonische Hepttaton< (ein Heptaton mit erhöhter sieb-


275-278). Im Falle der Subdominantreprise in Dur-Sonaten schlägt Haas als melodisches Tonfeld ein Hexaton (das Heptaton der Tonikatonart abzüglich der vierten Skalenstufe) vor, das durch das aus den Quinten von I, V und IV gebildeten Tetraton um den noch fehlenden Ton zum Heptaton der Tonikatonart ergänzt wird (2010, 273-275). Die durch die Subdominantreprise aufgebrachte Stufenfolge I-V-IV-I ist diejenige, die oben unter Rekurs auf Rohringer 2010a als Exempel des >Paradigmas des Stufengangs` angeführt wird. Allerdings gibt es einen gravierenden Unterschied zu Haas: In Rohringer 2010a wird von Akkorden als Repräsentanten von Stufen ausgegangen, während Haas gerade im Falle der Subdominantreprise auf die Hypothese eines akkordischen Feldes verzichtet. 
Das melodische Tonfeld tritt laut Haas das Erbe der Urlinie an (weshalb Haas den Begriff für das melodische Tonfeld auch übernimmt). Zweifelhaft ist aber, ob und gegebenenfalls inwiefern analog dazu auch das akkordische Tonfeld das Erbe der Bassbrechung antritt. Es scheint als Ganzes allein für deren Quint zu stehen. Nur unter der Voraussetzung, dass mit Blick auf den Naturklang die Quint als Ableitung des Grundtons zu gelten hat, könnte das akkordische Tonfeld trotz seines Gegensatzes zum melodischen zugleich als vermittelt angesehen werden.

Im Schenker'schen Ursatz werden zwei unterschiedliche Auffassungen von musikalischen Raum, der melodische und der harmonische, als ıEinheit der Differenz` (Niklas Luhmann) aufeinander bezogen. ${ }^{94}$ Zur $\mathrm{V}$ verbinden sich die melodische 2 der Urlinie (als der serste Durchgang، zwischen Terz- und Grundton des Tonikadreiklangs) und die durch die Bassbrechung hervorgebrachte Quint. Obgleich Schenker diese Verbindung kontrapunktisch als Konsonantmachung des Durchgangs herleitet, ist der Quintteiler, der dazu Verwendung findet, nur aus dem "Vorrang der Quint« heraus verständlich. ${ }^{95}$ Insofern bemerkt Haas zu Recht, dass die »Baßbrechung auch gleichursprünglich sei wie die Diatonik [der Urlinie]. ${ }^{96}$ Durch die Unterscheidung zwischen melodischem und akkordischem Tonfeld schreibt Haas diesen Gedanken einerseits fort und nimmt ihn doch andererseits zurück, insofern beide Felder einander sponderieren` (also zu einem übergeordneten Gleichgewichtszustand ergänzen), was strenggenommen ihre Zugehörigkeit zu einem Raum, dem alle Tonfelder zugehören, voraussetzt. ${ }^{97}$

Dies rückt Haas' Überlegungen in eine gewisse Nähe zu denjenigen Hauptmanns, wo es unmissverständlich nur noch einen Raum gibt. Ein weiterer Berührungspunkt ist, dass der Gedanke von der Darstellung der Tonart als einer Art Schwerpunktbildung, den

Eine Begründung kann dahingehend vermutet werden, dass I, IV und V bereits für sich genommen das vollständige Heptaton der Tonikatonart ergeben, wodurch das als melodisches Tonfeld angenommene Hexaton nur noch als dessen Teilfeld erscheinen würde. Damit verlöre es womöglich seinen Status als eigenständiges Tonfeld und würde, anders als in Haas' Modellen der Dur- und Moll-Sonate, obsolet. Aus dieser Problematik wird in Rohringer 2010a die Konsequenz gezogen, auf das Postulat eigenständiger melodischer Tonfelder im Zusammenhang mit dem 'Paradigma des Stufengangs zu verzichten.

94 Dass Schenker selbst den Begriff `Tonraum a ausschließlich als melodischen anerkennt („Unter dem Begriff Tonraum [im Original gesperrt] verstehe ich den Raum der horizontalen Urlinie-Erfüllung, erst durch diese ist ein Tonraum gegeben und beglaubigt." [Schenker 1956, §13, 43]), ändert nichts daran, dass es in seinem Ansatz faktisch zwei distinkte strukturelle Raummetaphern gibt.

95 "Daraus ergibt sich, daß es der sogenannten exotischen Musik an einer Diatonie fehlen muß, weil ohne kontrapunktischen Satz das Abstimmen und Sieben der Intervalle gar nicht möglich ist. [...] Umgekehrt hat heute der Verfall des Kontrapunktes den Verfall auch der Diatonie gebracht, und zwar durch die Schuld der Musiker, die noch immer nicht begriffen haben, daß, solange für den Naturklang der Quint bestimmend ist, und das wird ja immer bleiben, eine nach Anforderung der Natur auf die Quint sich stützende Stimmführung zu keiner anderen Diatonie wird führen können als zu der, die unsere Kunst bis heute aufweist.« (Schenker 1956, § 4, 41)

96 Diederen/Haas 2008, 163, Anm. 16.

97 Denkt man den Vergleich aus der Bildenden Kunst fort, ergibt sich bei Haas' Überlegungen die Frage, wo der Schwerpunkt zu liegen kommt. Sicher scheint nur, dass es sich weder um Tonika, noch Dominante handelt. Ferner wäre nach dem Körper zu fragen, innerhalb dessen der Schwerpunkt aus Gründen der Stabilität zu liegen kommen müsste. 
Haas in Form seiner Idee von der Ponderation aufbringt, auch bei Hauptmann begegnet. Deutlich wird das dort, wo Hauptmann modulatorische Übergänge beschreibt:

Wenn in der C-Durtonart der Ton fis, die Terz der Oberdominantquint eintritt, so spricht sich darin eine Tendenz nach der Oberdominantseite überhaupt aus, ein Verlangen, den Oberdominantaccord tonische Bedeutung erhalten zu lassen. In eben dem Masse als dies erstrebt wird, muss sich aber auch die Neigung zu der Unterdominantseite vermindert haben; in demselben Grade als die Oberdominantseite hervortritt, wird die Unterdominantseite zurücktreten müssen: der Schwerpunkt des Gleichgewichtes zwischen Beiden wird sich der Seite zuwenden, nach welcher die Tonart eine Hinneigung erhält. ${ }^{98}$

Entsprechend argumentiert Hauptmann:

Wenn dieser der Schwerpunkt in dem Systeme F-a-C-e-G-h-D in der tonischen Terz [im Original hervorgehoben], als der Mitte des mittleren Accordes [...] besteht, [...] so wird, wenn fis in das System eingetreten, [...] in a-C-e-G-h-D-fis dieser Schwerpunkt nicht mehr in der vorigen Stelle [...] gesetzt sein [...], [sondern] in der tonischen Quint [im Original hervorgehoben]. ${ }^{99}$

Dadurch werde der e-Molldreiklang vorübergehend tonisch und erst

[m] it dem Eintritte der Quint der Oberdominantdreiklanges [...] würde der Unterdominantdreiklang [...] völlig aufgegeben sein, indem $\operatorname{der}$ Ton $A$ die Unterdominantterz a ausschliesst. ${ }^{100}$

Folglich bestimmt der mittlere Ton eines jeden ıSystems` als dessen Terz den jeweiligen tonischen Dreiklang. Hauptmanns Überlegung hat zwei nicht explizit gemachte Voraussetzungen: 1.) Der tonale Raum ist zu denken als ein Tonnetz, das sich in Abständen aus reinen Quinten gliedert, die (in steigender Folge) durch große und kleine Terzen zu Dur-Dreiklängen ergänzt werden. 2.) Jedes ıSystem` einer Tonart umfasst sieben Töne als Ausschnitt des grundsätzlich unendlichen Tonraums.

Die Tonika als Ergebnis einer Schwerpunktbildung ${ }^{101}$ oder als Resultat eines dialektischen Prozesses - das scheinen auf den ersten Blick allerdings zwei nicht kongruente Konzeptionen in Hauptmanns Überlegungen zu sein, denn bei einer Schwerpunktbildung gibt es keine Bedeutungsverschiebung, sondern nur eine Kompensation. Die Paradoxie lässt sich allerdings auflösen, wird der Faktor Zeit ins Spiel gebracht.

Der Bedeutungswandel, den die einzelnen Stufen während des Prozesses der Tonartdarstellung erfahren (der Tonika von `Dominante sein $z u$ >Dominante haben im Falle

98 Hauptmann 1853, 47.

99 Ebd., $47 \mathrm{f}$.

100 Ebd., 48.

101 Bei Hauptmanns Schwerpunktbildung handelt es sich nicht um eine Ponderation. Ein Körper, innerhalb dessen es zur Schwerpunktbildung kommen muss, ist bei Hauptmann nicht vorausgesetzt. Vielmehr entsteht der Körper, unter dem die weiteren zur Tonart gehörigen Stufen verstanden werden könnten, dort, wo der Schwerpunkt zu liegen kommt. 
der authentischen Folge) hat als Ursache, dass sie in ihrer jeweiligen Bedeutung immer nur in Hinblick auf den gerade gegebenen Ausschnitt der Gesamtanordnung aller beteiligten Stufen verstanden werden. Die Qualität der Stufen schlägt um, sobald das gegebene Bild erweitert bzw. vervollständigt wird. Erst am Ende des Prozesses herrscht Klarheit darüber, wo der Schwerpunkt bzw. die Mitte liegt.

In diesem Sinne ergeben sich auch in Haas' Modell der 'Sonatenform Il qualitative Umschläge in der Bedeutung einzelner Feldsegmente: So kann das Pentaton des melodischen Feldes der Exposition als Teil eines Heptatons der Dominanttonart aufgefasst werden, bevor mit dem Eintritt des 4. Tons die Klärung zugunsten des Heptatons der Tonikatonart erfolgt. Umgekehrt können die beiden Stufen des akkordischen Feldes in der Exposition als Teil des tonikalen Feldes interpretiert werden, bevor sie durch die Reprise zu Bestandteilen des dominantischen Feldes erklärt werden.

Die Anordnung des `Systems in Terzen bei Hauptmann macht allerdings einen Unterschied zu einer Betrachtung aus der Perspektive der Tonfeldtheorie. Das ıSystem kann dort zwar als Heptaton abgebildet werden. Auch ist es ein Ausschnitt aus einer unendlich zu denkenden Folge. Als Quintenreihe aber bildet das Heptaton das Substrat für zwei Tonarten, die sich als parallele Dur- und Molltonart zueinander verhalten. ${ }^{102}$ Der von Hauptmann in seinem Beispiel gemachte Unterschied zwischen dem Ton a als Terz des Subdominantdreiklangs und als Quinte des Dominantdreiklanges verläuft innerhalb ein und desselben Heptatons. Daran wird ersichtlich, dass bei Hauptmann hinsichtlich der Darstellung der Tonart weder hinter den in Quintbeziehungen stehenden Dreiklang als Konstituente der Tonart zurückgegangen werden kann, noch die durch die Dreiklänge artikulierte Tonmenge unveränderlich ist. ${ }^{103}$ Von daher kann gesagt werden, dass in Hauptmanns Darstellung der Tonart das Tonmaterial als Heptaton einerseits und die über eine Quintenbreite von drei Quinten angeordneten Stufen IV, I und V andererseits gleichursprünglich sind. ${ }^{104}$

Im Unterschied dazu ist der gegenwärtige Stand der Theorie der Tonfelder dadurch geprägt, dass Felder, verstanden als Tonmengen, den alleinigen Ausgangspunkt der Ana-

102 Die Molltonart ist hier als reine Molltonart zu verstehen.

103 Denkbar erschiene ja auch, die tonische Terz als Mitte einer Quintenbreite von fünf Tönen im Quintabstand zu bestimmen: Ohne den Schwerpunkt zu verschieben, würde das dadurch artikulierte Tonfeld vom Heptaton zum Enneaton erweitert.

104 Insofern erscheint es problematisch, wenn in der späteren Harmonielehretradition Tonika, Subdominante und Dominante dem Tonmaterial vorausgehen und das Heptaton - als Skala - von diesen abgeleitet wird. So interpretiert Hugo Riemann die Dur-Tonleiter als einen mit Durchgangstönen aufgefüllten tonikalen Dreiklang, bei dem die Durchgangstöne sich aus den Akkorden der Subdominante und Dominante speisen. Der dabei zugleich vollzogene Rekurs auf den harmonischen Dualismus zeigt den szientistischen Hintergrund seiner Argumentation an: „Die Tonika erfordert, wenn ihre Bedeutung durch eine Skala unzweifelhaft ausgesprochen werden soll, eine derartige Wahl der Durchgangstöne, dass die Leiter nur nächstverwandte Klänge der Ober- und Untertonseite, welche sie selbst als den mitten innen stehenden, das Verständnis vermittelnden Klang erscheinen lassen." (Riemann 1883, 8) Und bei Rudolf Louis und Ludwig Thuille heißt es lapidar: »Durch die drei Dreiklänge der Tonika, Dominante und Unterdominante ist die Tonart vollständig und erschöpfend bestimmt. Indem wir, von der Tonika ausgehend, die von diesen Dreiklängen dargebotenen Töne stufenweise aneinanderreihen, erhalten wir die diatonische Tonleiter des reinen Dur.« (Louis/Thuille 1907, 3; Hervorhebung im Original gesperrt) 
lyse bilden. Fragen der Artikulation dieser Mengen und der Verhältnisse zwischen den Artikulationsformen werden zweifelsohne als zentral angesehen, scheinen in den Analysen und Modellen aber dennoch grundsätzlich nachgeordnet und variabel zu sein. Entsprechend heißt es bei Michael Polth:

Tonfelder besitzen bestimmte Klangeigenschaften. Diese resultieren unter anderem aus der Beschaffenheit des Tonfeldes selbst und aus der Art und Weise, wie das Tonfeld artikuliert, d. h. gegliedert wird. ${ }^{105}$

Aus dieser Perspektive ist es plausibel, wenn Polth mit Blick auf eine Beispielkomposition von Claude Debussy argumentiert:

\begin{abstract}
Auch Tonfeld-Kompositionen können lokale Tonarten ausprägen. Doch deren Funktion hat sich gegenüber der Funktion von Tonarten im 18. und frühen 19. Jahrhundert verändert. Bei Bach, Mozart und Chopin etwa gehörte die lokale Tonart zu den Konstituenten der (damals herrschenden) Tonalität, ebenso wie der Kontrapunkt (im Schenkerschen Sinne als Grundlage der Mehrstimmigkeit), die Akkorde und Akkordstufen, die Stimmführung, die Darstellung einer übergeordneten Tonart sowie eine bestimmte Art der Metrik (die der Darstellung der tonalen Verhältnisse dient). Für sich genommen lassen sich alle diese Momente auch in der zweiten Hälfte des 19. Jahrhunderts beobachten. [...] War die Darstellung einer Tonart für eine Komposition des 18. Jahrhunderts grundlegend, so geschieht sie bei Debussy optional. Sie ist eine unter vielen Möglichkeiten, Tonfelder zu artikulieren, und sie wird gewählt, um bestimmte Klangeigenschaften hervorzurufen. ${ }^{106}$
\end{abstract}

Demnach verdankten sich die tonalen Wirkungen solchen »Konstituenten«, wie sie in der Schenkeranalytik dargelegt werden. ${ }^{107}$ Obwohl Polths Definition abstrakt genug ist, um in der Ursatz-Tonalität eine skonkrete Artikulation` der Heptatonik zu sehen, ist die Ursatz-Tonalität bislang nicht explizit als ein Spezialfall der Tonalität der Tonfelder interpretiert worden. ${ }^{108}$

Allerdings verliert die Trennung zwischen Ursatz-Tonalität und Tonalität der Tonfelder in jüngeren Veröffentlichungen in dem Maße an Schärfe, wie versucht wird, den historischen Übergang zwischen beiden nachzuzeichnen. So erläutert Haas hinsichtlich des Modells »Sonatenform Il«, dass das melodische Tonfeld des Heptatons als

das simonistische Tonfeld hier die konkrete Voraussetzung schenkerianischer Ableitungen [ist]. Andererseits ist ein Tonfeld ein Tonfeld und es wird zu untersuchen sein, wie das - schenkerianische Ableitungen fundierende - Tonfeld als Tonfeld eventuell Vorgänge in den Kompositionen beeinflusst bzw. ermöglicht, die bei den älteren Komponisten nicht denkbar sind..$^{109}$

105 Polth 2011, 228.

106 Ebd., $235 \mathrm{f}$.

107 Vgl. auch Polth 2000, 2001.

108 Dafür wäre nicht entscheidend, auf welcher Schicht, sondern dass die Heptatonik hergestellt wird. 109 Haas 2010, 278. 
Freilich erhebt sich die Frage, wodurch die Termini Dominante, Subdominante und Tonika, die Haas in seiner Analyse verwendet ${ }^{110}$, fundiert sind. Es scheint, als verdankten die Akkorde des akkordischen Tonfeldes ihre funktionstheoretische Benennung allein der Zugehörigkeit zu den jeweiligen schenkerianischen Bassbrechungen in Exposition und Reprise. ${ }^{111}$ Damit käme den `Funktionen` nichts zu, was aus einem originären, aus der Tonfeldtheorie hervorgehenden Begriff von Funktionalität resultiert, der in einer >Funktion mehr sieht als das, was diese in Hinblick auf die Kategorie Klangeigenschaft mit allen übrigen Felder zu teilen scheint und für die nach Polth gilt:

Gemeinsam wäre allen konkreten Artikulationen eines Tonfeldes ein bestimmter Typ von Klangeigenschaft. ${ }^{112}$

Die terminologische Schnittmenge der Theorie der Tonfelder zur funktionsharmonischen Analyse und die daraus erwachsenden Konsequenzen sind bislang kaum aufgearbeitet und reflektiert worden. Dies mag damit zusammenhängen, dass die meisten ihrer Vertreter, wie auch der Verfasser selbst, aufgrund ihrer Nähe zur Schenkeranalytik in einer Tradition stehen, die sie in kritischer Distanz zu den herkömmlichen Harmonielehren hält. So resümiert etwa Konstantin Bodamer nach einem Vergleich der Ansätze von Lajos Bárdos, Zsoltán Gárdonyi und Ernö Lendvai:

Ihre Ansätze schreiben das zentrale Problem jedweder Harmonielehre fort: Die reduktive Erklärung des musikalischen Zusammenhangs mit Hilfe allgemeiner, quasi sa priorischer Regeln vermag dem einzelnen Kunstwerk kaum gerecht zu werden. ${ }^{113}$

Dem stellt Bodamer gegenüber:

Da Simon/Haas die Betrachtungen der Tonfelder nicht mehr mit Ansätzen der traditionellen Harmonielehre verbinden, vermeiden sie die Probleme, in die sich die eingangs besprochenen Autoren verstrickt hatten. Es ist schwer vorstellbar, wie ein Ansatz, der von der Erfahrung funktionaler Klangwirkungen ausgeht, mit einem traditionellen Ansatz vereinbar sein sollte, der Akkorde und Stufen als präexistente Grundelemente begreift. ${ }^{114}$

Freilich droht hier ein falscher Gegensatz. Auch die Tonfeldanalytik verzichtet nicht auf "präexistente Grundelemente«. Sie tut dies ebenso wenig wie jeder andere musiktheoretische Ansatz. Bereits dass mit Funktion, Konstrukt und Quintenreihe zwischen drei Typen von Tonfeldern spezifischer Ausprägung differenziert wird, und dass von Tonika,

110 Vgl. z. B. ebd., 273.

111 Das wiederum führt zu der Frage, wie durch schenkerianische Auskomponierungen tonale Wirkungen entstehen können, wenn der Systemkontext, der dem holistischen Konzept der funktionalen Analyse gemäß vollständig intakt sein muss, damit entsprechende Wirkungen überhaupt entstehen können, bereits von der Ursatz-Tonalität zur Tonalität der Tonfelder gewechselt hat.

112 Polth 2011, 230.

113 Bodamer 2011, 342.

114 Ebd., 346. 
Subdominante und Dominante die Rede ist (und entsprechend zwischen authentischen und plagalen Schritte unterschieden wird), gehört zu den spräexistenten Begriffsintensionen und Begriffsextensionen, die sich auf Elemente, die aus ihnen gebildeten Mengen, die spezifischen Klangeigenschaften dieser Mengen und ihre Teilmengen sowie auf weitere Bedeutungen beziehen, die sämtlich vor dem singulären Werk liegen. Wäre dem nicht so, so handelte es sich nicht nur um keine Theorie, es gäbe auch keine Möglichkeit das Besondere des singulären Werkes zu fassen. Die Differenzierung beispielsweise zwischen verschiedenen Formen der Subdominante in einer Schlussbildung, setzt den Begriff der Subdominante voraus. Wo es kein Gemeinsames gibt, kann nicht unterschieden werden.

Die Differenz zu den herkömmlichen Harmonielehren (und zu anderen musiktheoretischen Ansätzen) der von Bodamer zu Recht positiv bestimmten funktionalen Analyse liegt nicht im Verzicht auf Voraussetzungen, sondern in der Variabilität, mit der diese Voraussetzungen auf das singuläre Werk bezogen werden können. Diese Variabilität hat zwei Ursachen. Sie gründet zum einen in der größeren Menge denkbarer Figuren, durch die Tonmengen geordnet erscheinen, zum anderen in der größeren Anzahl von Relationen, in die auch identische Figuren durch ihre Verortung auf unterschiedlichen Schichten im Analysemodell gesetzt werden können. ${ }^{115}$

Dass die kybernetische Methode ${ }^{116}$ der funktionalen Analyse besagt, dass die je behauptete Figur immer im Hinblick auf das Ganze aller Figuren bestimmt wird, ändert nichts an dem durch die Theorie begrenzten Repertoire an konstitutiven und regulativen Regel ${ }^{117}$, die zuvor ausgegeben worden sind. Eben dies meint Schenkers dem Freien Satz vorangestellter Wahlspruch »Semper idem sed non eodem modo«. Die Frage, ob das Repertoire der Figuren und ihres Gebrauchs für die Erklärung spezifischer Fälle ausoder hinreicht, erweitert oder verringert werden sollte, ist Gegenstand des wissenschaftlichen Diskurses. Die Komplexität des Theoriedesigns sowohl der Schenker- als auch Tonfeldanalytik macht es in einer Vielzahl von Fällen unmöglich, hier zu einem abschließenden Urteil zu gelangen.

Ist der Status sa priorischer Regeln` geklärt, kann das, was vorausgesetzt wird, zur Diskussion gestellt werden. Hier wird vorgeschlagen, die Tonfeldtheorie mit den Hauptmann'schen Überlegungen dergestalt zu verknüpfen, dass Stufenfolgen unter Verwendung der I, IV und V als eine Möglichkeit der Tonartdarstellung im Hintergrund durmoll-tonaler Kompositionen begriffen werden. ${ }^{118}$ Die Stufen erscheinen dazu im Sinne

115 Entsprechende Vorgänge kennt man aus der Schenkeranalytik. Die Tonfolge a-g-f-e-d-c kann ein Sextzug sein. Möglich ist aber auch eine Ausfaltung paralleler Terzen, bei der auf die drei Töne der oberen Stimme drei Tönen der unteren folgen. Mit keinem von beidem ist entschieden, was die behauptete Figur im Rahmen des übergeordneten Kontextes ist, ob es sich also beispielsweise um einen Gang in die Mittelstimme oder einen Übergreifzug handelt.

116 Luhmann 1992, 418.

117 Vgl. zu diesem Unterschied Searle 1969.

118 An eine Inkorporierung der szientistischen Grundlegung, wie sie auch für Hauptmann, aber noch stärker für die Harmonielehren der zweiten Hälfte des 19. Jahrhunderts (und darüber hinaus) charakteristisch ist, ist dabei nicht gedacht. Nicht zuletzt deshalb auch wird hier an Hauptmann angeschlossen, dessen Verständnis von Musiktheorie sich größtenteils analog Hegels Verständnis von der Naturphilosophie verhält: »Die Naturphilosophie setzt nun die Physik voraus, sie bringt bloß eine 
Hauptmanns als Dreiklänge. Das Tonfeld des Heptatons ist dementsprechend auch hier mit den Stufen, die den tonalen Raum aufspannen, gleichursprünglich. ${ }^{119}$ Es wird zur Grundlage weiterer Auskomponierungen, die - darin Haas folgend - auf den von Schenker beschriebenen Verfahren beruhen oder auch nicht. ${ }^{120}$ Damit ist ein Unterschied gemacht zu einem historisch jüngeren Programm der Tonfeld-Tonalität, für das (möglicherweise) tatsächlich behauptet werden kann, alle dadurch zur Artikulation gebrachten Tonfelder seien gleichursprünglich. ${ }^{121}$

Vierstellige post-schenkerianische Ursatzform

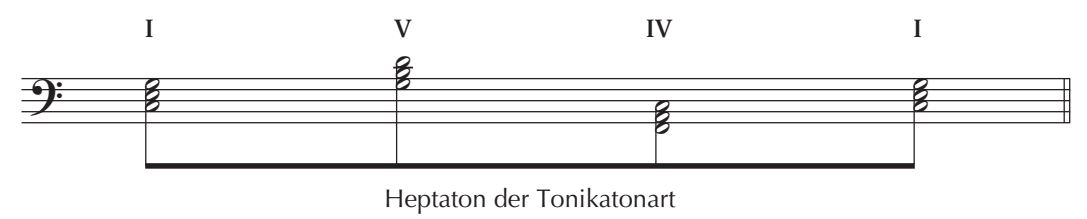

Beispiel 36: Vierstellige post-schenkerianische Ursatzform (für C-Dur)

Die vorgeschlagene Ursatzform ${ }^{122}$ für einen post-schenkerianischen dur-moll-tonalen Raum geht aus dem, was >Paradigma des Stufengangs` genannt worden war, hervor. Der Begriff spost-schenkerianisch impliziert dabei keine exakte historische Datierung, sondern setzt zwei unterschiedliche Tonalitätsprogramme in ein chronologisches Verhältnis,

andere Weise der Erkenntnis hervor. Diese philosophische Weise ist nicht eine Willkür, sondern es ist der Begriff, der dazu treibt und der dazu getrieben wird, weil die physikalische Weise den Begriff nicht befriedigt." (Hegel 2000, 72f. [36f.]) Eben weil Tonalität ein Kommunikationszusammenhang ist, kann er nicht hinreichend aus naturwissenschaftlichen Daten deduziert werden, sondern bedient sich Formen des Geistigen, die zu diskutieren Aufgabe der Musiktheorie ist. Damit ist zugleich gesagt, dass Hauptmanns Überlegungen keine leere Abstraktion sind, sondern auf einem Hören gründen.

119 Eine Notwendigkeit für die Verlagerung der Herstellung der Diatonik innerhalb der Schichtenfolge könnte solange als nicht gegeben erachtet werden, wie chromatische Töne als von diatonischen abgeleitet erscheinen (vgl. die entsprechenden Verfahren in der Schenkeranalytik, wie beispielsweise die >Mischung` [Schenker 1956, § 193, 115]). In dem Moment, wo Chromatik und (die aus ihr resultierende) Enharmonik jedoch autonome Ordnungen errichten (darauf verweisen die Tonfelder sFunktion` und 'Konstrukt nach Albert Simon), verlöre die Diatonik ihre »unvordenkliche Voraussetzung" und müsste gesondert in Abgrenzung zu den chromatischen Feldern behauptet werden. Die Einfachheit frühklassischer Kompositionen lässt allerdings zunächst ausschließlich an eine Reduktion von Komplexität gegenüber den spätbarocken Kompositionen denken. Dass die Diatonik im Hintergrund hergestellt wird, ist demnach wohl nicht eine Reaktion auf die Konkurrenz anderer Felder, sondern schafft vielmehr die Voraussetzung, die Qualität des mit I, IV und V einhergehenden Heptatons als Tonmenge zu fokussieren, was wiederum die Ausprägung anderer Felder motiviert haben mag.

120 Haas 2010, 278.

121 Nur unter dieser Bedingung könnten Rückgriffe auf Darstellungsformen des dur-moll-tonalen Raums, seien sie schenkerianisch oder, wie hier, post-schenkerianisch gedacht, zu einer sbloßen Artikulationsform von Tonfeldern werden.

122 >Form sind, weil für sie (noch) kein Werkkorpus angeführt werden kann. 
insofern spätere Stadien frühere voraussetzen. Die Form ist vierstellig und besteht aus den Dreiklängen der I, V, IV sowie der nochmaligen I und lässt sich als plagale Kadenz beschreiben. Darin, dass die beteiligten Stufen zusammen ein Heptaton artikulieren, folgt auch diese Ursatzform der Überlegung von Haas, dass im klassischen Sonatensatz die Diatonik im Hintergrund gegeben wird.

Die symmetrische Anordnung der Dreiklänge von IV und V um die mittige Tonika kann dabei als eine Transformation des Schenker'schen Ursatzes durch Analogiebildungen $^{123}$ verstanden werden (freilich unter Preisgabe der Urlinie und der Zweistimmigkeit), bei der der Quintanstieg I-V seine Entsprechung im Quintanstieg IV-I findet. ${ }^{124}$ Die hinzutretende Quintbeziehung des zweiten Paares überführt den dreistelligen zweistimmigen schenkerianischen Hintergrund in einen vierstelligen akkordischen post-schenkerianischen Hintergrund. Die Analogiebildung erwächst fraglos nicht aus der Schenkeranalytik

123 Vgl. die Ausführungen in Haas/Diederen 2008, wo Analogiebildungen als eine wesentliche Möglichkeit begriffen werden, gemäß der Direktive Schenkers die »streng logische Bestimmtheit [...] einfacher Tonfolgen mit komplizierten« aufzuweisen (Schenker 1956, § 29, 49). Während >die Analogie « das den nach Haas/Diederen bestimmende Ereignis des Hintergrund ist (der hier als erste Schicht nach dem Ursatz definiert wird; jede Schicht wird durch ein ihr spezifisches Ereignis bestimmt), ergeben sich auf der zwischen Mittelgrund und Vordergrund vom Autorenpaar postulierte Schicht des `Umrisses` die so bezeichneten ıvier Stufen`, die sich aus I, IV, V sowie der »Mollstelle (II., III. oder VI. Stufe bzw. in Mollstücken die Durstelle = III., VI. oder VII. Stufe) « zusammensetzen (2008, 163). Von den ıvier Stufen ‘ wird einerseits einschränkend behauptet, sie stellten nur »eine grundlegende Möglichkeit der Musik des 18. und 19. Jahrhunderts« dar, andererseits gelte aber auch für "Stücke in dieser Zeit, in denen nicht alle Stufen ausgeprägt sind «, dass »die Gesamtheit der vier als Möglichkeit in jedem Fall präsent« sei (ebd., 163). Bemerkenswert ist ferner, dass den svier Stufen ‘ durch ihre Verortung im tonalen Raum zugesprochen wird, »an ihnen selbst - ohne die Beteiligung bestimmter Stimmführung - gewisse Wirkungen [zu] erzielen.« (ebd., 162) Das leitet zu Überlegungen über, wie sie von Haas mit Blick auf die »Sonatenform Il« späterhin geäußert wurden (2010). Hierzu zählt auch der in Haas/Diederen 2008 gegebene Hinweis, dass schon bei Bach »die meisten« (ebd., 150) der durch `die Analogie` gegebenen beiden Akkordpaare zusammen ein Heptaton ergeben (ebd.).

124 Die in Haas/Diederen 2008 gemachten Angaben zu den »vier Stufen« in der Klaviersonate DDur op. 10/3 von Beethoven zeigen, dass für das Autorenpaar die Errichtung des tonalen Raums und die Konstituierung der Tonika zweierlei sind. Zwar postulieren Haas/Diederen für den Eintritt der Reprise des Hauptthemas, sie wäre »der Punkt, in dem die I. Stufe sich in ähnlicher Weise im Verhältnis zu den anderen Stufen ausbreitet«, sie sei »die Wiedergewinnung der Tonika nach dem Aufenthalt in anderen Regionen«, doch zeigt die Platzierung der Subdominante erst in der Coda mit Takt 298 an, dass sie für diese »Wiedergewinnung« nicht erforderlich ist. Haas/Diederen beziehen sich (wie auch Haas 2010) in ihrer Argumentation auf Philip Herschkowitz (1997), dem zufolge »der Hauptsatz [...] erst in der Reprise seinen vollen Wert als Exponent der Haupttonart « erhält (99). Herschkowitz unterscheidet im Gebrauch der Subdominante allerdings zwei Funktionen: Ihre erste Aufgabe sei es in der Durchführung, zusammen mit der Tonika (!) »gegen die Zur-Tonikagewordene-Dominante« (ebd., 100) zu wirken. Ferner erscheine sie in der Coda, dort aber nur noch als »absolute[r] Untertan der Tonika» (ebd.). Die von Haas/Diederen genannte Stelle in Beethovens op. 10/3,i kann nur die zweite dieser beiden Funktionen der Subdominante betreffen. Sucht man mit Herschkowitz in der Durchführung des Satzes nach einer diatonischen IV, so wird man nicht fündig. In Haas' Überlegungen zur »Sonatenform II« findet sich im Hintergrund des Modells der Dur-Sonate keine IV im akkordischen Tonfeld; die im Hintergrund des Modells der Moll-Sonate auftretende IV im akkordischen Tonfeld ist das erste akkordische Feld (am Ende der Durchführung) überhaupt; damit kann diese IV nicht die ihr bei Herschkowitz zugesprochene zentrale Aufgabe erfüllen. Gerade dort, wo es sich anbieten würde, ihr diese Funktion zuzuordnen, nämlich im Falle der Subdominantreprise, verzichtet Haas auf die Behauptung akkordischer Tonfelder (Haas 2010, 273-275). 
selbst; sie ist hier entwicklungsgeschichtlich gedacht und begründet die Anschlussfähigkeit der neuen Ursatzform. ${ }^{125}$ Gleichwohl ist auch für diese neue Ursatzform der »Vorrang der Quinte« maßgeblich; er gehört zu den »unvordenklichen Voraussetzungen« (was nichts über seine Ursache sagt). ${ }^{126}$

Freilich gilt auch für diese Überlegungen, dass sich die behauptete Hintergrundstruktur im Rahmen einer funktionalen Analyse als Teil einer selbsttragenden Konstruktion bewahrheiten muss.

\section{Schichten}

Im vierstelligen Ursatz ist das tonikale Heptaton bereits mit dem Erscheinen der IV vollständig. Daher kann zwischen zweierlei `Schlüssen` unterschieden werden: dem `konstitutiven Schluss`, der mit der Vervollständigung des hintergründigen Tonfeldes einhergeht, und dem sinterpunktischen Schluss`, der durch die resultierende Tonika vollzogen wird. ${ }^{127}$

125 Um Ableitungen des »Systems der Töne« aus der Obertonreihe zurückzuweisen, behauptet Schenker bereits in der Harmonielehre (Schenker 1906, 32) ohne genauere Angabe von Gründen, dass »[d] ie wirkliche künstlerische Beziehung zwischen der Obertonreihe und unserem System « darin bestehe, dass »[d]as menschliche Ohr [...] der Natur [...] nur bis zur großen Terz als der letzten Grenze [folge], also bis zu jenem Oberton, dessen Teilungsprinzip fünf ist.« (Ebd., 37) Entsprechend kann die Unterquint, anders als die Oberquint, nicht Teil einer Entfaltung des Naturklangs sein, der durch den Ursatz in Bewegung gebracht wird. Für Schenker wäre eine auf die IV folgende I nicht die durch einen Prozess hervorgebrachte Tonika, sondern nur die von einer eine Quint tiefer liegenden Stufe abgeleitete Brechung in deren Oberquint und damit nicht schlussfähig. Vgl auch die Zurückweisung des oben im Haupttext zitierten Zusammenhangs von Hauptstufen und Skala in Louis/ Thuille 1907 in Schenker 1910, 35f.

126 Angesichts seines weitreichenden Vorschlages kann vom Verfasser erwartet werden, dass er außer den Kompositionen der Salzburger Notenbuchtradition ein repräsentatives Corpus an Belegwerken anführt. In diesem Rahmen muss es bei einigen wenigen Hinweisen bleiben, anhand derer das hier vorgeschlagene Hören individuell erprobt werden kann. Dabei wird durch die Taktangabe in Klammern immer auf jenen Eintritt der IV verwiesen, in dem sich für den Verfasser die vierstellige post-schenkerianische Ursatzform im Besonderen manifestiert: W. A. Mozart: Klaviersonate KV 331,ii, Trio (T. 39) und Così fan tutte, Ouvertüre (T. 149, was Anlass böte, über die Bedeutung sogenannter falscher Reprisen in der Subdominanttonart neu nachzudenken); L. v. Beethoven: Missa solemnis, Kyrie (T. 140); F. Schubert: 5. Sinfonie D 485,i (T. 171), stellvertretend für die zahlreichen Subdominantreprisen dieses Komponisten, aber auch Streichquartett D 887,i (T. 334); R. Schumann, Symphonische Etüden op. 13, 2. Fassung, Finale (T. 98); R. Wagner, Großer Festmarsch (152). Daneben kann eine Reihe von Ursatzparallelismen beobachtet werden, die kürze Formabschnitte beherrschen, darunter W. A. Mozart: Le nozze di Figaro, Ouvertüre (T. 59-67) und KV 550,i (T. 44-51); R. Schumann: 1. Sinfonie op,38,i (T. 39-54) und als rhythmisch-metrisch stark verzerrte Variante auch: 2. Sinfonie op. 61,i (T. 50-58). Nicht zuletzt sei darauf aufmerksam gemacht, dass sich die im 19. Jahrhundert insbesondere in den Kompositionen der Neudeutschen herbeizitierte Diatonik durch die zumeist starke Betonung der Subdominante eher als Exempel der hier postulierten postschenkerianischen als einer schenkerianischen Tonalität ausnimmt (obgleich sich derartige Exempel immer auch mit der Schenkeranalytik dekomponieren lassen): Das Walhall-Motiv aus Das Rheingold und das Grals-Motiv aus Parsifal sind zwei Beispiele Richard Wagners, ein Heptaton durch I, IV und $\mathrm{V}$ mit authentischer Stufenfolge herzustellen.

127 Der sinterpunktische Schluss` erfolgt gemäß Hauptmanns Beobachtung spätestens seit der zweiten Hälfte des 18. Jahrhunderts regelmäßig als authentische Kadenz. In Mozarts Menuett I D-Dur aus KV 7 wird der konstitutive Schluss bereits mit der Taktgruppe 15-16 vollzogen, der interpunktische Schluss jedoch erst mit der Taktgruppe 21-22. 
Bleibt die erste Stelle im Ursatz unbesetzt, fallen konstitutiver und interpunktischer Schluss im Hintergrund zusammen. Insofern der durch die Stufen I, IV und V aufgespannte tonale Raum vorausgesetzt ist und ein je einmaliges Vorkommen von I, V und IV genügt, das tonikale Heptaton vollständig zu artikulieren, können zwei um zwei Quinten differierende Stufen als Dominante und Subdominante die mittige Tonika fordern, ohne dass eine Anfangstonika vorausgegangen sein müsste. ${ }^{128}$ Die vierte Stelle unbesetzt zu lassen, ist eine Möglichkeit späterer Schichten. Von beiden Möglichkeiten macht Brahms im Intermezzo Gebrauch.

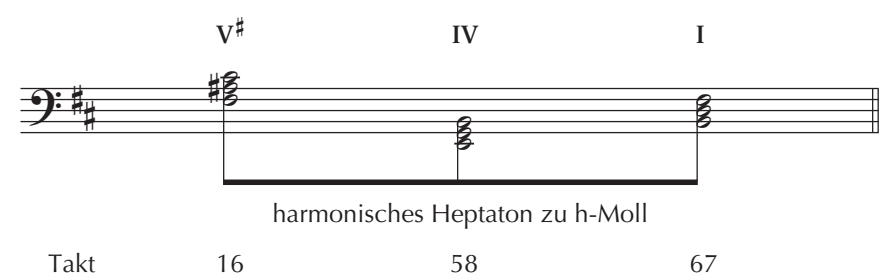

Beispiel 37: Johannes Brahms, Intermezzo h-Moll op. 119/1, Hintergrund

Den Hintergrund der Komposition bildet der Stufengang V-IV-I in h-Moll. Eine Anfangstonika fehlt. Der plagale interpunktische Schluss IV-I am Ende der Komposition verweist auf den hintergründigen Stufengang. ${ }^{129}$

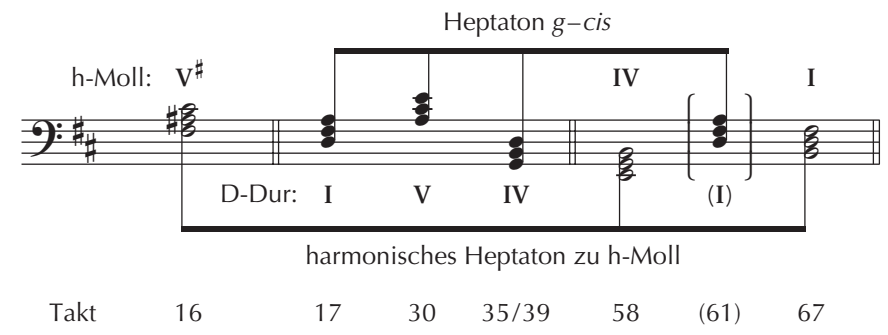

Beispiel 38: Johannes Brahms, Intermezzo h-Moll op. 119/1, hinterer Mittelgrund

Im hinteren Mittelgrund findet sich in den Stufengang des Hintergrundes eingelassen der von diesem abgeleitete Stufengang I-V-IV in D-Dur. Der interpunktische Schluss dieses `Nachbildes` fehlt. Der scheiternde Versuch ihn doch noch herzustellen, bildet den Inhalt der Takte 58-61.

128 Die im Sinne Hauptmanns sich selbst entfremdete Anfangstonika durch einen dialektischen Prozess auf einer qualitativ höheren Ebene als resultierende Tonika wiederzugewinnen, ist nur eine Möglichkeit der prozessualen Tonartdarstellung.

129 Die Reprisen innerhalb von Rahmenteil (T. 47) und Mittelteil (T. 31) dienen - so wie es am Beispiel des Menuetts aus KV 7 oben gezeigt wurde - zunächst dazu, den plagalen Schritt $V^{(*)}$-IV durch zwei authentische Schritte auszufüllen. Damit gehören sie einer späteren Schicht an. 


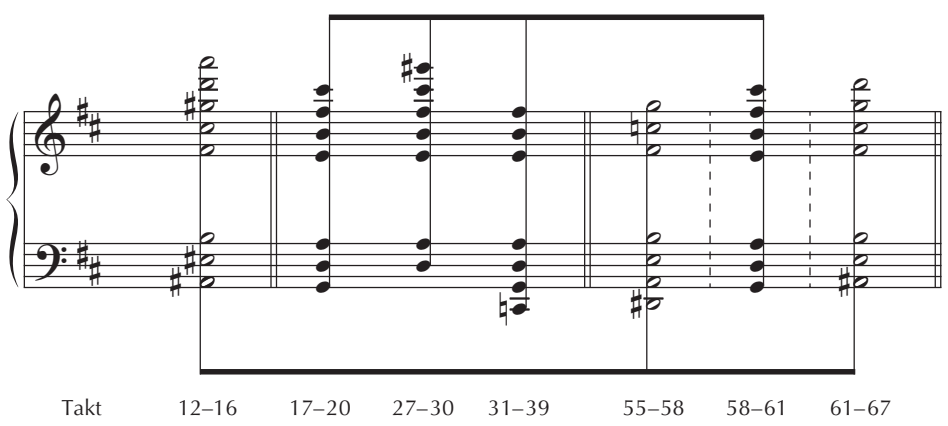

Beispiel 39: Johannes Brahms, Intermezzo h-Moll op. 119/1, vorderer Mittelgrund

Im vorderen Mittelgrund werden die Stufen als Felder auskomponiert. Dabei wird jeder Dreiklang in dasjenige Heptaton derjenigen Tonart überführt, in dem er lokale Tonika ist. Davon abgewichen wird nur für den ersten Klang des Hintergrundes: Die Ambivalenz zwischen a und ais im Vordergrund spricht für ein harmonisches Oktoton zu fis. Zwar wird in der Taktgruppe 58-61 der interpunktische Schluss in D-Dur verweigert, doch erscheint das zugehörige Heptaton. ${ }^{130}$

Das harmonische Heptaton zu h-Moll und das reine Heptaton zu D-Dur bilden die beiden `Tonfelder des Ganzen ‘. ${ }^{131}$ Sie unterscheiden sich nur in einem Ton: ais bzw. a. Der chromatische Konflikt zwischen beiden Tönen durchzieht das gesamte Stück.

Die drei reinen Heptatone ergeben zusammen das Enneaton $c-$ gis, das allerdings nicht als Feld in Erscheinung tritt. Die drei harmonischen Felder zu fis, e und $h$ ergeben dasselbe Enneaton zusätzlich der drei Leittöne. Das aus den Leittönen gebildete Triton dis-ais-eis ergänzt das Enneaton c-gis zum Zwölftonfeld.

Eine zentrale Idee des Werkes ist es, das im vorderen Mittelgrund durch Quintenreihen organisierte Zwölftonfeld lokal auch in den Vordergrund der Komposition zu bringen, dabei aber Artikulationsformen zu wählen, die nicht diatonisch, sondern chromatisch-enharmonisch sind. Diese Vorgänge verbinden sich mit dem, was im Folgenden das >dritte Feld genannt wird.

\section{'Drittes Feld und sPeripeties}

Das >dritte Feld s ist kein Tonfeld im eigentlichen Sinn. Seine genaue Ausdehnung ist unklar. Dies ist Ausdruck davon, dass eine auf (reinen) Quinten basierende Tonmenge prinzipiell unbegrenzt ist - im Unterschied zu den Feldern `Funktion die auf Algorithmen beruhen, welche unter Einschluss der Enharmonik in einen Zirkel, und dadurch zu einer endlichen Anzahl an Tönen führen. Das `dritte Feld steht für die

130 Deshalb wird hier, anders als in Beispiel 36, auf eine Einklammerung verzichtet.

131 Durch die zwischen ihnen bestehende Polarität steuern die `Tonfelder des Ganzen` den harmonischen Prozess im Stück (vgl. Haas 2004, 71). 



Beispiel 40: Johannes Brahms, Intermezzo h-Moll op. 119/1, Tonfelder T. 17-26 
Gefahr, dass die Tonmenge im Stück unkontrolliert steigt und die hintergründige Heptatonik unverständlich wird. Daher ist es notwendig, das Wuchern des >dritten Feldes` durch einen ostentativen Akt im Stück zu beenden. Dieses Ereignis wird hier `Peripetie genannt; es bildet das Zentrum des Mittelteils (Beispiel 40).

Ausgangspunkt des >dritten Feldes ist das Triton dis-ais-eis, gebildet aus den drei Leittönen der drei harmonischen Felder zu fis, e und $h$. Die Deformation der reinen Quintenreihe zu einer harmonischen bringt durch die verminderte(n) Quinte(n) eine Asymmetrie im Quintenturm mit sich. Das sdritte Feld s dient dazu diese Asymmetrie zu beseitigen. Es wächst durch den Versuch, möglichst viele reine Quinten an das Triton dis-ais-eis anzubinden. Die Dynamik dieser Tendenz ist dabei im harmonischen Raum vornehmlich aufwärts gerichtet.

Die Auskomponierung des reinen Heptatons der Anfangstonika D-Dur des Nachbildes vollzieht sich als authentische Kadenzfolge in den Takten 17-20 (als ein um die resultierende Tonika vervollständigtes Re-entry des Stufengangs aus dem hinteren Mittelgrund). Allerdings erscheinen weit mehr Töne als hierfür erforderlich sind: In der Begleitung des Basses betrifft dies nur den chromatischen Durchgangston gis (T. 18.3); im Akkordsatz der rechten Hand werden allerdings neben gis auch noch ais und eis eingestreut. Satztechnisch sind diese Töne, analog zum Bass ${ }^{132}$ als betonte chromatische Durchgänge eingebunden: ais (T. 18) zwischen a und $h$, eis und gis (T. 19f.) zwischen e und $g$ und fis und a. Zusätzliche Aufmerksamkeit verdient die Überlänge des Septvorhalts fis in der Mittelstimme Takt 18 bevor der Auflösungston e mit dem letzten Sechzehntel im Takt erreicht wird (offenkundig eine Analogie zu den Vorgängen in der Oberstimme in den Takten 2 und 3). Der große Durseptakkord über g erscheint dadurch wie eingefroren; im vorausgehenden Klang entsteht durch die Verbindung von Vorhalt und chromatischem Durchgang der übermäßige Dreiklang $d$-fis-ais. Das ais effiziert mit der leeren Quinte g-d im Bass einen sfalschen g-moll-Klang. Das mittige fis verhindert, den Ton ais snur als Ergänzung im Rahmen der lokalen subdominantischen Funktion ( $g$ - $d$, $b$-f, des-as, e- $h$ ) zu verstehen. Es entsteht ein fünf-töniges Konstrukt lb ( $g$ - $d, h$-fis, ais). ${ }^{133}$

Infolge der Taktgruppenordnung korrespondiert die fünf-tönige Funktion $(d$-a, eis, gis, $h)^{134}$ zu Beginn von Takt 20 mit dem Konstrukt. ${ }^{135}$ Ein Vergleich zwischen dem Original und der idealtypischen Rekomposition des Vierers (Beispiel 41) verdeutlicht allerdings, dass auch noch Konstrukt la beteiligt ist. ${ }^{136}$

Dadurch, dass Brahms die rhythmische Gruppe der rechten Hand zu Beginn des zweiten Zweiers um ein Achtel vorzieht, wird es ihm möglich, die beiden chromatischen Durchgangstöne eis und gis noch über dem Grundton der lokalen Dominante im Bass zu platzieren. So entsteht als ein weiterer übermäßiger Dreiklang die Grundtonreihe von la. Die Quinttöne e und gis ergänzen sie zur Fünf-Tönigkeit. Ib und la verhalten sich in

132 Man beachte die Andeutung eines (weiteren) Kanons!

133 Ohne dis/es.

134 Ohne his/c, dis/es und fis/ges.

135 Der Ton $h$ durchbricht die melodische Sequenz und verhilft hinsichtlich der Anzahl der Töne beider Klangbildungen zur Mengenähnlichkeit von jeweils fünf Tönen.

136 la enthält die Quinten $f$-c, a-e und cis-gis. 




Beispiel 41: Johannes Brahms, Intermezzo h-Moll op. 119/1, Alternativfassung T. 17-20

Bezug auf das chromatische Total komplementär. Zum Zwölftonfeld fehlen noch die Töne dis (in Ib) und his (in la). Seine Vervollständigung ist der Inhalt der nachfolgenden Taktgruppe. Satztechnisch handelt sich um ein Oktavregelsegment. Startpunkt ist die 3., Zielpunkt die 5. Bassstufe, die durch die vorangestellte kleine 6. Bassstufe als Halbschluss inszeniert wird. Der Bassgang wird bis zum Erreichen des Supersemitoniums $b$ als Fauxbourdon ausgearbeitet.

Durch den Bezug zur Oktavregel verhalten sich die harmonischen Vorgänge im mittleren Vordergrund, wie schon bei der authentischen Kadenz des vorangegangenen Vierers, diatonisch in D-Dur. Im äußersten Vordergrund dagegen führen weitere rhythmische Verschiebungen in Takt 22.1 und 23.2 zu übermäßigen Quinten im Rahmen einer steigenden 5-6-Konsekutive, die durch die Töne der Mittelstimme zu übermäßigen Dreiklängen aufgefüllt werden. Es ergeben sich die Grundtonreihen der Konstrukte Ib und la. Dadurch wird es möglich, die beiden durch Doppelleittönigkeit satztechnisch eingebundenen dis-Moll- (T. 21.3) und eis-Moll-Sextakkorde (T. 23.1) ebenfalls auf Ib und la zu beziehen. ${ }^{137}$ Beide Akkorde ergänzen jeweils denjenigen Ton, der im ersten Vierer zum vollständigen Konstrukt noch fehlte. Dass dis und eis jeweils in Verbindung mit ihrem zugehörigen Quintton ais und his als stabile sekundäre Quarten in Erscheinung treten, macht den Bezug besonders sinnfällig.

Die Taktgruppe 17-23 nimmt eine veränderte Akzentuierung zweier Momente vor, die bereits die Takte 12-16 prägen. War die skonstruktive Klangwirkung in den Takten 12-16 bereits im mittelgründigen Tonfeld (dort: das harmonische Oktoton) angelegt, so wird sie in den Takten 17-23 in denkbar stärkstem Kontrast zu diesem (hier: das reine Heptaton) hervorgebracht. Und während die zur Zwölftönigkeit verbundenen Töne in den Takten 12-16 noch von höchst unterschiedlicher Provenienz waren, erscheinen sie in den Takten 17-23, wo sie aus den komplementären Konstrukten hervorgehen, weitaus fester gekoppelt.

Die Beschleunigung des harmonischen Tempos über den chromatisch ansteigenden Bass dient der Vorbereitung der `Peripetie`, wie erneut eine Rekomposition verdeutlichen kann.

137 Dadurch verändert sich auch die Bedeutung des chromatischen Bassdurchgangs gis, der in Takt 18 ausschließlich als Quintton der subdominantischen Funktion erscheint. 




Beispiel 42: Johannes Brahms, Intermezzo h-Moll op. 119/1, Alternativfassung T. 20.3-25

Beispiel 42 zeigt, dass im Intermezzo eine eigentlich viertaktige Gruppe auf drei Takte gestaucht wird. Die reguläre Bassführung des Vierers lautet a-ais- $h$; die von Brahms gewählte tenorisierende Mi-Kadenz ist hingegen nicht nahe gelegt; sie könnte allerdings auf der Seite des Abstiegs als chromatischer Durchgang nachgereicht werden. Die Hemiole des Originals hilft das diatonische Schema, das auf dem Wechsel von Halbton- und Ganztonschritten beruht, zu durchbrechen. Ihre Betonungsverhältnisse setzen an dessen Stelle eine reale Sequenz, die ganztönig fortschreitet.

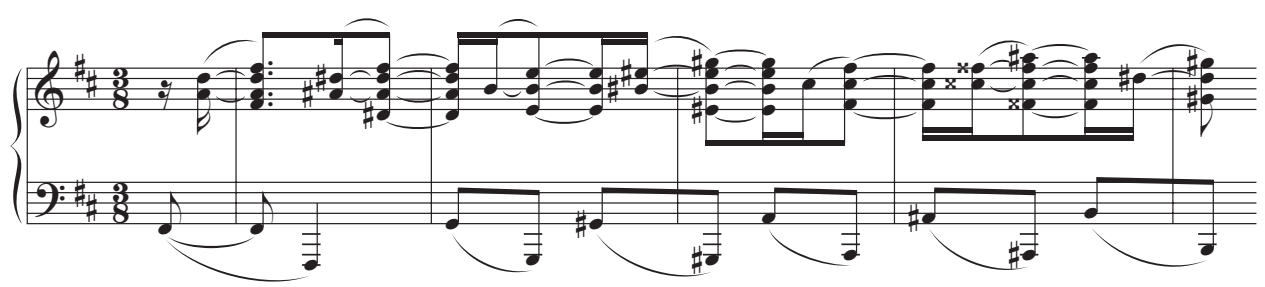

Beispiel 43: Johannes Brahms, Intermezzo h-Moll op. 119/1, Alternativfassung T. 20.3-25.1

Beispiel 43 zeigt, wie bei konsequenter Fortsetzung der realen Sequenz die diatonische Schwelle des Supersemitoniums in der hinteren Schicht überrannt würde. Bemerkenswert ist dabei, dass die Fortschreitung auf der ersten Zählzeit des vierten Taktes im Beispiel die enharmonische Variante des originalen Notentextes darstellt. Die Rekomposition sensibilisiert dafür, dass im Intermezzo zu Beginn von Takt 24 eine "gleichzeitige Gleich- und Ungleichsetzung der enharmonisch Unterschiedenen « komponiert ist. ${ }^{138}$ Brahms' Notierung orientiert sich dabei an der tatsächlichen Fortsetzung. Das Supersemitonium hat die Funktion eines Deus ex machina; es verhindert, dass die Chromatik im Stück überbordet. Mit großer Vehemenz wird so die Anzahl der Töne im Stück begrenzt.

Die Stelle fügt sich in den Gesamtzusammenhang der Komposition ein. Im gesamten Intermezzo finden sich 16 verschieden notierte Töne. Neben den 12 Tönen des vorderen

138 Bernhard Haas hat mit Blick auf Wagner und Bruckner darauf aufmerksam gemacht, dass die "gleichzeitige Gleich- und Ungleichsetzung der enharmonisch Unterschiedenen [...] ein großes Thema« sei (2012, 202f.). Ein sgroßes Thema kann dieses Phänomen nur sein, solange die chromatischen Felder `Funktion` und `Konstrukt` noch nicht als gleichursprünglich zu Diatonik der Heptatonik (und der von ihr abgeleiteten Quintenreihen) verstanden werden. Dass Schönberg Enharmonik nur noch als ein Problem der Notation begreift, zeigt den veränderten historischen Entwicklungsstand an (vgl. 1986, 307). 
Mittelgrundes c-eis sind dies die Töne his und gisis (nach `oben im Quintenturm) und die Töne $f$ und $b$ (nach sunten`). Der Ton gisis erscheint dabei als Ausreißer. Er tritt im Rahmen einer Terzkoppelung gemeinsam mit his auf und kommt nur an zwei analogen Stellen vor (T. 8.3 und T. 54.3). Im Quintenturm ist er der höchste, und, von sunten in reinen Quinten gezählt, der 18. Ton. Dementsprechend fehlen notiert die Töne Nummer 16 und 17 fisis und cisis. Dies aber sind genau jene beiden Töne, die im Moment der sgleichzeitigen Gleich- und Ungleichsetzung der enharmonisch Unterschiedenen die Lücke im Quintenturm füllen, ohne als Notat sichtbar zu sein. Notiert sind nur ihre enharmonischen Varianten $g$ und $d$, mit denen sie in eins fallen.

Dieses Ereignis wird zum Umschlagspunkt des gesamten harmonischen Verlaufs. Die Fortsetzung von ais als $b$ und damit korrespondierend das Elidieren der Töne eis (die entsprechende absolute Tonhöhe klingt T. 26.3 als f, das einzige Vorkommen dieses Tones im gesamten Stück und durch den verminderten Septakkord in hörbarem Bezug zur Klangbildung T. 15.1, wo die absolute Tonhöhe noch eis hieß), his (diese absolute Tonhöhe klingt T. 28 und T. 30 als C) und gis (melodisch sehr nachdrücklich im Übergang von T. 26 zu 27 und von T. 28 zu 29) durch ihre diatonischen Stammtöne e, $h$ und $g$ beendet das Anwachsen des >dritten Feldes`.

Die Takte 24-26.2 $2^{139}$ artikulieren im mittleren Vordergrund ein harmonisches Heptaton zu D-Dur (fis-cis-g-d-a-e-b). Daran, dass es sich vom reinen Heptaton zu D-Dur nur um den Ton $b$ statt $h$ unterscheidet, wird seine vermittelnde Bedeutung ersichtlich. Dazu gehört, dass der Ton $h$ im äußersten Vordergrund zugleich als Durchgang ins Spiel gebracht wird (T. 25.3).

Der harmonische Umschlag findet auch in der tonräumlichen Gestaltung des realen Satzes eine Entsprechung: Auf den steigenden Ast in Verbindung mit der steigenden Oktavregel folgt ab T. 24.2 ein fallender Ast, in der Melodielinie ausgehend vom $\mathrm{e}^{3}$, dem höchsten Ton des Stückes. Den ıUmsturz versinnbildlicht auch durch das an gleicher Stelle aus der tenoralen Lage hinabfahrende Bassarpeggio.

Ein weiteres Detail ist in diesem Zusammenhang bemerkenswert. An mehreren Stellen des Mittelteils (T. 19 bzw. 33, 25, 27 und 37) erscheinen auf metrisch starker Zeit Klangbildungen, die aus traditioneller Sicht Vorhalte in Kadenzen nach D-Dur sind. Die Setzweise lässt dabei die durch Quart- und Quintintervalle geprägte Klanglichkeit besonders deutlich hervortreten. Aus der Perspektive der Tonfeldtheorie handelt es sich um satztechnische Einrichtungen, die der vordergründigen Artikulation des Tritons $g-d-a$ (T. 25 und 37) bzw. des daraus hervorgehenden Tetratons g- $d$-a-e (T. 19/33 und 27) dienen. Der besondere Status dieser Quintenreihe(n) wird daran ersichtlich, dass Brahms auf eine entsprechende Inszenierung anderer Töne verzichtet. Der Kern des >dritten Feldes` ist, wie oben gezeigt, das Triton dis-ais-eis, das aus den drei Leittönen der drei harmonischen Felder zu fis, e und $h$ gebildet ist Das Triton $d$-a-e ist sein >diatonisches Pendant . Die Anlagerung des Tones $g$ betont die Rücknahme des vorherigen gis.

139 Takt 26.3 hingegen artikuliert sämtliche Grundtöne der Tonika. 


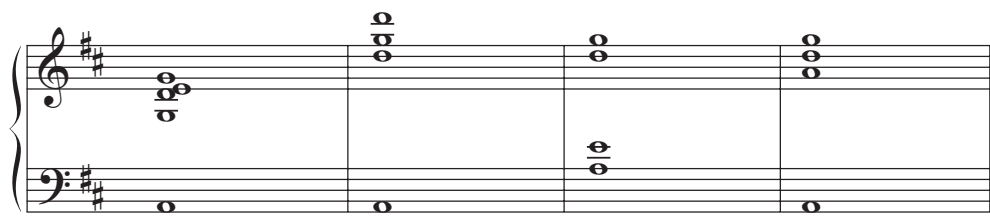

Takt $19 / 33$

25

27

37

Beispiel 44: Johannes Brahms, Intermezzo h-Moll op. 119/1, Quintenreihen T. 19/33, 25, 27 und 37

Die Prolongation des Halbschlusses am Ende des Vordersatzes Takt 27-30 rekapituliert durch ihre gegenläufige Chromatik das vorausgegangene Ereignis: Zweimal folgt auf einen steigenden (ais- $h$ ) ein fallender Halbton $(b-a)$ in Manier des `Omnibus` (Victor Yellin). Die direkte Folge der Dominantseptakkorde über $c$ und a führt das Feld der lokalen Dominante sechs-tönig aus (Beispiel 45).

Wenn im Übergang zum korrespondierenden Nachsatz der mittigen Periode abermals der Ton eis erklingt (T. 30.3), deutet sich die Möglichkeit einer nochmaligen Eskalation an. Aber das in der Mittelstimme Takt 32.1 gegen das unmittelbar vorausgehende cis gesetzte c zeigt den Übergang zum Heptaton c-fis an, das gemäß des hinteren Mittelgrundes auf D-Dur als interpunktischem Schluss des Mittelteils verweist. Im Vordergrund wird jedoch das zu D-Dur gehörige Heptaton g-cis zum harmonischen Heptaton zu h-Moll verändert. Als satztechnische Einrichtung hierzu dient eine ausgeflohene Kadenz über dem chromatisch steigenden Bass (T. 33-34). Auch ein zweiter Anlauf ab Takt 37 wird ausgeflohen. Wie schon in den Takten 35-36 verharrt die Musik ab Takt 39 erneut auf der subdominantischen Funktion. Dass c zu cis realteriert und auch als Basston gesetzt wird (T. 40-42), schafft die Möglichkeit, die sSeite` von D-Dur zu h-Moll zu wechseln.

\section{Der Anfang}

An dieser Stelle ist es nun möglich, den noch fehlenden Teil der oben bereits begonnenen Tonfeld-Analyse des Anfangs einzufügen (Beispiel 46).

Die Takte 1-10 sind nicht im Hintergrund verankert. Sie ergeben sich durch die Vorverlagerung einzelner Ereignisse des Mittelgrundes. Dazu gehört insbesondere der Wechsel zwischen den beiden Tonfeldern des Ganzen, dem reinen Heptaton zu D-Dur und dem harmonischen Heptaton zu h-Moll. Da das Heptaton g-cis auch alle Töne der natürlichen Mollskala von h-Moll enthält, vermag die Oberstimmenmelodik - sofern man überhaupt von einer Melodie sprechen möchte - vollständig auf das reine Heptaton zurückgreifen, während der zu a konkurrierende Ton ais grundsätzlich nur im Begleitsatz vorkommt. ${ }^{140}$ Der Ton a wird erstmals in Takt 4 durch ais abgelöst, aber schon in Takt 5 zu a realteriert. Von hier aus nimmt die zentrale Idee der nachfolgenden Takte ihren Ausgang, beide Töne zunächst durch einen sukzessiven (T. 5.3) und dann durch einen

140 Takt 7.3 kollidieren beide Töne in dieser unterschiedlichen Funktion miteinander. 

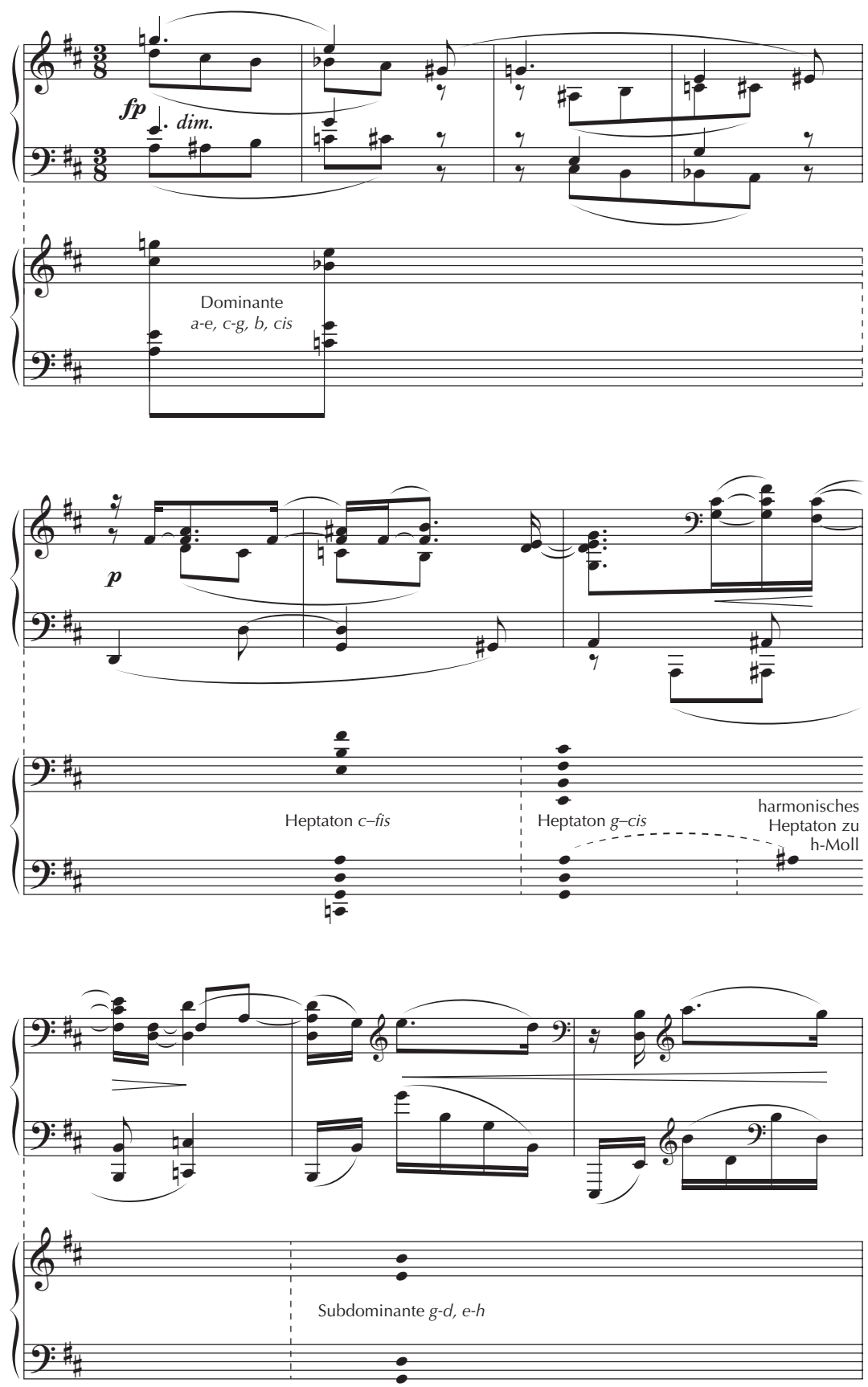

Beispiel 45: Johannes Brahms, Intermezzo h-Moll op. 119/1, Tonfelder T. 27-36 


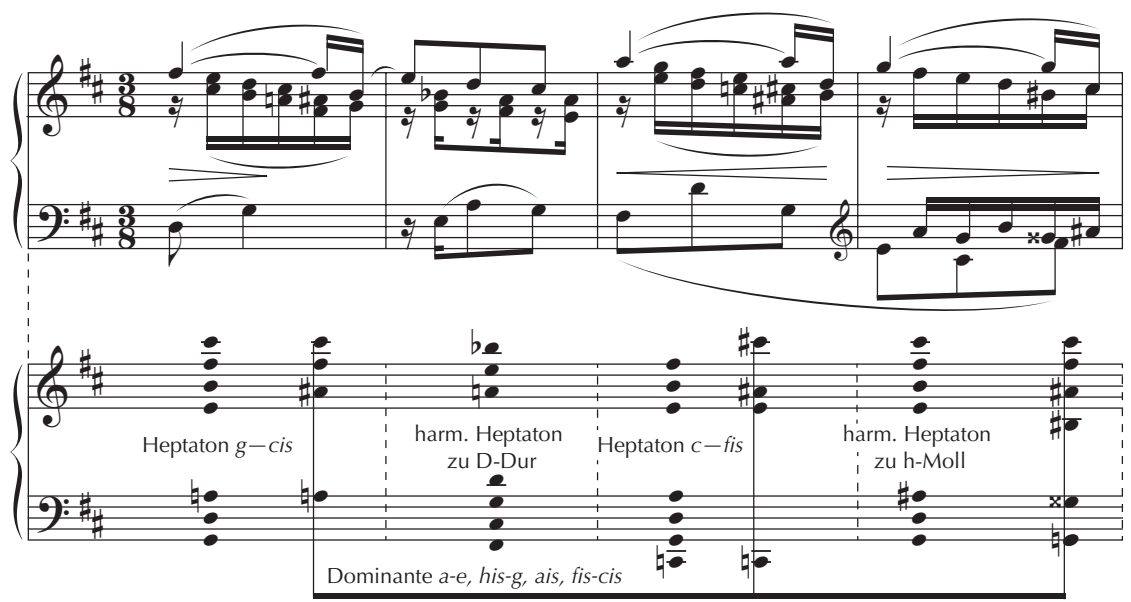

Beispiel 46: Johannes Brahms, Intermezzo h-Moll op. 119/1, Tonfelder T. 5-8

simultanen Querstand (T. 7.3) immer näher aneinander heranzuführen, bis am Ende der Phrase der Ton a durch seine enharmonische Variante gisis, dem Leitton zu ais, ersetzt wird (T. 8.3).

Nicht nur die enharmonischen Varianten a und gisis belegen eine Taste mit zwei unterschiedlichen Tonbedeutungen, sondern auch die Töne ais und b. Takt 6 ist Sequenz von Takt 4: Aus dem harmonischen Heptaton zu h-Moll wird nun das harmonische Heptaton zu d-Moll. Dieses Heptaton aber fungiert, wie bereits gezeigt wurde, als Vermittlungsfeld im Anschluss an die sPeripetie des Mittelteils. Das zeitliche Nacheinander der enharmonischen Varianten bereitet ihre Inszenierung als igleichzeitige Gleich- und Ungleichsetzung der enharmonisch Unterschiedenen vor.

Ein weiteres Feld wird in der Eröffnungsphrase antizipiert. In Takt 7 erscheint das Heptaton $\mathrm{C}-\mathrm{fis}$, das im vorderen Mittelgrund den Dreiklang der lokalen Subdominante G-Dur des Mittelteils auskomponiert. Die Vorwegnahme des Heptatons, ermöglicht es, die doppelte Belegung einer weiteren Taste, hier durch die Töne $c$ (T. 7) und his (T. 8), vorzuführen.

Mit Ausnahme der Töne eis und $f$ sind damit in den Takten 1-8 alle Töne im Stück, deren enharmonischen Varianten notiert erscheinen, in ihrer paarigen Konstellation bereits aufgerufen worden. Sie sind durch die Querständigkeit klanglich und durch die Taktposition metrisch aufeinander bezogen, so dass sie sich zu einem Feld zusammenfügen und im Vordergrund der Komposition eine sieben-tönige Dominante ergeben (a-e, his-g, ais, fis-cis). ${ }^{141}$ Diese Feldbildung lässt sich als Analogie zur Dominantprolongation am Ende des ersten Teilsatzes im Mittelteil Takt 27-30 verstehen.

141 Ohne dis/es. Das mag ein Grund dafür sein, dass das verbleibende Paar eis/f fehlt. 


\section{Die Rückleitung als Vorgeschichte}

Wie schon die Interpretation des Beginns der Komposition im ersten Textteil zeigte, ermöglicht es das Ordnungsprinzip Quintenreihe klangliche Phänomene, die vor dem Hintergrund der traditionellen Satztechnik fragwürdig erscheinen, neu zu qualifizieren. Dies zeigt sich insbesondere bei der enigmatischen Taktgruppe 43-46, die der Vorbereitung der Reprise des Rahmenteils dient. Durch die Verbindung von Reihenprinzip und Terzfallmechanik verdrängt Brahms mit äußerster Kühnheit eine herkömmliche Satzstruktur. Nur zu Beginn des Abschnitts verhalten sich Reihentechnik und traditionelle Mehrstimmigkeit kongruent, insofern die ersten Sets in Form von Septakkorden noch eine Quintfallsequenz hervorbringen (T. 43f.) (wobei auch hier schon die Inszenierung als steigende Folge eine extreme Form des Übergreifens darstellt).

Wie in Beispiel $47 \mathrm{zu}$ sehen, gehen die terzgeschichteten Klänge nach dem Algorithmus auseinander hervor, dass das jeweils vorletzte Glied eines Sets zum ersten des nachfolgenden wird: (n1-n4) (n3-n6) (n5-n8) (n7-n10). Unmerklich erfolgt die Erweiterung des fünften Sets am Ende von Takt 45 von vier auf fünf Töne. Der Einsatzabstand wird dabei nicht verkürzt: (n9-n13) (n12-n16) (n15-n19). Aus dem Quintfall wird ein Septimfall, d.h. ein Sekundanstieg. Zwar lässt sich die in den Takten 45-46 auf der jeweils letzten Zählzeit vorgenommene Supposition einer weiteren Terz als Vorausnahme desjenigen Basstones verstehen, der mit dem zu Beginn des Folgetaktes erscheinenden Oberstimmenstimmenton als Teil des Dezimariums $\left.h / d^{2}-c i s^{1} / e^{2}-d^{1} / f i s^{2}\right)$ verständlich wird. ${ }^{142}$ Doch verändert sich der Blick auf die Passage, sobald bemerkt wird, dass der Algorithmus zwei Takte später in den ersten Takt des Stückes führt. Konsequent hebt dieser ebenfalls fünf-tönig an und antizipiert durch das nachgereichte $a^{2}$ eine sechstönige Terzschichtung (T. 47), die dann im Folgetakt erstmals als durchgehender Terzfall inszeniert wird. Der Einsatzabstand bleibt wiederum erhalten: (n15-19) (n18-n23). Es handelt sich also um eine reihentechnische Herleitung des Anfangs. Brahms trägt hier eine Vorgeschichte nach, bei der das noch 'ges(ch)ichtslose (Ton-)Material in seiner Nacktheit vorgestellt wird.

Gleichwohl ist der Prozess mit Ende der Rückleitung noch nicht zum Abschluss gekommen. Die sechs-tönige Terzschichtung aus Takt 48 findet sich in veränderter Formfunktion am Ende jener Taktgruppe wieder, in der vergeblich versucht wird, D-Dur als Schlusstonika des Mittelteils interpunktisch zu bestätigen (T. 61). Die erneute Verdrängung des Tones a durch ais verweist bereits auf die Takte 65-66, das tatsächliche Ende der Komposition, wo das einzige Mal im Stück eine sieben-tönige Terzschichtung erscheint. Sie umfasst das gesamte harmonische Heptaton von h-Moll (Beispiel 47).

Vor dem Hintergrund der Terzfallmechanik tritt das >chromatische Motiv d-dis-e-eisfis der Takte 45-47 hervor, das als Untergreifzug zum Kopfton die Reprise des Rahmenteils mit vorbereitet. Es handelt sich um ein Echo des Mittelteils. Dieselbe Linie erscheint in den Takten 20.3ff., also im Vorfeld der sPeripeties in gleicher Lage und in schenkerianisch gleicher Funktion. Das >chromatische Motiv bildet die motivische Außenseite des 




Beispiel 47: Johannes Brahms, Intermezzo h-Moll op. 119/1, Reihe T. 43-46, 61-62, 65-67

'dritten Feldes`, ist dessen gestalthaft feste Kopplung. ${ }^{143}$ Dort im Mittelteil ist es in die Darstellung des Zwölftonfeldes durch die beiden komplementären Konstrukte Ib und la eingebunden. Hier in der Rückleitung hingegen wirkt es wie eine Erinnerung an bereits Vergangenes. Den Mittelteil im Ohr wird man dazu neigen, den in Takt 46 eingeführten Ton ais, der das reine Heptaton g-cis in das harmonische Heptaton zu h-Moll abermals überführt, als mittleren Ton des Tritons dis-ais-eis zu bestimmen. Satztechnisch wird diese Interpretation durch das Quart-Quint-Zickzack dis-ais-eis unterstützt. Das Triton bildet einen Rest des >dritten Feldes«, ruft es nochmals auf. ${ }^{144}$ Jenseits der Formgrenze wird mit Beginn der Reprise (T. 47) zunächst wieder zum Heptaton g-cis zurückgefunden. Währenddessen erscheint in Verbindung mit dem hier neu eingeführten Nebennotenmotiv ${ }^{145}$ auch noch der Ton his und ergänzt das Triton zum Tetraton. Da aber der Ton gis fehlt, bleibt das Tetraton vom Heptaton separiert. Ein Zwölftonfeld entsteht nicht mehr (Beispiel 48).

Ein letztes Mal klingt das >chromatische Motiv in den Takten 55-56 an. Durch das mittelgründige harmonische Heptaton zu e-Moll und die damit verbundene Verdrängung des Tones $d$ durch den Ton dis ist ihm allerdings der bisherige Ausgangston genommen: Die Linie setzt nun auf dis an. Die Einbindung in den satztechnischen Kontext ist gegenüber den Takten 45ff. nochmals geschmälert. War der Zielton fis bislang metrisch betont, so fügt sich das Motiv nun ganz in die Grenzen des Taktes und führt, erneut untergreifend, auf die Vorhaltsauflösung der Oberstimme am Ende von Takt 56. Damit ist sein Verschwinden komponiert. Auch andere Relikte des >dritten Feldes« sind weiter

143 Man könnte auch von der motivischen Konkretion einer sich aus diversen Leittonauflösungen speisenden 'Subthematikı (Carl Dahlhaus) sprechen. Die Linie geht aus der stetigen Folge mehrerer solcher leittönigen Bewegungen hervor.

144 In Verbindung mit dem Triton kommt es zu Allusionen an die Klanglichkeit des Mittelteils und an das Ende des ersten Rahmenteils: So bilden die Töne des im Oberstimmensatz von Takt 45 entstehenden übermäßigen Dreiklangs $g$ - $h$-dis die Grundtonreihe des Konstrukts Ib. Im folgenden Takt entsteht ab dem zweitem Sechzehntel ein fünf-töniges Konstrukt Ilb (fis-cis, $d$, ais-eis), das an die Klanglichkeit der Takte $14-16$ erinnert.

145 Das Nebennotenmotiv verbindet zwei vorherige Gestaltungselemente: Rhythmisch greift es auf die triolische Sechzehntelgruppe zurück, die ab Takt 37 zur Steigerung beim zweiten Kadenzversuch nach D-Dur erstmals Verwendung findet. Als aufwärts gerichtete Halbtonbewegung partizipiert es an der das gesamte Stück bestimmenden Subthematik. 



Beispiel 48: Johannes Brahms, Intermezzo h-Moll op. 119/1, Tonfelder T. 43-49

auf dem Rückzug. Das Nebennotenmotiv führt in Takt 57 nochmals die Töne eis und ais herbei. Die Bildung des Tritons dis-ais-eis wird aber, weil ein Quart-Quint-Zickzack fehlt, satztechnisch nicht mehr unterstützt, und das mittelgründige harmonische Heptaton zu e-Moll bringt den Ton $c$ ins Spiel, der sein enharmonisch Ungleiches, den Ton his saufsaugtı. Es entsteht die ‘falsche Quinte eis-c. Nachdrücklich verweist sie darauf, dass das Tetraton dis-ais-eis-his nicht mehr zu Gebote steht (Beispiel 49).

Die verbliebenen Chromen bringen harmonische Irrlichter hervor: Zunächst entsteht zu Beginn von Takt 57 eine sechs-tönige Tonika (ohne $d$ und gis). Wenn auf der letzten Zählzeit in der Oberstimme nochmals das Nebennotenmotiv mit dem Tonschritt ais-h in Erscheinung tritt, so wird die satztechnische Konstellation zu Beginn von Takt 18 und die zugehörige Klanglichkeit von Konstrukt lb aufgerufen.

Trotz dieser Anklänge steht die Stelle für sich. Dies liegt an der Rigidität, mit der der Terzfallmechanismus das mittelgründige Tonfeld artikuliert und die reguläre Satztechnik 


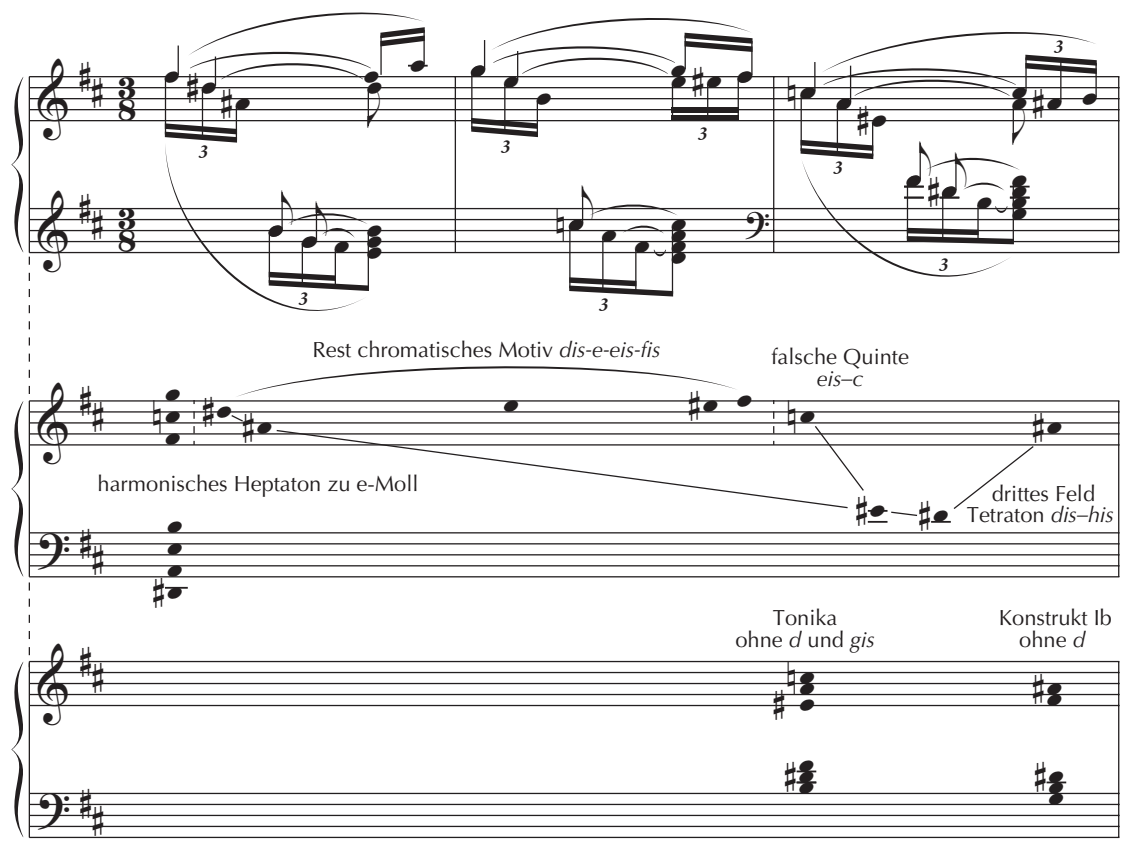

Beispiel 49: Johannes Brahms, Intermezzo h-Moll op. 119/1, Tonfelder 55-57

überformt. Wie oben gezeigt, verhalten sich die Takte 2 und 3 zu Beginn des Intermezzos als Ausschnitt einer doppeltaktigen Quintfallsequenz. Das harmonische Heptaton zu e-Moll bringt es nun mit sich, dass nicht nur in Takt 55, d durch dis als Mittelstimme verdrängt wird, sondern auch in Takt 55, wo $d$ in Takt 2 Bassfunktion hatte. Die Fortsetzung mit Takt 57 zeigt sich davon aber gänzlich unberührt, obwohl eine übermäßige Quinte als Fundamentschritt entsteht. ${ }^{146}$ Ähnliches gilt für den Verlauf der Oberstimme. Im Rahmen der diatonischen Fortschreitung vom strukturellen Oberstimmenton fis $^{2}$ zum strukturellen Mittelstimmenton $h^{1}$ beim Übergang von Takt 2 zu Takt 3 entsteht, weil $h$ durch cis vorgehalten ist, die Quarte fis-cis. Im Übergang von Takt 56 zu Takt 57, weil c und nicht cis Ton des mittelgründigen Tonfeldes ist, kommt es zur sungelenken übermäßigen Quarte fis-c. Insofern c als Vorhalt auch noch in gleicher Bewegungsrichtung fortgesetzt wird, verstößt die Konstellation gegen Verbindlichkeiten der traditionellen Stimmführung. Ähnlich der Takte 21-24.1 scheint es eine besondere Bewandtnis mit dieser Stelle zu ha-

146 Auf das Besondere des Tones dis hat bereits Diergarten hingewiesen. Aus der Perspektive der Tonfeldtheorie verwechselt Diergarten allerdings Mittel und Zweck, wenn er schreibt: »Möglich wird diese Umfärbung allein dadurch, daß der ganze Abschnitt durch den hintergründigen Sequenzrahmen zusammengehalten wird.» $(2003,49)$ Das dis erscheint Diergarten »lediglich als Farbwert des $d$ « (ebd.). Die Gegenüberstellung von 'Struktur und 'Farbe` hat in der deutschsprachigen Musiktheorie eine lange (und fragwürdige) Tradition: „Ob [...] allerneueste Bestrebungen, die Harmonik ganz von den Gesetzen tonaler Logik zu emanzipieren und nur noch in stimmungskoloristischem Sinne anzuwenden (Debussy) eine grosse Zukunft haben, mag dahingestellt bleiben.« (Louis/Thuille 1907, 395) 
ben, nur, dass sie in Form einer Antiklimax, einem Verdämmern statt einer dramatischen Entwicklung gestaltet ist. ${ }^{147}$ Auf der anderen Seite des Nadelöhrs erfolgt ein Neuansatz: ${ }^{148}$ Die luzide Diatonik der Takte 58ff. prägt den denkbar schärfsten Gegensatz zur vorausgegangenen Eindunklung aus. ${ }^{149}$

\section{Schluss}

Die aus Sicht der traditionellen Satztechnik entbehrlichen Optionstöne gewinnen vor dem Hintergrund des Ordnungsprinzips `Quintenreihe` an Bedeutung. ${ }^{150}$ Freilich würde auch eine reguläre vierstimmige Quintfallsequenz, deren zweite Station jeweils aus einem quintlosen Septakkord bestünde, das reine Heptaton durchmessen. Allerdings kann durch die zusätzlichen Optionstöne eine höhere Dichte und schnellere Folge der Artikulation erzielt werden. Ohne die zusätzlich angelagerte Mittelstimmentöne cis (T. 60) und $h$ (T. 61) käme jeweils kein vollständiges Heptaton auf der zweiten Akkordstation zustande.

Die Takte 58-61 sind paarig angelegt. In den Takten 58 und 60 liegt jeweils ein unvollständiges Heptaton $g$-cis ohne $d$ vor, in den Takten 59 und 61 hingegen das vollständige Heptaton, wodurch der fehlende Ton zwei Mal nachgereicht wird Im Falle des zweiten Paares erfolgt gleichzeitig mit der Ergänzung des $d$ die Einführung des ais, durch welches das Heptaton $g-c i s$ in das harmonische Heptaton zu h-Moll überführt wird.

In Takt 62 klingt zunächst das ais des vorigen Taktes fort. Obwohl damit die Entscheidung gegen D-Dur und für h-Moll als interpunktischer Schluss bereits gefallen scheint, kehrt in Takt 63 das Heptaton g-cis wieder. Wieder sorgt die Mixturtechnik für die dichte und rasche Artikulation der Quintenreihe. Hier gewährt der zusätzliche Mittelstimmenton $g$ Vollständigkeit. In Takt 64 ist es das fis, das zusätzlich ins Spiel gebracht wird. Der melodische Schlenker in der Oberstimme liefert auf dem letzten Sechzehntel das a nach, dem die erwartete Qualität als Bassstufe verwehrt wird. So kommt es erst in Takt 65 zum endgültigen Übergang in das harmonische Heptaton von h-Moll.

Die zweimalige Aussparung von $d$, des erwarteten Grundtons des letztlich ausbleibenden interpunktischen Schlusses in D-Dur, würde nicht derart fokussiert werden, fehlten weitere Töne. Nur an einer Stelle wird mit Blick auf eine noch hintergründigere Strategie von dieser Maßgabe abgewichen: Der in Takt 61 zum Heptaton fehlende Ton $h$ wird als Schlussstein der gesamten Anordnung gesetzt. Er erscheint erst mit dem siebentönigen Vorhaltsklang, der zugleich das komplette harmonische Heptaton zu h-Moll artikuliert, in den Takten 65-66 (Beispiel 50).

147 Deutlich erscheint auch die Anspielung auf den Mittelteil durch den dis-Moll-Klang zu Beginn von Takt 55 im Vergleich zu Takt 21.

148 Was das Anschlussverhalten anbelangt, hat sich die Situation in Takt 58 gegenüber Takt 12 nochmals verschärft.

149 Beide Stellen - Mitte des Mittelteils und Mitte der Reprise - prägen im Sinne der >materialen Formenlehre` (Th.W. Adorno) ein Gegensatzpaar aus: dort aktiver Zugriff und Durchbruch, hier passives Loslassen und Erfahrung von Gnade; dort Welt, hier Transzendenz.

150 Hinsichtlich der Behandlung der Optionstöne ist die Nähe zu Schumanns op. 133/1 auffällig. 

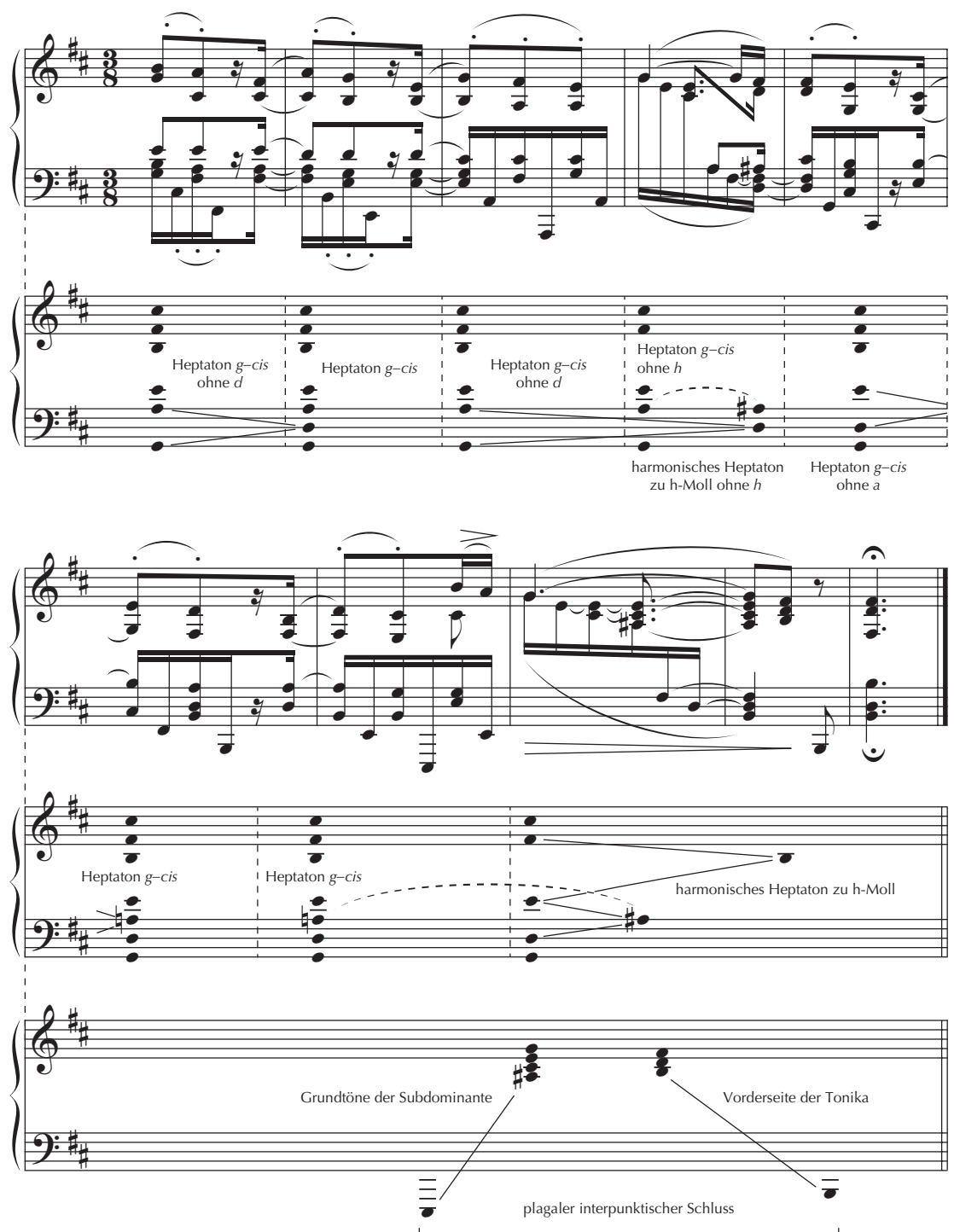

Beispiel 50: Johannes Brahms, Intermezzo h-Moll op. 119/1, Tonfelder und interpunktischer Schluss T. 58-67 


\section{Literatur}

Breyer, Knud (2009), »Historische Schichten miteinander sverflöztı: Die Übersendung der Klavierstücke opp. 116-119 als passendes Gegengeschenk für Philipp Spittas Aufsatz ,Über Brahms«", ZGMTH 6/1. http://www.gmth.de/zeitschrift/artikel/423.aspx

Cadwallader, Allen (1983a), Multileveled Motivic Repetition in Selected Intermezzi for Piano of Johannes Brahms, Diss. Uni. Rochester.

(1983b), »Motivic Unity and Integration of Structural Levels in Brahm's B-Minor Intermezzo, Op. 119, No. 1, Theory \& Practice 8/2, 5-24.

Cadwallader, Allen / William Pastille (1999), „Schenker's unpublished work with the music of Johannes Brahms", in: Schenker Studies 2, hg. von Carl Schachter und Hedi Siegel, Cambridge: Cambridge University Press.

Cai, Camilla (1986), Brahms' short, late piano pieces - opus numbers 116-119. A source study, Diss. Boston University.

Caplin, William E. (1998), Classical Form: A Theory of Formal Functions for the Instrumental Music of Haydn, Mozart and Beethoven, Oxford und New York: Oxford University Press.

Christensen, Thomas (2008), Rameau \& Musical Thought Enlightment (= Cambridge Studies in Music Theory and Analysis 4), Cambridge: Cambridge University Press.

Clements, Peter J. (1977), »Johannes Brahms: Intermezzo, Opus 119, No. 1«, Canadian Association of University Schools of Music journal 7: 31-51.

Danuser, Hermann (2005), »Nachglanz -Vorschein - Schein. Über Historizität und Ästhetik bei Johannes Brahms", in: Werk und Geschichte: Musikalische Analyse und historischer Entwurf - Rudolf Stephan zum 75. Geburtstag, hg. von Thomas Ertelt, Mainz: Schott, 125-141.

Diergarten, Felix (2003), »Melancholie des Unvermögens: Der Brahmssche Ton und das Intermezzo op. 119,1«, Musik \& Ästhetik 26, 42-53.

Domek, Richard Caharles, Jr. (1976), A syntactic approach to the study of rhythm applied to the late piano works of Johannes Brahms, Bloomington: Indiana University Press.

Dunsby, Jonathan (1976), Structural Ambiguity in Brahms: Analytic Approaches to Four Works, Doctoral Thesis Leed University, daraus: „Brahms the Progressive and Intermezzo, Op. 119, No. 1, 85-105.

Eybl, Martin und Evelyn Fink-Mennel (Hg.) (2006), Schenker-Traditionen: Eine Wiener Schule der Musiktheorie und ihre internationale Verbreitung, Wien u. a.: Böhlau.

Forte, Allen / Steven E. Gilbert (1982), »Introduction to Schenkerian Analysis«, New York und London: W. W. Norton \& Company.

Gjerdingen, Robert O. (2007), Music in the Galant Style, Oxford: Oxford University Press.

Goebels, Franzpeter (1983), »Adagio h-moll. Bemerkungen zum Intermezzo h-moll op. 119 Nr. 1 von Johannes Brahms«, Musica 3/37, 230-231.

Haas, Bernhard (2004), Die neue Tonalität von Schubert bis Webern. Hören und Analysieren nach Albert Simon, Wilhelmshaven: Noetzel. 
(2010), „Zur Sonatenform II mit analytischen Bemerkungen zum ersten Satz von Mozarts Sonate KV 570«, in: Funktionale Analyse. Musik - Malerei - Antike Literatur. Analyse Fonctionelle. Musique - Peinture - Littérature classique, hg. von / édité par Bernhard Haas und Bruno Haas, Hildesheim u. a.: Olms, 261-94.

—_ (2011) »Zu zwei Bartók-Analysen von Albert Simon«, ZGMTH 8/2, 299-334. http:// www.gmth.de/zeitschrift/artikel/640.aspx

(2012), „Über das Thema von Max Regers ıfis-moll-Variationen op. 73«, in: Konfession - Werk - Interpretation (= Reger-Studien 9. Kongressbericht Mainz 2012), hg. Jürgen Schaarwächter, Echterdingen: Carus, 197-212.

Haas, Bernhard / Veronica Diederen (2008), Die zweistimmigen Inventionen von Johann Sebastian Bach, Hildesheim u.a.: Olms.

Hauptmann, Moritz (1853), Die Natur der Harmonik und Metrik, Leipzig: Breitkopf \& Härtel.

Hegel, Georg Friedrich Wilhelm (2000), Vorlesung über Naturphilosophie 1823/24. Nachschrift von Karl Gustav Julius von Griesheim (= Hegeliana. Studien und Quellen zu Hegel und zum Hegelianismus 12), hg. und eingeleitet von Gilles Marmasse, Frankfurt a. M.: Lang.

Heider, Fritz (1926), »Ding und Medium«, Symposion 1/2, 109-157.

Herschkowitz, Philip (1997), Über Musik. Viertes Buch, Wien: Eigenverlag.

Hollander, Hans (1972), „Die Terzformel als musikalisches Bauelement bei Brahms», Neue Zeitschrift für Musik 113/8, 439-441.

Jordan, Roland / Emma Kafalenos (1989), »The double trajectory: Ambiguity in Brahms and Henry James, 19th-century-music 13/2, 129-144.

Lendvai, Ernö (1953), „Einführung in die Formen- und Harmoniewelt Bartóks«, Wiederabdruck in: Béla Bartók. Weg und Werk. Schriften und Briefe, hg. von Bence Szabolcsi, München: dtv 1972, 105-149.

Lietzmann, Berthold (1927), Clara Schumann. Johannes Brahms. Briefe aus den Jahren 1853-1896, Bd. 2, Leipzig: Breitkopf \& Härtel.

Louis, Rudolf / Ludwig Thuille (1907), Harmonielehre, Stuttgart: Grüninger (Klett \& Hartmann).

Luhmann, Niklas (1992), Die Wissenschaft der Gesellschaft, Frankfurt a. M.: Suhrkamp.

Newbould, Brian (1977), »A New Analysis of Brahms Intermezzo in B-Minor op. 119 no. 1«, The Musical Review 38, 33-43.

Polth, Michael (2000), Sinfonieexpositionen des 18. Jahrhunderts: Formbildung und $\ddot{A} s$ thetik, Kassel u. a.: Bärenreiter.

_ (2001), »Nicht System - nicht Resultat«, Musik und Ästhetik 18, 12-36.

(2006a): »Tonalität der Tonfelder: Anmerkungen zu Bernhard Haas >Die neue Tonalität von Schubert bis Webern. Hören und Analysieren nach Albert Simon««, ZGMTH 1/2006, 167-178. http://www.gmth.de/zeitschrift/artikel/210.aspx

(2006b): »In den Freiräumen der Schenkerschen Tonalität: Harmonische Effekte durch Tonfelder in der Prager Sinfonie«, Dutch Journal of Music Theory 11/3, 151-163. 
(2011), "Zur Artikulation von Tonfeldern bei Brahms, Debussy und Stockhausen«, ZGMTH 8/2, 225-265. http://www.gmth.de/zeitschrift/artikel/645.aspx

Riemann, Hugo (1883), Neue Schule der Melodik. Entwurf einer Lehre des Contrapunkts nach einer gänzlich neuen Methode, Hamburg, K. Grädener \& J. F. Richter.

Rimski-Korssakow, Nikolai (1922), Praktisches Lehrbuch der Harmonie, 3. durchgesehene und ergänzte Auflage, Leipzig: Belaieff.

Rings, Steven (2012), »The learned self: Artifice in Brahms's late intermezzi«, in: Expressive intersections in Brahms. Essays in analysis and meaning, hg. von Heather Platt, Peter H. Smith, Bloomington: Indiana University Press, 19-50.

Rohringer, Stefan (2009), »Tonalität in Franz Schuberts späten Sonatenformen: Überlegungen zum Kopfsatz des Klaviertrios B-Dur D 898«, ZGMTH 2-3/2009. http:// www.gmth.de/zeitschrift/artikel/458.aspx

(2010a), »Von der Oktavzugmusik zur Terzzugmusik: Die Salzburger Notenbuchtradition und die Geschichte der Ursatz-Tonalität», in: Funktionale Analyse. Musik-Malerei - antike Literatur, hg. von Bruno und Bernhard Haas, Hildesheim 2010, 203-60.

(2010b), Art. „Diatonik-Chromatik-Enharmonik«, in: Lexikon der Systematischen Musikwissenschaft. Musikästhetik-Musiktheorie-Musikpsychologie-Musiksoziologie (= Handbuch der Systematischen Musikwissenschaft 6), hg. von Helga de la Motte Haber, Heinz von Loesch, Günther Rötter und Christian Utz, Laaber: Laaber, 82-86.

Salzer, Felix (1960), Strukturelles Hören. Der tonale Zusammenhang in der Musik (= Deutsche Übertragung und Bearbeitung von: Structural Hearing. Tonal Coherence in Music, New York: Dover 1952), 2 Bde., Wilhelmshaven: Heinrichshofen.

Schenker, Heinrich (1906), Harmonielehre (= Neue musikalische Theorien und Phantasien 1), Stuttgart und Berlin: J. G. Cotta'sche Buchhandlung Nachfolger.

(1910), Kontrapunkt. Erster Halbband. Cantus firmus und zweistimmiger Satz (= Neue musikalische Theorien und Phantasien, Bd. 2 ), Stuttgart und Berlin: J. G. Cotta'sche Buchhandlung Nachfolger.

_ (1921-24), Der Tonwille: Flugblätter zum Zeugnis unwandelbarer Gesetze der Tonkunst einer neuen Jugend dargebracht von Heinrich Schenker [1.-6. Heft 1921-1923], Vierteljahreszeitschrift Flugblätter zum Zeugnis unwandelbarer Gesetze der Tonkunst einer neuen Jugend dargebracht von Heinrich Schenker [1. Heft 1924] Wien u. Leipzig: Tonwille-Flugblätterverlag [1921-1923], Wien: Universal Edition [1924].

(1956), Der freie Satz (= Neue musikalische Theorien und Phantasien, Bd. 3), hg. und bearbeitet von Oswald Jonas, 2. Aufl., Wien: Universal Edition 1956.

_ (o. J.), [Skizzen zu Johannes Brahms' Intermezzo h-Moll op. 119/1] Oster Collection, Film 34/item 2, 3 und 5 sowie Film 35/item 98.

Schönberg, Arnold (1986), Harmonielehre, Reprint der 7. Auflage Wien: Universal Edition 1966.

(1950), „Brahms the Progressive«, in: Style and Idea, New York: Philosophical Library, Wiederabdruck in: Style and Idea. Selected Writings of Arnold Schönberg, Berkeley und Los Angeles: University of California Press, 1975, 398-441.

Searle, John (1969), Speech Acts. An Essay in the Philosophy of Language. London: Cambridge University. 